\title{
The Partisan Sorting of "America": How Nationalist Cleavages Shaped the 2016 U.S. Presidential Election
}

\author{
Bart Bonikowski $^{\mathrm{a}}$, Yuval Feinstein ${ }^{\mathrm{b}}$, and Sean Bock ${ }^{\mathrm{c}}$ \\ ${ }^{a}$ New York University \\ ${ }^{\mathrm{b}}$ University of Haifa and Harvard University \\ ${ }^{c}$ Harvard University
}

\begin{abstract}
Political scientists have acknowledged the importance of nationalism as a constitutive element of radical-right politics, but have typically empirically reduced the phenomenon to specific out-group sentiments. Sociologists, in contrast, have devoted more attention to theorizing and operationalizing nationalism but have only sporadically engaged in debates about institutional politics. The present study brings these literatures together by considering how nationalist beliefs shaped respondents' voting preferences in the 2016 U.S. presidential election and how the election outcome built on long-term changes in the distribution of nationalism in the U.S. population. The results suggest that competing understandings of American nationhood were effectively mobilized
\end{abstract}


by candidates from the two parties in both the 2016 primaries and the general election. Furthermore, over the past 20 years, nationalism has become sorted by party, as Republican identifiers have come to define America in more exclusionary and critical terms and Democrats have increasingly endorsed inclusive and positive conceptions of nationhood. These trends point to the rising demand for radical candidates among Republicans and suggests a potentially bleak future for U.S. politics, as nationalism becomes yet another among multiple overlapping social and cultural cleavages that serve to reinforce partisan divisions and undermine the stability of liberal democratic institutions.

\section{Introduction $^{1}$}

The mainstreaming of radical-right politics - a category that subsumes most European far-right parties but also Donald Trump's presidency, and the Brexit referendumhas brought renewed scholarly attention to the role of identity-based intergroup conflict as a driver of political behavior. ${ }^{2}$ Reflecting the radical right's widespread re-

\footnotetext{
${ }^{1}$ Funding for this research was provided by the US-Israel Binational Science Foundation (Bonikowski and Feinstein), the Stanford Center for Advanced Study in the Behavioral Sciences (Bonikowski), the Harvard University Dean's Fund for Innovation (Bonikowski), and the Marie Curie Career Integration Grant (Feinstein). We are grateful for helpful feedback from Jeff Manza, Kiyoteru Tsutsui, Marco Garrido, Steve Morgan, Paul Pierson, and Sarah Roberts; audiences at Stanford; University of California, Berkeley; University of California, Riverside; University of California, Santa Barbara; Stony Brook; New York University; Massachusetts Institute of Technology; University Institute of Lisbon; Deakin University; Queen's University; McGill; the American Political Science Association; the American Sociological Association; and the Association for the Study of Ethnicity and Nationalism; and participants in the 2019 Canadian Institute for Advanced Research Successful Societies Workshop. Direct correspondence to Bart Bonikowski, Puck Building, Room 4143, 295 Lafayette Street, New York, New York 10012. Email: bonikowski@nyu.edu.
} 
liance on socially exclusionary rhetoric, scholars have increasingly emphasized xenophobia, racism, Islamophobia, and anti-Semitism (often grouped under the label of "cultural" grievances) in explanations of these parties' successes (Ivarsflaten, 2008; Mudde, 2007; Parker, 2016; Rooduijn, 2014; Sides et al., 2018). The growing interest in symbolic politics among sociologists and political scientists is warranted, but the resulting empirical research has four limitations.

First, it lacks a theoretical framework that can account for the extensive variation in ethnic, racial, and religious out-group antipathies mobilized by the radical right. Second, the emphasis on inclusion and exclusion ignores other aspects of the radical right's nationalist discourse, such as invocations of national decline, nostalgia, and chauvinism. Third, the literature tends to focus on radical-right candidates' and parties' exclusionary claims without placing them in the context of the broader political-cultural field. This ignores the fact that collective identity is not exclusively the domain of the radical-right: center-left and center-right candidates also routinely mobilize identity commitments in their campaigns, typically by offering a contrasting vision of the nation to that of their political competitors. Fourth, existing research rarely examines long-term changes within parties in the distribution of preferences for social exclusion and inclusion (and associated attitudes), which may correspond

\footnotetext{
${ }^{2}$ The technical term "radical right" is commonly used in the literature and is preferable to alternatives that conflate this form of politics with one of its ideological components (e.g., "populism") or that privilege one component over others (e.g., "populist radical right"). At the same time, we acknowledge that the "radical right" label is problematic, because it assumes a single political continuum that cannot account, e.g., for parties that combine economic redistribution with exclusionary nationalism. We also note that our use of the term is not normative but analytical and that we do not equate all right-wing politics with the radical right.
} 
to shifts in partisans' demand for more or less radical candidates. These limitations, as we will argue, inhibit scholarly understanding of the relationship between collective identities and the radicalization of politics in contemporary democracies.

Our article addresses these research gaps using the empirical case of the 2016 U.S. primary and general presidential elections and the attitudinal realignments of the preceding two decades. Building on recent advances in nationalism research (Bonikowski and DiMaggio, 2016; Delehanty et al., 2018; Jardina, 2019; Whitehead and Perry, 2020), we argue that the various out-group antipathies associated with support for the radical right are partly rooted in underlying exclusionary conceptions of nationhood, which compete in the political sphere with more inclusive alternatives. At the same time, nationalist beliefs are not reducible to social exclusion and inclusion and radical-right actors do not hold a monopoly on nationalist political mobilization. Conceptions of nationhood also involve varied levels of domainspecific national pride and chauvinistic comparisons of the nation with the rest of the world. Together, these attitudes cohere into patterned configurations that constitute robust - and increasingly politically salient - cultural cleavages in the U.S. population. Using original survey data collected the week before the 2016 presidential election, our study demonstrates that distinct nationalist dispositions - and not exclusionary beliefs alone-were strongly associated with intent to vote for Donald Trump or Hillary Clinton in the general election, as well as with differential support for other Republican and Democratic candidates in the two parties' primaries. Moreover, a longitudinal analysis of five survey waves reveals that 2016 marked a culmination of a 20-year trend in the partisan realignment of nationalism, which 
Table 1: Attitudinal Composition of the Four Nationalism Types

\begin{tabular}{lcccc}
\hline & \multicolumn{4}{c}{ Nationalist Attitudes } \\
\cline { 2 - 5 } Nationalism Types & Attachment & Membership Criteria & Pride & Chauvinism \\
\hline Creedal & Moderate & Inclusive & High & Moderate \\
Disengaged & Moderate & Inclusive & Low & Low \\
Ardent & High & Exclusionary & High & High \\
Restrictive & High & Exclusionary & Low & Moderate \\
\hline
\end{tabular}

Note.-Summary of the distribution of constitutive nationalist attitudes (23 variables grouped into four dimensions) across the four types of nationalism (i.e., latent classes).

helps explain Donald Trump's capture of the Republican Party and Hillary Clinton's victory in the Democratic primary.

What are the distinct configurations of nationalist beliefs that played such a central role in the 2016 election? Using latent class analysis of 23 variables measuring strength of national attachment, inclusive or exclusionary criteria of legitimate national membership, domain-specific national pride, and chauvinism, we identify four distinct types of American nationalism, which we label creedal, disengaged, restrictive, and ardent. In terms of their attitudinal composition, these varieties of nationalism are crosscutting rather than monotonic, so that they cannot be arranged on a single continuum from least to most nationalist. To aid in the interpretation of our arguments - and foreshadow our subsequent empirical findings - we illustrate the composition of these attitudinal configurations in terms of their four constitutive components (i.e., attachment, membership criteria, pride, and chauvinism) in table 1. This typology is consistent with past findings in political sociology (Bonikowski and DiMaggio, 2016), but it has never been applied to electoral politics. 
We find that even after controlling for sociodemographic covariates and partisan identification, adherence to restrictive and ardent nationalism (both are exclusionary, but the former is characterized by moderate national attachment and low levels of national pride and chauvinism, and the latter by high levels of all three) was significantly predictive of endorsing Trump over the moderate candidates in the Republican primary and of voting for Trump over Clinton in the general election. Moreover, a disengaged disposition toward the nation (consisting of inclusive criteria of belonging and low levels of attachment, pride, and chauvinism) was predictive of support for Sanders over Clinton in the Democratic primary, and for Trump over Clinton in the general election.

These results are placed into further relief by a striking finding from our longitudinal analysis: while the conceptions of America associated with Trump support did not become more prevalent in the U.S. population before the 2016 election, we observe strong evidence of persistent partisan sorting of nationalist beliefs over the preceding two decades. The four varieties of nationalism observed in our study had not been strongly associated with partisan identities in 1996, but by 2016, respondents identifying with the Republican Party predominantly subscribed to exclusionary, unproud, and chauvinistic conceptions of nationhood, while a large majority of those identifying with the Democratic Party saw the nation in inclusive and positive terms. This suggests that demand for a candidate like Donald Trump had long been growing among Republican voters, as had demand among Democrats for a creedal nationalist candidate like Hillary Clinton (and presumably Barack Obama before her and Joe Biden after her). 
The novelty of our research, therefore, lies in its synthesis of relational approaches to the study of belief structures from cultural sociology with a long-standing interest among nationalism scholars in the heterogeneity of nationalist beliefs within countries, as well as the application of these two research traditions - using original survey data - to the study of electoral outcomes. ${ }^{3}$ Unlike other work that focuses on specific forms of nationalism (Whitehead and Perry, 2020; Thompson, 2021) or on particular out-group antipathies (Reny et al., 2019) as predictors of Trump support, our study examines the full range of competing visions of America that are associated with both voting choices and sentiments toward specific racial, ethnic, and religious groups.

In addition to demonstrating the centrality of nationalist beliefs in the 2016 election and their increasing alignment with partisan identities over the preceding two decades, our findings have implications for the future of U.S. politics and for crossnational research on radical-right parties. First, although nationalist beliefs are not reducible to partisanship (as evidenced by the persistent marginal effects of nationalism in our statistical models), the increasing alignment between nationalist and partisan identities is likely to reinforce other sociodemographic and ideological cleavages, potentially leading to greater partisan animosities and diminished prospects for political compromise in the coming years (Manza and Brooks, 1999; Rokkan and Lipset, 1967; Mason, 2018; Jardina, 2019).

\footnotetext{
${ }^{3}$ While scholars have speculated that popular conceptions of nationhood may have affected vote choices in the 2016 presidential election (Bonikowski, 2019), our study is the first to prove this empirically and to place these findings in the context of long-term shifts in the partisan alignment of nationalism in the U.S. population.
} 
Second, the shifting composition of nationalist beliefs among partisans is likely to generate constraints and opportunities for future candidates from both parties. For instance, given the growing prevalence of creedal nationalism among Democratic identifiers, progressive candidates' lukewarm engagement with assertive nationalism may inhibit their political support within the party ranks. Among Republicans, the predominance of restrictive nationalism may limit the party's ability to reinvent itself following its 2020 presidential loss. Unless nationalism becomes less salient in future elections, Republican candidates will have strong incentives to continue mobilizing the restrictive-nationalist Trump constituency using exclusionary, unproud, and chauvinistic discourse.

Finally, our findings suggest that scholars of political culture and electoral politics should take varieties of nationalism - and not just the out-group antipathies associated with them - more seriously, both as predictors of radical-right support and as cultural-political cleavages that may increasingly overlap with other collective identities. Our framework is sufficiently analytically capacious to account for cross-national variation in the content of nationalist beliefs and the framing of specific out-groups as ostensibly threatening to the nation. As a result, it has the potential to enable a synthetic, general account of radical-right mobilization across a wide range of cases.

The article proceeds as follows. We begin with a discussion of existing explanations of the rise of radical-right politics and argue that scholars have not sufficiently engaged with the sociological literature on popular nationalism, a political-cultural phenomenon that is becoming increasingly salient in contemporary democracies. Following a description of our data and methods, we use LCA to identify four distinct 
varieties of American nationalism among our survey respondents. On the basis of the content of these attitudinal configurations, we develop hypotheses about the possible relationships between respondents' nationalist beliefs and their voting preferences. These predictions are also informed by our review of campaign media coverage and a supplementary computational text analysis of campaign speeches, which allow us to characterize how nationalist claims were used by the 2016 primary candidates and presidential nominees. After formulating additional hypotheses concerning the long-term trends in the realignment of nationalist beliefs during the two decades preceding the 2016 election, we then turn to our empirical results. First, we model candidate support in the primary and general elections using the four types of nationalist beliefs, along with relevant controls. Second, we track changes in the aggregate proportions of the nationalist cleavages in the sample as a whole and within the Democratic and Republican Parties. We conclude with a more extensive discussion of the implications of our results for understanding contemporary U.S. politics and the rise of the radical right across democratic polities.

\section{"Cultural" Sources of Radical-Right Support}

Explanations of popular support for radical-right parties tend to fall into two categories: those stressing economic factors - such as exposure to financial crises, income inequality, deindustrialization-driven unemployment, trade shocks, or the redistributive consequences of capital mobility - and those emphasizing "cultural" fac-

tors (Golder, 2016). ${ }^{4}$ The latter perspective rests on the claim that economic anxiety 
is neither a necessary nor sufficient cause of voters' favorability toward candidates who capitalize on out-group antipathies. Instead, it is voters' deep-seated racism and xenophobia (Ivarsflaten, 2008; Lucassen and Lubbers, 2012; Mutz, 2018; Sides et al., 2018) — or a general distaste for multicultural and cosmopolitan cultural norms (Norris and Inglehart, 2018) - that gives resonance to such campaign messages, especially under conditions of collective status threat (Bobo, 1999; Parker, 2016). In addition to furnishing correlations between the relevant attitudes and radical-right support, scholars favoring cultural explanations often point to the weaknesses of the economic framework: that radical-right supporters tend not to be the worst off in society, that they often oppose economic redistribution (especially if it involves benefits for the groups they dislike), and that racial segregation is a more typical characteristic of the areas in which these voters live than is having borne the brunt of economic decline (Sides et al., 2018).

We view the economy-versus-culture dichotomy as misplaced (Gidron and Hall, 2017) - it ignores that culture shapes economic perceptions and that economic anxieties are themselves mediated by cultural frames - but we also take issue with the vague concept of "cultural" explanations on which it is predicated. This category comprises a wide range of attitudes, including xenophobia, racism, Islamophobia, and anticosmopolitanism, without specifying the cultural mechanisms that connect them

\footnotetext{
${ }^{4}$ In addition to explaining the demand side of radical-right politics, political scientists stress the importance of institutional mechanisms, such as changes in candidate selection processes and the weakening of party organizations, as well as the impact on public opinion of the rise of social media and the growth of partisan cable news (Golder, 2016; Levitsky and Ziblatt, 2018). We bracket these factors, because our interest is primarily in the relationship between political claims making and individual-level correlates of political behavior.
} 
(but see Jardina 2019; Lubbers and Coenders 2017; Mason 2018; Rydgren 2017). While these phenomena are easily operationalized, they are analytically inadequate, not least because they are able to explain radical-right support only in some country cases but not others. For instance, Islamophobia is useful for understanding the successes of the National Front (now the National Rally) in France, but xenophobia against Polish immigrants is more relevant for making sense of the Brexit referendum in the United Kingdom. In the U.S. case, the vilification of Mexican migrants was centrally important to the Trump campaign while overt racial claims were less prominent than racial dog-whistles (Bobo 2017; Lamont et al. 2017) - and yet, both racism and anti-immigrant sentiments were highly predictive of people's decision to vote for Trump (Sides et al. 2018).

One way in which scholars have sought to bridge these distinct phenomena is to subsume them under the category of nativism: the principle "that states should be inhabited exclusively by members of the native group ('the nation') and that nonnative elements (persons and ideas) are fundamentally threatening to the homogenous nation-state" (Mudde 2007:19). This is a more promising analytical category than "culture" writ large, because it places emphasis on definitions of legitimate membership in the nation, which are core to people's collective identities. Nativism, however, is overly narrow: it customarily emphasizes foreign birth over other bases of nationalist exclusion (Higham 1955; cf. Bonikowski 2017a; Manza and Crowley 2018; McVeigh and Estep 2019) and it misses other aspects of nationalism apart from membership criteria, such as domain-specific national pride and perceptions of national superiority. Together, all of these beliefs constitute people's cultural schemas 
of the nation, which have important consequences for political preferences and are empirically tractable using survey data. ${ }^{5}$. Bringing these configurations of nationalist (as opposed to merely "nativist" or "cultural") beliefs to bear on the 2016 U.S. presidential election is the primary objective of our study.

\section{Nationalist Cleavages in the United States}

In his influential book, Rogers Smith (1997) demonstrates that American national identity has never been characterized by singular adherence to the liberal values of the American Creed. Instead, it has vacillated between distinct and competing belief systems (liberalism, but also republicanism and ascriptive Americanism), the residues of which Smith traces across the patchwork of U.S. citizenship law. The notion that conceptions of nationhood are heterogeneous within countries has also motivated survey researchers, who have shown that distinctions similar to those observed in archival data are found in public opinion and that these beliefs are strongly associated with policy preferences (Citrin et al. 2001; Edgell and Tranby 2010; TheissMorse 2009; Schildkraut 2010). More recently, Bonikowski and DiMaggio (2016) used inductive survey analysis methods to identify distinct schemas of American nationhood. Their findings differed from past studies in three important ways: (1) they were based on a wider range of items that tapped criteria of national membership, national pride, chauvinism, and the strength of national attachment; (2) instead of

\footnotetext{
${ }^{5}$ Another advantage of "nationalism" is that it allows for direct comparisons between different varieties of the phenomenon, a strategy we employ in this article. It is less clear what constructs should be employed in juxtaposition with "nativism."
} 
aggregating variables (e.g., as in factor analysis), they clustered respondents on the basis of the latter's shared attitudinal profiles; and (3) they demonstrated that the resulting configurations of nationalist beliefs were not only patterned and correlated with political preferences, but also largely invariant in their composition over time. ${ }^{6}$

Bonikowski and DiMaggio's (2016) results suggest that alternative types of nationalism can be thought of as cultural cleavages in the U.S. population, which function as the public-opinion counterparts to the policymaking traditions documented by Smith (1997). These cleavages are likely to be latent during settled historical times, operating largely in the cultural background (Bonikowski, 2016). Under such circumstances, nationalist beliefs may manifest themselves in microinteractions, as sources of either in-group cohesion or intergroup animosity, but not as primary features of electoral campaigns or voting behavior (although their policy correlates may well be more salient). Occasionally, however, a confluence of structural conditions, particularly those that threaten existing ethnoracial status hierarchies, may bring disputes about the nation's meaning to the forefront of political claims making and individual-level political preferences (Anderson 2016; Bobo 1999; Jardina 2019;

\footnotetext{
${ }^{6}$ Although our measurement of nationalism and the resulting typology is inspired by Bonikowski and DiMaggio (2016), our study innovates in a number of important ways. First, we focus on the relationship between nationalism and voting preferences rather than general social and political attitudes. Second, we examine long-term trends in nationalist beliefs using five waves of survey data, extending the analysis into the second term of the Obama presidency and the 2016 election. Third, the emphasis in our temporal analysis is on the sorting of nationalist beliefs by party and not solely on aggregate changes in the population. Fourth, our research contributes to literatures on polarization and the rise of radical politics in both sociology and political science. Fifth, our hypotheses are informed by an analysis of campaign discourse, which allows us to integrate the supply and demand sides of politics and shed light on how radical actors mobilize support through nationalist claims making.
} 
McVeigh and Estep 2019; Parker and Barreto 2014; Parker 2016). Given the prominence of antiminority discourse in contemporary radical-right politics, the current era appears to represent such a conjuncture. ${ }^{7}$

Why should we expect nationalist beliefs in general - and not just exclusionary conceptions of national membership - to affect people's political preferences? For one thing, past research has shown that national attachment, chauvinism, and pride are important predictors of social and political attitudes. Strong identification with the nation has been associated with xenophobia (Ariely 2012; Pehrson et al. 2009), particularly when threats to the nation are made salient in political discourse ( $\mathrm{Li}$ and Brewer 2004). Similarly, chauvinism - which political psychologists equate with nationalism tout court - has been correlated with support for aggressive foreign policy, authoritarianism, antipathy toward ethnic minorities and immigrants, and opposition to supranational institutions (Blank and Schmidt 2003; de Figueiredo Jr and Elkins 2003; Feinstein 2016a, 2018; Feinstein and Bonikowski 2019; Huddy and Khatib 2007; Kosterman and Feshbach 1989; Müller-Peters 1998). The findings for

\footnotetext{
${ }^{7}$ We view our work as complementary to the existing literature on the role of racism and white nationalism in U.S. politics (e.g., Anderson 2016; Jardina 2019; Kendi 2017; Smith 1997). As we will demonstrate later, the nationalist belief types we identify are correlated with whites' ethnoracial antipathies, which have been a central feature of American political culture since the country's founding. Our conceptual framework, however, is flexible enough to encapsulate other criteria of exclusion in the United States and elsewhere, including those based on religion, language, and cultural values (Brubaker 2009; Wimmer 2013). Moreover, the nationalist beliefs on which we focus are not limited to criteria of national belonging, but extend to the strength of national attachment, domain-specific national pride, and chauvinism. These are distinct components of nationalist schemas, even if their meaning is partly shaped by their relationship to inclusive or exclusionary beliefs. We return to this point in subsequent sections of the article.
} 
national pride are more equivocal: high levels of pride can be associated with stronger national identification and support for national institutions without generating outgroup hostility (Blank and Schmidt 2003; Evans and Kelley 2002; Gangl et al. 2016), but in some circumstances pride has also been correlated with ethnoracial exclusion (Li and Brewer 2004), social dominance orientation (Sidanius et al. 1997), and disregard for democratic principles (Parker 2010). ${ }^{8}$ These conflicting results point to the polysemy of nationalist attitudes (and of cultural meaning more generally): what each attitude means and what implications it has depends on which other attitudes it is associated with in an individual's belief system. To capture this mutual conditionality of nationalist beliefs, our study relies on combinatorial survey analysis methods (specifically, LCA) that identify groups of respondents with common patterns of responses across multiple survey questions. We describe this approach in more detail in the methods section.

Our focus on a wide range of nationalist beliefs is also motivated by the fact that exclusionary conceptions of nationhood are not the only prominent discursive frame employed in contemporary radical politics. On both the right and left, radical candidates frequently deploy moral critiques of the nation's political, cultural, and economic trajectory, seeped in nostalgia for a long-lost golden age and accompanied by promises of widespread systemic change (Elgenius and Rydgren 2019). Such tropes are commonly associated with the populist vilification of morally corrupt

\footnotetext{
${ }^{8}$ Political psychologists label these two tendencies as blind and constructive patriotism, respectively (Schatz et al. 1999). We do not employ these terms because we view them as unnecessarily normative, but also because we find the term "patriotism" to be a misnomer for what is actually a core dimension of nationalist beliefs.
} 
elites, who are blamed for leading the nation in the wrong direction and whose removal is seen as a prerequisite for national restoration (Taggart, 2000). Donald Trump's inauguration speech featuring the dark symbolism of "American carnage" is case in point, but a more restrained variant of this dystopian register can also be observed in the left-populist campaign of Bernie Sanders. In contrast, mainstream candidates tend to celebrate the nation's virtues and limit their critique to issues that can be addressed through incremental reforms rather than systemic change. These distinct moral assessments are especially likely to resonate with the evaluative aspects of voters' nationalist beliefs, such as domain-specific pride and chauvinism.

If we find that nationalism did in fact influence the 2016 election, the next question is whether this was a result of shifts in the prevalence of nationalist beliefs in American society or of their partisan alignment. In line with the former mechanism, perhaps a growing proportion of Americans came to hold nationalist beliefs consistent with the Trump campaign's messaging in the months leading up to the 2016 primary and general elections, as a consequence of either the campaign itself or of contemporaneous exogenous shocks that engendered a sense of symbolic threat among the white majority. Such a pattern would be consistent with media accounts of a sudden surge in nativism, xenophobia, and racism in 2015 and 2016 (e.g., Guynn 2016; Stevens 2016). Yet, there are multiple reasons to be skeptical of this scenario.

First, past research has shown that out-group hostility in the U.S. population has been constant or has declined over the past decade (Jones 2019; Sides et al. 2018; for similar findings among whites, see Morgan and Lee 2017). It would be surprising if the distribution of nationalist beliefs contradicted this trend. Second, 
even though Trump harnessed exclusionary discourse in his campaign, he did not invent it: racist, anti-immigrant, and Islamophobic frames had long been a feature of Republican politics and conservative media (Anderson 2016; Bail 2014; Gilens 2009; Parker and Barreto 2014). Third, even though a confluence of economic, social, and cultural changes may have affected the self-perceived status of white Americans, it would be difficult to argue that 2015 or 2016 witnessed major punctuations in such contextual trends. Fourth, while the Trump campaign may have undermined existing norms of acceptable speech and behavior, political science research on the limited size and durability of campaign persuasion effects (as opposed to short-term priming and turnout effects) suggests that it is unlikely for Trump's rhetoric to have produced major attitudinal changes in the population (Gerber et al. 2011; Iyengar and Simon 2000; Jacobson 2015). Together, these arguments imply that sudden shifts in nationalist beliefs immediately before the election are less probable than more crescive trends or perhaps even attitudinal stability.

Alternatively, it is possible that net of any shifts in the aggregate prevalence of nationalism, the demand for Trump-style nationalist politics has increased among some segments of the population, and possibly declined among others. Such a scenario could underlie a variety of aggregate patterns in the population, including long-term attitudinal stability. A particularly relevant source of division in contemporary U.S. political culture is partisanship. A large literature on polarization has shown that even though Americans' attitudes have been generally stable (with some exceptions, like those concerning abortion), they have become increasingly sorted by party (Baldassarri and Gelman 2008; DiMaggio et al. 1996; Fiorina and Abrams 
2008; Hetherington and Weiler 2009), in part due to persistent cues from polarized political elites (Druckman et al. 2013; Layman and Carsey 2002; Levendusky 2009). As a result, people's partisan identities have become highly predictive of their beliefs and vice versa, their attitudinal profiles have become indicative of their partisanship. There is considerable debate about the origins of polarization - with frequently cited causes including Southern realignment (Rohde 1991), rising immigration and inequality (McCarty et al. 2016), congressional redistricting (Carson et al. 2007), changes in candidate selection mechanisms (Stroud 2010), the nationalization of U.S. politics (Hopkins 2018), and the transformation of the media landscape (Levendusky 2013) - but there is relative consensus about its dangers. As a growing number of issue positions come to overlap with party identity and the parties become divided along sociodemographic dimensions, there are fewer issues that can generate bipartisan consensus and there is less room for meaningful debate between the two partisan camps (Abramowitz and Webster 2016; Jones 2001; Mason 2018). The resulting mutual reinforcement between multiple social, political, and cultural cleavages threatens social cohesion and democratic stability (Manza and Brooks 1999; Rokkan and Lipset 1967).

Nationalist beliefs may represent yet another cultural domain that has undergone partisan alignment over the past two decades (Hanson and O'Dwyer 2018). Not only would this be consistent with the broader trend toward polarization in U.S. political culture, but it would also help explain support for Donald Trump's exclusionary and antisystem politics - and perhaps that of predecessor movements and candidates like the Tea Party and Sarah Palin - in the presence of aggregate stability in nationalist 
beliefs: even if demand for this type of politics did not increase in the population as a whole, it may have grown among the subset of (predominantly white) Americans who identify with the Republican Party.

We investigate this possibility using repeated cross-sectional data on nationalist beliefs that span the two decades between 1996 and 2016. If nationalism did become increasingly sorted by party in this time period, this would represent an additional cultural cleavage overlaid on existing, and increasingly proliferating, divisions in U.S. political culture (DellaPosta 2020). The implications of such a development would be particularly concerning for the country's political stability. After all, definitions of nationhood are not simply another policy issue; they give meaning to master identities that constitute people's collective sense of self. If Americans cannot agree on what their country means to them, what lessons to draw from its past, and what core principles should guide its future path, this is likely to further exacerbate zero-sum partisanship — predicated on perceiving the political opposition as fundamentally unAmerican - that poses a dire threat to the country's liberal democratic institutions (Levitsky and Ziblatt 2018). ${ }^{9}$

\footnotetext{
${ }^{9}$ Our empirical focus is on the United States, but the conceptual and methodological approach we develop is intended to be easily extended to other cases of radicalright politics, even if partisan sorting is likely to take on distinct forms in multiparty systems (perhaps operating via cleavages between party families or between traditional and new parties). Should future research find a more general cross-national trend in the polarization of nationalist beliefs, this could represent an important contributing factor to the rise of radical politics in contemporary democracies.
} 


\section{Data and Methods}

The main data used for the cross-sectional analysis of the 2016 election were collected by YouGov on November 3-8, the six days leading up to Election Day, as part of a larger comparative survey on nationalism funded by the US-Israeli Binational Science Foundation. The sample of 956 respondents was drawn from YouGov's panel using census-based quotas and then matched to the U.S. noninstitutionalized population using poststratification weighting.

The survey asked respondents a wide range of questions about their collective identities, social attitudes, and political preferences. Our study focuses in particular on a battery of 23 items that measure multiple aspects of popular nationalism, including strength of national attachment, criteria of legitimate membership in the nation, domain-specific national pride, and chauvinism. This battery was directly modeled on questions from the General Social Survey (GSS) - collected under the auspices the International Social Survey Programme (ISSP) - which have been the subject of numerous scholarly studies (e.g., Huddy and Khatib 2007; Kunovich 2009; Wright 2011). The wording of the nationalism questions along with the descriptive statistics for the 2016 wave of data are provided in Appendix A. We perform listwise deletion on all observations with missing data on the nationalism variables, which yields a sample size of $782 .{ }^{10}$

Our dependent variables are voting preferences in the 2016 primary and general elections. The fact that the data were collected in the leadup to Election Day allows

\footnotetext{
${ }^{10}$ In the results section, we consider whether listwise deletion affected our findings, by comparing them to those generated with a multiply imputed data set.
} 
us to obtain reliable measures of vote intention (Atkeson 1999) among a sample that includes late-deciders, a particularly important group in the 2016 election (Morgan 2018). ${ }^{11}$ At the same time, because we have no information about respondents' actual voting behavior, we are cautious to interpret our findings as indicative of candidate support rather than candidate vote. Finally, data on primary vote choices are based on retrospective accounts and are therefore susceptible to bias in favor of the primary winner. The overestimation of the primary winners' votes, however, should make our results more conservative. ${ }^{12}$

For the longitudinal analysis, we rely on a unique data set of nationally representative, repeated cross-sectional surveys that feature a consistent set of nationalism items. We compile these from the 1996, 2004, and 2014 GSS, a 2012 GfK Custom Research Survey, and the 2016 YouGov data described above. The GSS is a long-established and highly reputable attitudinal survey in the United States, collected annually by the National Opinion Research Center at the University of Chicago through in-person interviews and full-probability sampling. The nationalism items were administered as part of the National Identity 1, 2, and 3 supplements coordinated by the ISSP. The 2012 GfK survey was administered through the com-

\footnotetext{
${ }^{11}$ Four respondents who began the survey on Nov. 7 or 8 completed it on Nov. 9, i.e., after the election had been called for Trump. Removing these observations from the general election analyses does not meaningfully alter the results.

${ }^{12}$ Under the null hypothesis of no relationship between nationalism and primary vote, the retrospective overestimation of Trump and Clinton support should make little difference, while under the alternative hypothesis, it should have a downward bias on the nationalism coefficients, by conflating true Trump/Clinton primary supporters who espouse one set of nationalist beliefs with false-recall supporters who espouse contrasting conceptions of the nation.
} 
pany's KnowledgePanel, an online panel initially recruited by random-digit dialing and address-based sampling methods $(\mathrm{N}=3,136 ; 58.5 \%$ response rate).

All five surveys featured 23 identical nationalism items, along with a consistent set of sociodemographic variables. To the best of our knowledge, the resulting composite data set represents the most complete time series of Americans' nationalist beliefs available to researchers. The data cover a period of important developments in U.S. politics - including rising polarization, growth in executive power, the September 11, 2001 attacks, and the Great Recession-spanning the Clinton, Bush, and Obama presidencies, and the 2016 presidential election. The sample characteristics for the five waves of data are shown in Appendix B. ${ }^{13}$

To identify varieties of American nationalism, we use LCA, a data reduction method that groups observations on the basis of their shared response patterns across multiple variables - in this case, the 23 nationalism indicators specified earlier. We do so both for theoretical reasons - because we view this relational and inductive approach as most appropriate for measuring domain-specific cognitive representations (Mohr 1998; Knight and Brinton 2017) —and for practical reasons, because this has been a method effectively used in past research to segment nationalist beliefs in survey data (Bonikowski and DiMaggio 2016; Bonikowski 2017b; Alemán and Woods 2018), enabling direct comparisons between our results and those of past studies and contributing to the cumulation of knowledge in this domain of inquiry. ${ }^{14}$

\footnotetext{
${ }^{13}$ Study materials are avaication able at https://doi.org/10.7910/DVN/WYFB8G.

${ }^{14}$ Our commitment to conceptualizing and measuring meaning in relational terms draws on a long - and arguably, dominant - tradition in cultural sociology (see DiMaggio 1997; Mohr 1998; Zerubavel 2009). In recent years, scholars have drawn
} 
The logic of LCA is combinatorial, in that it is the configuration of multiple attitudes rather than the net effect of each attitude that is assumed to matter for a given outcome. As an example, consider a hypothetical survey respondent's stated opinion that speaking English is an important criterion of national belonging. Solely on the basis of this attitudinal response, it is difficult to determine whether the respondent in question adheres to an exclusionary or a civic republican conception of nationhood (i.e., whether he or she sees language as basis for legitimate ethnic exclusion or simply as an important prerequisite for full participation in the nation's economy and politics). One way to distinguish these alternative dispositions is to observe the same respondent's answers to other nationalism items: if the respondent also views ancestry and birth in country as important criteria of nationalist membership, it is likely that he or she adheres to exclusionary beliefs; if the respondent does not endorse ascriptive criteria of belonging but instead places importance on people's respect for the country's laws and institutions, we can conclude that he or she adheres to civic republican ideals. Similarly, the contradictory findings of past research concerning the invidious or benign consequences of national pride suggest that the implications of pride for political preferences are likely to be conditional on other aspects of a given respondent's nationalist beliefs. By clustering respondents on the basis of their responses to multiple survey items, LCA enables these types of relational distinctions.

on this work to propose combinatorial and relational methods for empirically measuring cultural schemas (Boutyline and Vaisey 2017; Goldberg 2011; Hunzaker and Valentino 2019; Yeung 2005; Sotoudeh and DiMaggio 2021); we see our approach as part of this broader effort. 
In technical terms, LCA uses a set of indicator items to estimate a latent categorical variable and predict a posterior probability of each respondent obtaining a particular value on that latent variable (McCutcheon 1987). Each value on the latent variable corresponds to a discrete latent class and the posterior probability represents each respondent's likelihood of assignment to each class. Using modal classification, respondents are then assigned to those classes for which their probability of assignment is highest. The LCA algorithm, implemented in the software package Latent Gold 5.0, uses maximum likelihood and the Newton-Raphson method to simultaneously estimate multiple model parameters under the assumption that conditional on the latent variable, the indicator variables are independent (in practice, this assumption can be relaxed for specific pairs of indicators with highest model residual scores, a model fitting technique we take advantage of in our analysis) (Vermunt 1997).

Our use of a discrete rather than continuous latent modeling strategy, such as confirmatory factor analysis, necessarily sacrifices some of the variation observed in the sample. We view this cost, however, as well worth the analytical payoff. In light of our arguments about the relationality of nationalist beliefs, an adequately specified continuous latent approach would require multiple continuous factors - at least one each for attachment, inclusive/exclusive criteria of national belonging, pride, and chauvinism (but likely more, as shown by Kunovich 2009) — and regressions of vote choice on these factors would likely involve multiway interactions. Such a model would be extraordinarily difficult to interpret. A discrete latent approach, such as LCA, is far more parsimonious: it automatically identifies those unique combinations of responses that are prominently represented in the data without the need for 
complicated interaction models. To further justify our modeling choices, we directly compare results obtained with LCA and confirmatory factor analysis in the online supplement.

The LCA models in all of our analyses are fully heterogeneous; that is, both content (i.e., the conditional probability of a particular response to each nationalism indicator within each class) and the posterior distribution of the latent classes in the sample are allowed to vary (Kankaraš et al. 2012). We employ this strategy in order to inductively determine whether the content of classes is broadly stable from yearto-year and to examine how the prevalence of the resulting classes changes over time. As we will demonstrate, the heterogeneous model yields highly comparable classes across survey waves, with only minor year-specific variations that are likely due to measurement error. We rely on statistical goodness of fit and interpretive criteria to select the appropriate number of classes (Bonikowski and DiMaggio 2021). As in past studies, a four-class solution provides the best compromise between precision and interpretability (apart from not offering an advantage in model fit, the introduction of a fifth class does not add theoretically meaningful information to the analysis). For more details about model selection and the comparability of the resulting LCA classes over time, see Appendix C.

Once we identify the four types of nationalism in the data, we regress on them respondents' voting preferences in the general and primary elections. To do so, we use logistic regression and report the results in terms of predicted probabilities and average marginal effects (AMEs). Unlike logit coefficients or odds ratios, AMEs enable direct cross-model comparisons; furthermore, similarly to predicted probabil- 
ities, they are expressed in the natural metric of the dependent variable (Long and Mustillo 2018; Mize et al. 2019). The term "effect" should not be mistaken for causal language, however; in our application, AMEs are indicative of associations not causal effects.

\section{Varieties of American Nationalism}

The LCA analysis yields four types of nationalist beliefs, summarized in figure $1 .^{15}$ Following Bonikowski and DiMaggio (2016), we label them creedal, disengaged, restrictive, and ardent (despite the addition of the 2014 and 2016 waves of data, our LCA results bear a strong resemblance to theirs). Creedal nationalists favor elective criteria of national belonging, rating subjective identification with the nation and respect for American laws and institutions as very important; they are more equivocal than others about the importance of lifelong residence and language skills, and view birth in the country, having American ancestry, and being Christian as not very important. They display moderate levels of national pride (with pride in America's scientific accomplishments ranking highest and pride in its social security system ranking lowest) and low levels of chauvinism (e.g., only $26 \%$ agree that the world would be a better place if others were more like Americans). This response pattern is broadly consistent with the central tenets of the American liberal creed (Lipset 1967).

\footnotetext{
${ }^{15}$ We report the relationship between sociodemographic variables and class membership in the online supplement.
} 
The disengaged class is characterized by an arm's-length relationship to the nation, which for some, may verge on dissatisfaction with and perhaps even animus toward it. Respondents in this group do not view any criteria of national membership as particularly important (and thus understand the nation's symbolic boundaries in inclusive terms), they are not especially proud of any aspect of American nationhood, and they do not view America as exceptional or superior compared to other countries. While we hesitate to go so far as to label these respondents as "nonnationalist" or "postnationalist," it does appear that for at least some of them, the national frame of reference is not particularly salient. To the degree that some of these respondents do find America meaningful, they are likely to view in negative terms, given that they espouse the lowest levels of national pride in the sample. Given these characteristics, the absence of overt nationalism in Bernie Sanders' campaign-but also his negative evaluation of the economic foundations of U.S. society - may have held particularly strong appeal for these respondents. It is also possible, however, that Trump's darkly dystopian depiction of America resonated with the low levels of national pride among some of the disengaged.

Finally, restrictive and ardent nationalists endorse both elective and ascriptive criteria of national belonging, rating them all as very important (with the importance of Christian faith ranking lowest, endorsed by $73 \%$ of ardents and $76 \%$ of restrictives). The two classes differ, however, in their degree of attachment to the nation, pride in America's accomplishments, and evaluation of the country's relative standing in the world. Restrictive nationalists exhibit considerably lower levels of attachment and pride than ardent nationalists and these differences are most pronounced for the 
pride items related to national institutions, such as pride in the way the country's democracy works (with $11 \%$ of restrictives expressing strong pride compared to $70 \%$ of ardents), its political influence in the world (7\% vs. 55\%), and its economic achievements (14\% vs. $73 \%$ ). With respect to chauvinist attitudes, restrictives are also less effusive in their celebration of American exceptionalism than ardents, with, for instance, only $41 \%$ of the former, compared to $71 \%$ of the latter, strongly agreeing that America is better than most countries and $45 \%$ of the former, compared to $62 \%$ of the latter, endorsing the idea that the world would be a better place if others were more like Americans.

For restrictive nationalists, unlike ardent nationalists, then, high barriers to national membership are accompanied by muted affect toward the nation-and the state - at least in its contemporary form. The fact that pride in America's history is an exception to this pattern suggests that restrictive nationalists may espouse a sense of nostalgia for a (real or imagined) bygone America, one that is at odds with contemporary social and cultural changes (Lipset and Raab 1970). If so, this would place their beliefs squarely in line with the rhetoric of the Trump campaign, epitomized by its campaign slogan "Make America Great Again." At the same time, the exclusionary and chauvinistic beliefs of the ardent nationalists are likely to have attracted them to the Trump message as well. ${ }^{16}$

\footnotetext{
${ }^{16}$ Our measures of exclusionary conceptions of national belonging could be interpreted as capturing xenophobia rather than broad antipathy toward a wide range of ethnic, racial, and religious minority groups. We reject this interpretation on the basis of a voluminous literature on ethnic nationalism, past studies that have shown the same items to be adequate measures of broadly exclusionary beliefs, and our own supplementary analyses of the relationship between the four nationalism types yielded by LCA and racial attitudes. For more details, see the online supplement.
} 


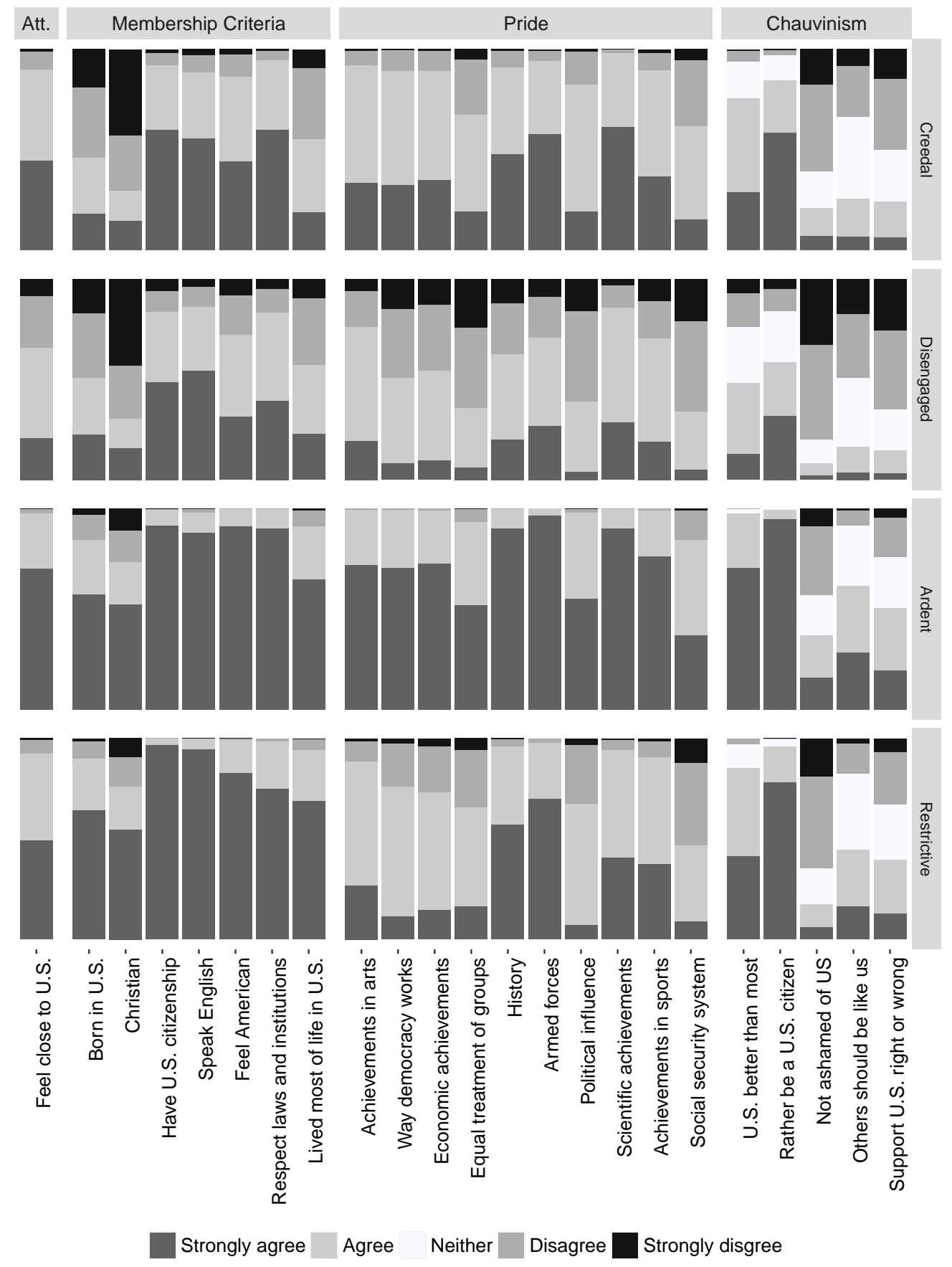

Figure 1: Posterior probabilities of nationalist item responses by latent class. Data come from the 2016 YouGov online panel. 


\section{Hypotheses}

Our interest in the relationship between the four types of nationalism and voting preferences is based on the observation that candidates in the 2016 presidential election consistently invoked nationalist rhetoric in their campaigns. Donald Trump is the most obvious example. His primary and general election messaging escalated xenophobic, religious, and racial fearmongering to levels not seen in decades, by unabashedly portraying Mexican migrants as immoral and dangerous, MexicanAmericans as un-American, and Muslim refugees as national security threats (Balz 2016). This rhetoric emerged out of Trump's earlier championing of the "birther" movement, which questioned the legitimacy of President Barack Obama as an elected official and a native-born American. Against this backdrop, Trump's persistent appeals to white working- and middle-class Americans had a decidedly white nationalist undertone, only further reinforced by his refusal to disavow the support of extremist movement leaders like former KKK Grand Wizard David Duke (Lamont et al. 2017).

Trump also consistently depicted America as a nation that had lost its way, having been dominated by corrupt liberal elites that routinely prioritize the interests of immigrants and minorities over those of "real" (read: white, nonurban) Americans (Mercieca 2020). Trump promised to "make America great again" by "draining the swamp" of corruption, restoring U.S. jobs, and defending the collective status of his predominantly white supporters (not least through restrictions on immigration, as epitomized by his infamous border wall). Thus, his discourse invoked not

only exclusionary notions of national identity but also a dark, populist vision of a morally debased nation that had been led astray by enemies within, a narrative 
that echoed the combination of attitudes - ethnocultural exclusion, low pride, and chauvinism - typical of restrictive nationalists, but that may have also appealed to ardent nationalists (through exclusion) and the disengaged (through low pride).

Donald Trump was not, however, the only Republican to make these types of claims. Ted Cruz, though less explicit, was eager to compete with Trump on the latter's terms, frequently signaling his toughness on immigration and his national security bona fides (Raju 2016). Moreover, like Trump, Cruz portrayed America in negative terms, as having been subjected to the nefarious influence of self-interested, morally corrupt political and intellectual elites (Kazin 2016; Newmyer 2015). By imbuing their nationalist vision with nostalgic and populist themes (Bonikowski and Gidron 2016; Gest et al. 2018), both Cruz and Trump sought to reach voters who were dissatisfied with the national status quo and yearned for a bygone era, presumably one in which white, Christian Americans occupied an unquestionably dominant place in the status hierarchy (Whitehead and Perry 2020). In contrast, the remaining candidates for the Republican nomination either downplayed nationalism altogether or relied on boilerplate patriotic imagery typical of creedal nationalism (Brooks 2015; Thompson 2015).

On the Democratic side, Hillary Clinton's campaign was more centrally concerned with policy proposals than identitarian appeals, but when she did reference nationalist claims and imagery, she did so in a decidedly creedal register, depicting America as an exceptional imagined community whose egalitarian ideals and human achievements are deserving of deep national pride (Karni 2016). These themes were featured especially prominently in the Democratic National Convention, the overtly patriotic 
pageantry of which bore striking resemblance to traditional Republican campaigns (Hohmann 2016). In contrast to Clinton, her chief rival in the primary election, Bernie Sanders, eschewed nationalism altogether and focused instead on a broadly populist economic message, one that vilified corporate and moneyed elites for having corrupted U.S. politics in pursuit of policies that systematically hurt the interests of everyday Americans (Cassidy 2016; Kim 2015). In formal terms, this deeply moral discourse shared some features with Trump's populism, even if the policy consequences and target constituencies of the two candidates differed sharply (Bonikowski and Gidron 2016).

Given the dearth of empirical studies of campaign content during the 2016 U.S. presidential election, the above characterization of the candidates' discourse has been based primarily on media reports. To further ensure that our assessments of the campaigns - and the resulting expectations concerning the relationship between nationalism and candidate support in the 2016 primary and general elections - are correct, we performed a systematic analysis of the candidates' campaign speeches, using word embeddings, a vector-space method for representing word similarities in a text corpus (Mikolov et al. 2013; Kozlowski et al. 2019). The results, summarized in Appendix D, are consistent with the above account. Clinton and Sanders defined the nation in inclusive terms, whereas Trump stressed the dangers of immigrants and refugees and conflated these group categories with criminality and terrorism. At the same time, Sanders and Trump framed politics in morally binary terms typical of populism: as a battle of the virtuous people against corrupt elites, while Clinton celebrated political institutions and stressed the importance of compromise and 
bipartisanship. Finally, the moderate Republican candidates' discourse resembled Clinton's more than Trump's or Sanders' (sample size limitations precluded us from analyzing Ted Cruz's campaign speeches using computational methods, but a close reading revealed similar frames to those employed by Donald Trump's campaign).

In light of these discursive patterns, we can generate some broad expectations for the survey data analysis. We divide our hypotheses between those concerning voters' preferences in the Republican and Democratic primaries and those specific to the general election. ${ }^{17}$ In generating the former, we were guided by the combinatorial logic of our theoretical approach and corresponding survey analysis methods: rather than looking for net effects of particular attitudes, we were concerned with which configurations of beliefs - represented by the four latent classes - were likely to have been activated by each candidate. This approach assumes that political mobilization outcomes are multicausal, that is, that they are the result of multiple concurrent

\footnotetext{
${ }^{17}$ Given the strength of partisan identification in the United States and the resulting prevalence of party-line voting, the question of why Donald Trump won the general election may appear less interesting than why he was able to capture his party's nomination in the first place. We challenge this assumption on two grounds. First, although it is true that in typical elections Republicans tend to vote for the Republican nominee and Democrats for the Democratic nominee with turnout being a differentiating factor for the election outcome, 2016 was not a typical election precisely because the Republican nominee was so brazenly ethnonationalist. To the degree that Republicans voted for Donald Trump, they did so either because they endorsed his extremist claims or because they did not see those claims as sufficiently objectionable to warrant withholding their support. This suggests that nationalism among Republicans may have been a crucial factor in the general election and not only in the primary. Second, if nationalism were to be predictive of Trump or Clinton support even net of partisan identification, this would suggest that some partisans defected from their party loyalties - or that Independents were swayed one way or another - on the basis of their nationalist beliefs. For both of the above reasons, we see the analysis of general election voting preferences as important.
} 
causal pathways (Viterna 2006). In general, this means that different voters may favor the same candidate for distinct reasons, but more concretely within the scope of our study, it also suggests that the nationalist discourse of a given candidate may simultaneously resonate with different types of nationalism in the electorate.

We expect Donald Trump's supporters to be particularly likely to espouse forms of nationalism that privilege ethnoculturally exclusionary criteria of national membership (Manza and Crowley 2018; Thompson 2021), low levels of national pride, and moderate to high levels of chauvinism. Three of the four types of nationalism identified by LCA fit this profile. The closest match for Trump's discourse is found among the restrictive nationalists, who combine exclusion with low pride (especially in institutions) and moderate chauvinism (consistent with Trump's alarmist depiction of contemporary American society and his disparaging view of the rest of the world). At the same time, his campaign is likely to have appealed to ardent nationalists as well, because of their strong endorsement of all exclusionary barriers to national membership, extreme chauvinism, and prideful exultation of the nation that is in line with traditional Republican beliefs. The third potentially relevant configuration of nationalist beliefs is found among the disengaged: although these respondents are broadly inclusive when it comes to the nation's symbolic boundaries, their extremely low lever of national pride may have favorably predisposed some of them toward Trump's dystopian narrative.

All three of these patterns should be particularly notable in the general election, since the Clinton campaign invoked a sharply contrasting view of the nation that would have appealed to voters espousing inclusive definitions of national membership, 
high levels of national pride, and at most moderate levels of chauvinism - that is, to creedal nationalists. This suggests the following hypothesis:

Hypothesis 1 (Trump support in the general election): In the general election, support for Trump, as opposed to Clinton, was significantly associated with adherence to restrictive, ardent, and disengaged conceptions of American nationhood, whereas support for Clinton over Trump was significantly associated with adherence to creedal nationalism.

In the primaries, we should observe little difference in the nationalist beliefs of Trump and Cruz supporters, given that both candidates engaged in persistent appeals to ethnocultural exclusion, the moral vilification of elites, and a dystopian nostalgia for an idealized national past. The attitudinal profiles of respondents who favored mainstream Republican candidates, like John Kasich, Jeb Bush, and Marco Rubio, however, should differ sharply from Trump (and Cruz) supporters. Given the less exclusionary and more exultant conceptions of America invoked by the mainstream Republican candidates, we should expect their supporters to share the creedal nationalist beliefs of Clinton voters, even if the two groups would have fundamentally disagreed on other political issues.

For Democratic primary candidates, the main difference between Clinton and Sanders supporters should consist of endorsement or rejection of affirmative nationalism, respectively, with Sanders supporters more likely to be disengaged from the nation (i.e., to view national membership in inclusive terms, while expressing low levels of national pride and chauvinism.). Sanders' use of populist rhetoric may have 
found appeal among this group as well, given their low level of pride in both the nation and the state. These predictions lead to the following three hypotheses:

Hypothesis 2 (Trump vs. Cruz in the Republican primary): In the Republican primary election, there should be no significant differences in nationalist beliefs between Trump and Cruz supporters.

Hypothesis 3 (Trump vs. moderates in the Republican primary): In the Republican primary election, support for Trump, as opposed to the mainstream candidates, should be significantly associated with adherence to restrictive, ardent, and disengaged conceptions of nationhood.

Hypothesis 4 (Clinton vs. Sanders in the Democratic primary): In the Democratic primary election, support for Sanders, as opposed to Clinton, should be significantly associated with a disengaged conception of nationhood.

We conclude with hypotheses concerning the temporal trends in nationalist beliefs, which are informed by competing explanations of Trump's success identified in the literature and described earlier in the article. The first considers the possibility of a sudden surge in restrictive, ardent, and disengaged nationalism - the attitudinal configurations we hypothesized to predict Trump support - in the sample as a whole before the 2016 election. Such a trend would be consistent with common arguments in the media that Trump's victory was enabled by — and itself catalyzed - short-term shifts toward ethnoracial exclusion and institutional distrust among white Americans. The second, alternative hypothesis focuses on the possibility of the long-term partisan sorting of nationalist beliefs, which could have stemmed from earlier historical events (e.g., 9/11, the Iraq War, right-wing responses to the Obama presidency) and 
been further exacerbated by Republican Party strategy long before Donald Trump captured the party in 2016.

Hypothesis 5 (nationalist surge): Ardent, restrictive, or disengaged conceptions of nationhood increased in prevalence between 1996 and 2016, reaching a peak before the 2016 election.

Hypothesis 6 (partisan sorting): Ardent, restrictive, or disengaged conceptions of nationhood became more closely associated with Republican partisan identification between 1996 and 2016, while creedal nationalism became more closely associated with Democratic partisan identification in the same time period.

\section{Results}

\section{Nationalism in the 2016 Election}

Having generated the latent classes and assigned respondents to each using modal assignment based on posterior membership probabilities, we regress self-reported voting preferences on class assignment. We do so using stepwise logistic regression, beginning with a baseline model, then adding respondents' sociodemographic attributes (birth in the United States, age, gender, race, geographic region, income, education, and religion) in the second model, and partisan identification in the third model (we include partisanship only in the general election analyses). All analyses were carried out in LatentGold and Stata using a three-step model with a Bolck-Croon-Hagenaars $(\mathrm{BCH})$ correction for classification bias, along with sampling weights (Bakk et al. 2013; Bolck et al. 2004; Roberts et al. 2018). For ease of interpretation, we focus our 
discussion and visualizations on the nationalism variables, but the complete regression results and model comparisons are available in Appendix E.

\section{General Election}

The results of the general election models are presented in the top-left panels of figures 2 and 3. The former illustrates the AMEs of the nationalism classes on vote intention and enables direct between-class comparisons, whereas the latter visualizes the predicted probabilities of candidate support for respondents belonging to each nationalism class (for reference purposes, the solid horizontal lines in fig. 3 indicate the level of candidate support in the sample as a whole). ${ }^{18}$

Consistent with our expectations, in the baseline model, creedal nationalism is negatively associated with Trump support, compared to support for Clinton, whereas restrictive and ardent nationalism are both positively associated with intention to vote for Trump. The AME of the disengaged class on Trump support is positive, but it does not reach significance. Once we account for respondents' sociodemographic characteristics and the partisan alignment of nationalism, however, an even clearer picture emerges: creedal nationalism is a consistent and significant predictor of respondents' intention to vote for Clinton, whereas adherence to ardent, restrictive,

\footnotetext{
${ }^{18}$ When dealing with categorical variables, AMEs represent the average discrete change from the reference category in the probability of the outcome. Note that the confidence intervals demonstrate uncertainty in the predictions and are not testing statistical significance between the predictions and the mean vote share for the sample, represented by the solid horizontal lines in fig. 3. See fig. 2 for direct tests of the differences in estimates between the four nationalist clusters.
} 


\section{National Election: Trump vs. Clinton}
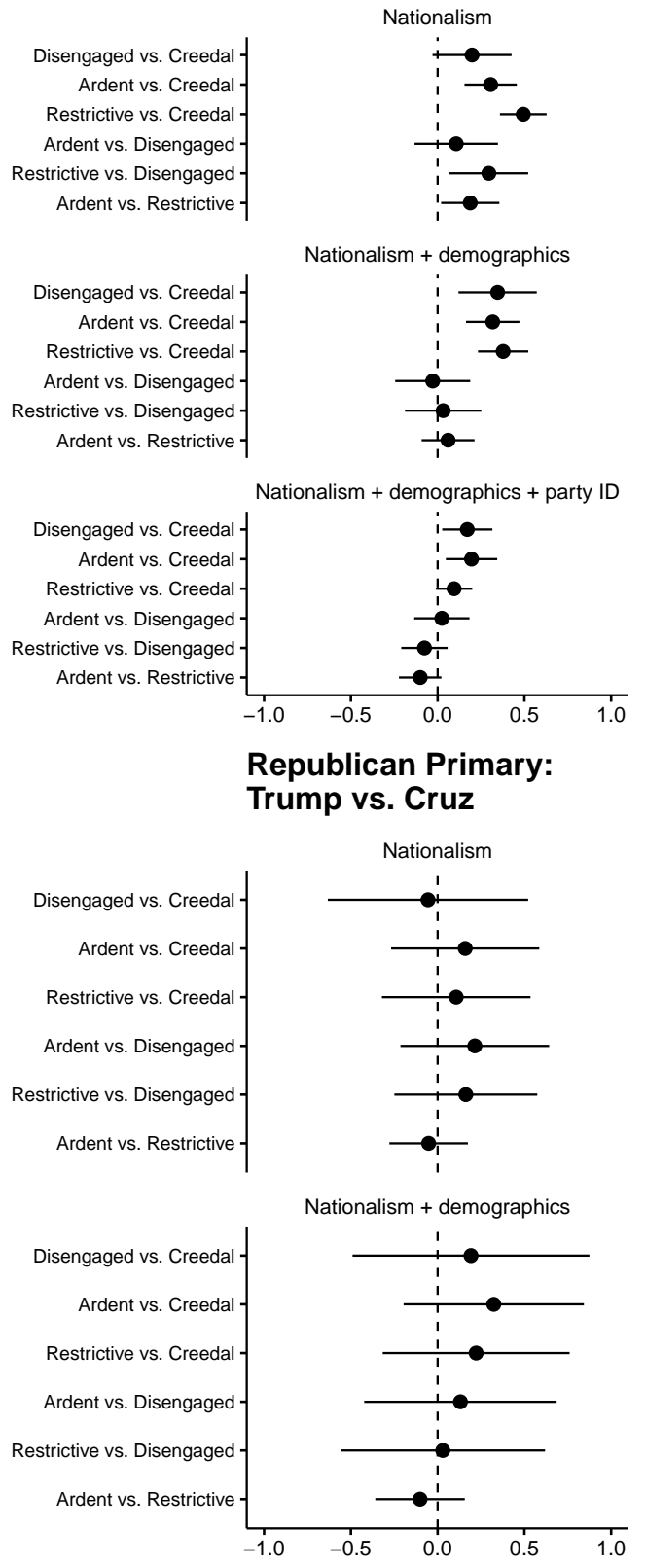

Republican Primary:

\section{Trump vs. Moderates}

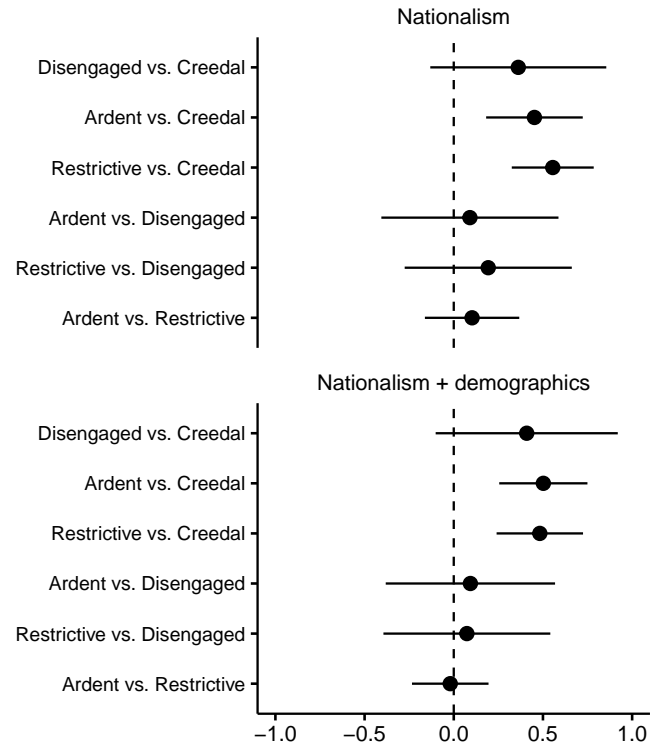

Democratic Primary: Clinton vs. Sanders
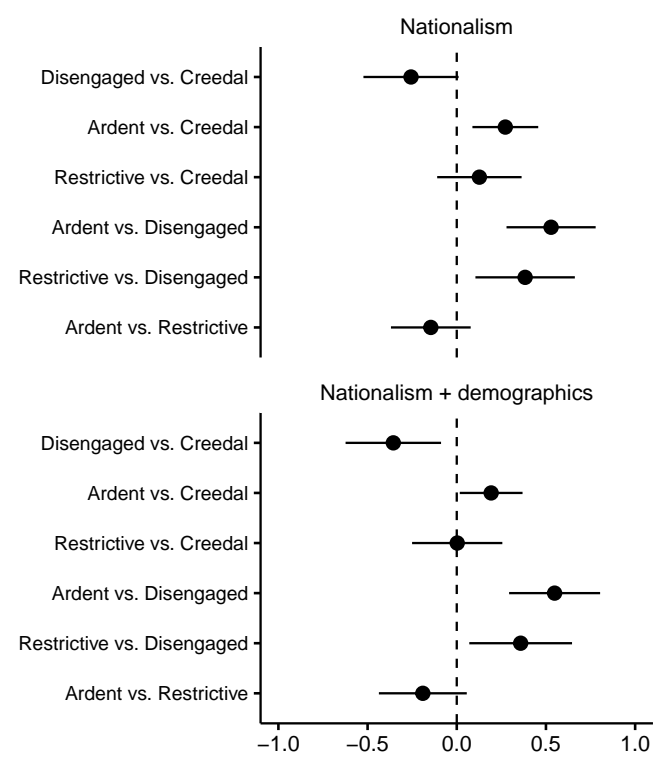

Figure 2: Logistic regression of general and primary election vote preferences on nationalist attitudes: average marginal effects. Data come from the 2016 YouGov online panel. Greater AME values correspond to higher probability of support for the first candidate in each pair. 

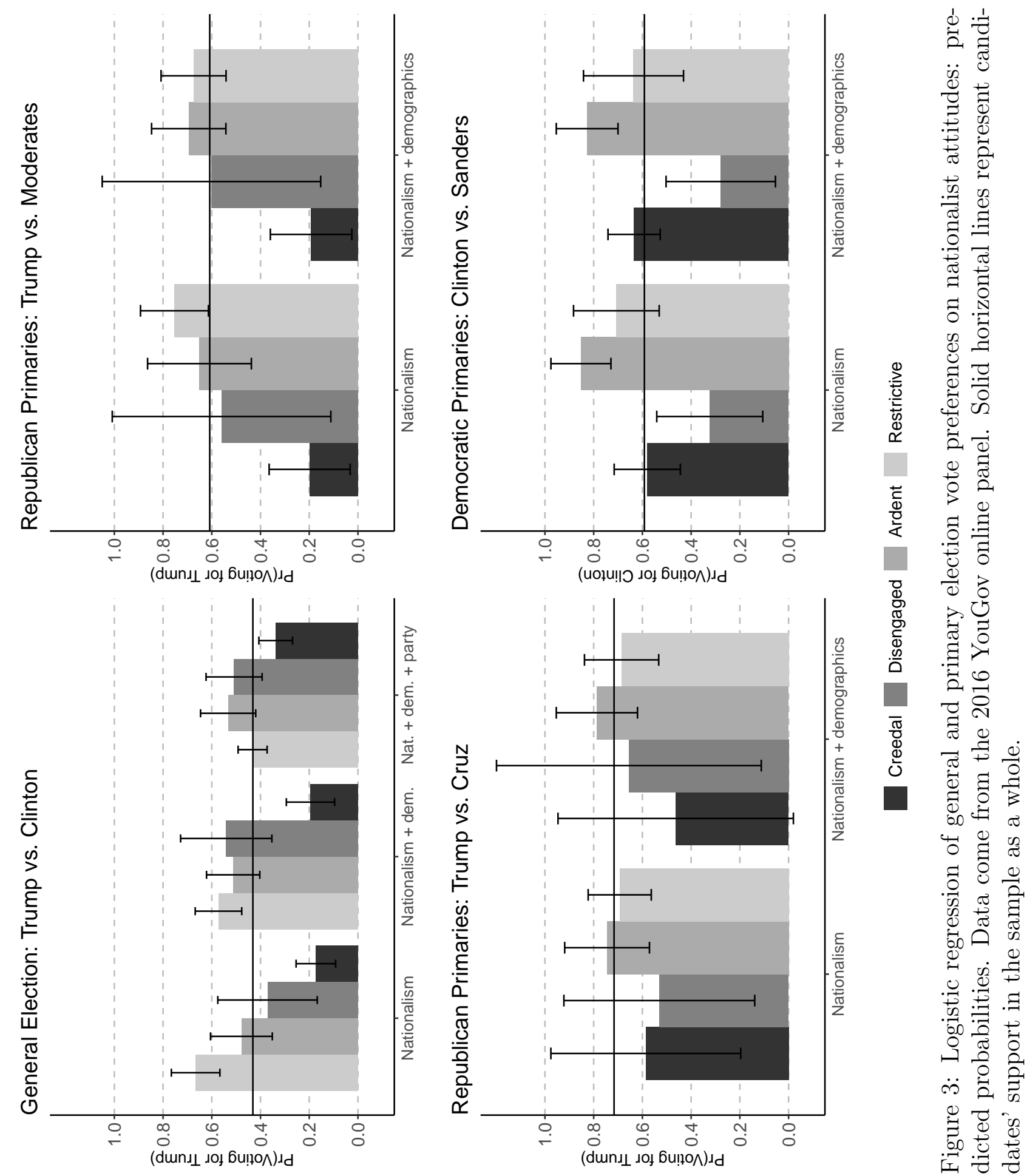
and disengaged conceptions of nationhood is significantly associated with Trump support (see Appendix E for model comparison tests).

This is in line with hypothesis 1 . Trump's campaign discourse activated nationalist beliefs among the American public that consisted of varied configurations of exclusionary conceptions of national membership (for ardents and restrictives), low levels of national pride (for restrictives and the disengaged), and moderate-to-high levels of chauvinism (for ardents and restrictives). Conversely, Clinton's emphasis on diversity and positive evaluations of the nation mobilized voters who subscribed to creedal conceptions of nationhood, characterized by inclusive criteria of national membership, high pride, and moderate chauvinism.

Furthermore, these results suggest that the pathways through which nationalism mobilized voters' support for Trump were indeed multicausal: whereas Trump's campaign discourse was most closely aligned with restrictive nationalism, some of its features also resonated with the nation schemas of the ardents and the disengaged. ${ }^{19}$ Importantly, given the relational logic of our analytical approach, these patterns should not be interpreted in the conventional framework of "net effects" of specific components of nationalism (e.g., criteria of membership, pride, or chauvinism) but rather as the aggregate associations of the overall attitudinal configurations captured by the latent classes with respondents' voting preferences. This reaffirms our argument that nationalist mobilization is not limited to claims based on ascriptive in-group identity and out-group hostility - it is the synthesis of these claims with populist critiques of political elites and institutions, nostalgic glorification of

\footnotetext{
${ }^{19}$ For a comparison of these results with those generated by continuous latent factors, see the online supplement.
} 
the nation's past and indictment of its moral decline, and chauvinist distrust of the international order that gives radical-right frames their symbolic power.

While supportive of our theory, the persistently significant AMEs of nationalism in the model that controls for partisan identification may be seen as counterintuitive. As suggested by the literatures on partisan polarization, motivated reasoning, and negative partisanship (for a recent synthesis, see Mason 2018), partisan identity typically outweighs all other predictors of vote choice in U.S. presidential elections. Once candidates are chosen by the parties, Republicans tend to vote for a Republican and Democrats for a Democrat, regardless of who is at the top of each ticket (Bartels 2016). In the full model, the party marginal effects are indeed large and highly significant (see Appendix E), but this does not reduce to nonsignificance the associations of the ardent, restrictive, and disengaged classes with Trump support. Was it the case then that partisans crossed party lines on the basis of their nationalist beliefs to support the opposing party's candidate?

The answer to this question appears to be a qualified 'yes.' To better understand the sources of the persistent association of nationalism with vote choice, we ran the same general election model with an interaction between party and nationalism. The results, presented in figure 4, demonstrate that the observed pattern was driven primarily by Democrats. Those Democratic respondents who subscribed to ardent and disengaged conceptions of nationhood were significantly more likely than their creedal counterparts to support Trump over Clinton. In contrast, none of the AMEs for Republicans and Independents are significant. Considering the potent discursive mix offered by the Trump campaign, this result makes sense: a small minority of 
Democrats whose nationalist beliefs were consistent with Trump's messaging were sufficiently mobilized by it to abandon their partisan commitments in favor of their nationalist aspirations. In contrast, Clinton's conventional creedal nationalism did not offer a comparably tempting alternative for Republicans to do the same.

A skeptical reader may wonder how the general election results relate to racial attitudes, identified by past research as important predictors of Trump support (Reny et al., 2019). We have argued that nationalism is an analytically useful category because it captures a more general conception of national group membership than any specific measure of out-group prejudice and it entails other sentiments toward the nation beyond social exclusion, such as national pride and chauvinism. If so, nationalism should be correlated with racial exclusion and racial demographics, but its association with voting preferences should persist when the latter variables are held constant. In other words, nationalism should not be empirically reducible to racism, and its association with political preferences should hold within racial groups, not just across them.

The empirical evidence is consistent with these expectations. Supplementary analyses reported in Appendix F demonstrate that (a) nationalist beliefs are correlated with sentiments toward multiple ethnoracial minority groups, and (b) the inclusion of a composite out-group feeling thermometer measure in the general election models (limited to white respondents) leads to a modest attenuation of the association of the two exclusionary nationalism classes (i.e., ardent and restrictive nationalism) with support for Trump over Clinton but does not change the significance of any of the nationalism coefficients. Moreover, general election models that 

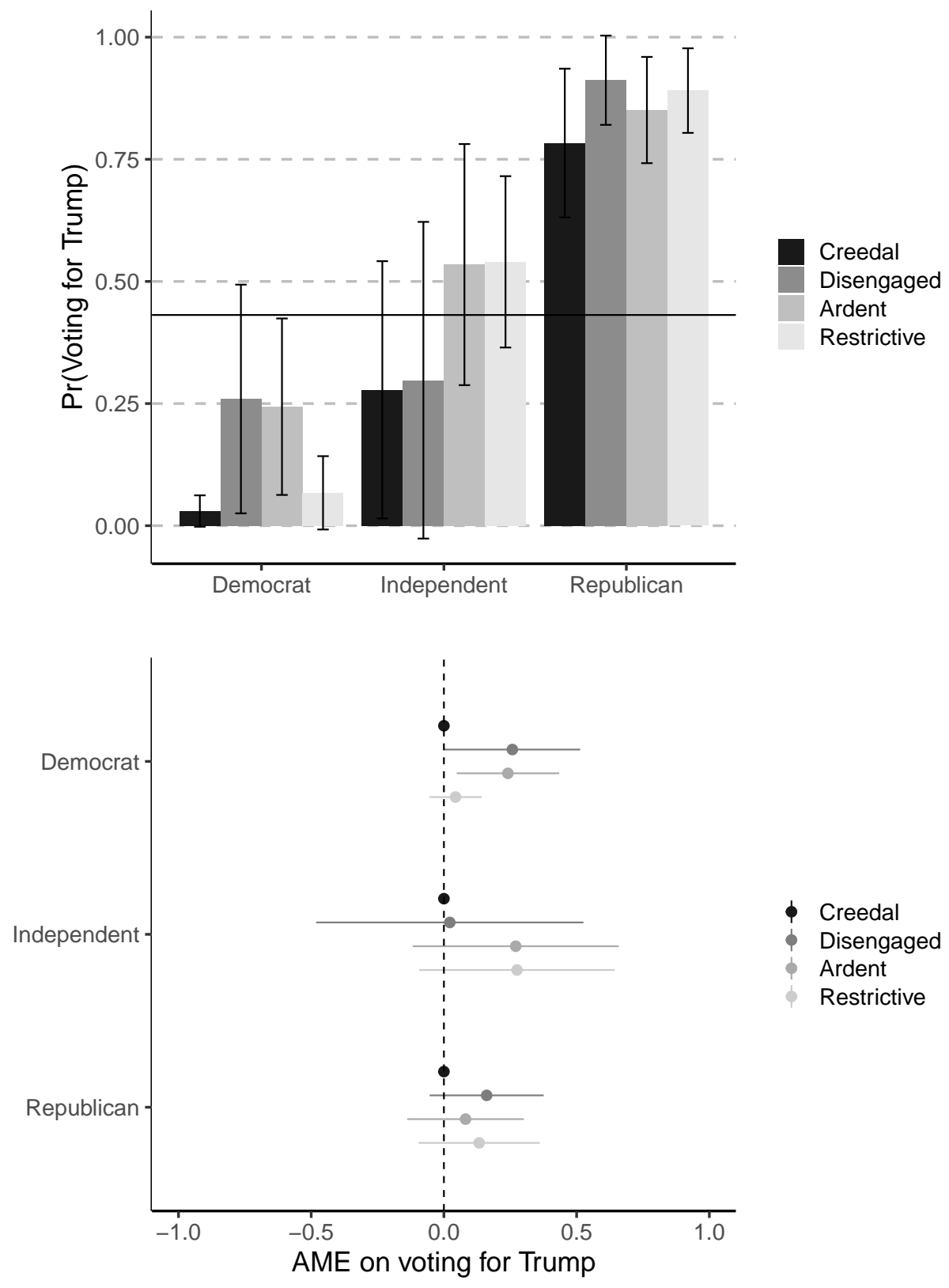

Figure 4: Interaction between party identification and nationalism predicting support for Trump over Clinton in the general election. Data come from the 2016 YouGov online panel. Top, predicted probabilities; bottom, average marginal effects. Solid horizontal line in predicted probability graphs represents candidates' support in the sample as a whole. 
include respondents' racial self-identification show small mediation effects for the disengaged and restrictive classes, but these - along with the main race coefficientscease to be statistically significant once partisan identification is included in the models (whereas nationalism remains significant). Together, these results lead us to conclude that even though racial demographics, racial antipathies, and exclusionary nationalism are correlated, they are not coterminous.

We have shown that nationalism was predictive of candidate support in the general election, but is the magnitude of the differences in voting intentions between the four nationalist classes substantively meaningful? Figures 2 and 3 suggest that it is. In the baseline model, the probability of a creedal nationalist voting for Donald Trump is 0.17 , compared to 0.37 for a disengaged respondent, 0.48 for an ardent nationalist, and 0.67 for a restrictive nationalist (the mean for the sample as a whole is 0.43$)$. In other words, creedal nationalists were nearly four times less likely than restrictives and more than two times less likely than ardents to support Trump. Not surprisingly given the strong relationship between partisanship, nationalism, and voting preferences, these differences decrease considerably in the full model that includes sociodemographic variables and partisan identification. Even net of these controls, however, creedal nationalists were less likely than other respondents to support Trump over Clinton, at a probability of 0.33 . These are sizable differences that point to the substantive importance of nationalist beliefs in the 2016 election. 


\section{Primary Elections}

We now turn to the two party primaries. The upper-right panels of figures 2 and 3 present results for the Republican race, comparing Trump support with support for the moderate candidates (i.e., John Kasich, Jeb Bush, and Marco Rubio). Compared to creedal nationalism, adherence to restrictive and ardent nationalism is associated with greater support for Trump over his moderate rivals (the difference between restrictive and ardent nationalism is not significant). The AMEs comparing disengagement from the nation to creedal nationalism are positive as well, but they fail to reach statistical significance. There are no major differences between the baseline model and a model that includes sociodemographic covariates. As figure 3 illustrates, the resulting predicted probabilities range from 0.2 for creedal nationalists to 0.75 for restrictive nationalists in the base model, and from 0.19 to 0.67 for the same classes, respectively, in the model with sociodemographic controls (compared to 0.61 in the sample as a whole).

These results provide partial evidence for hypothesis 3: in a pattern resembling the differences between Trump and Clinton supporters in the general election, respondents who favored Trump over the moderate Republican candidates in the primary were more likely to adhere to nationalist beliefs that combined exclusionary criteria of national membership with either high levels of pride and chauvinism (as in ardent nationalism) or low levels of pride and moderate chauvinism (as in restrictive nationalism). In contrast, the conventional conceptions of American nationhood invoked by the moderate candidates resonated with those respondents who viewed the nation in inclusive terms and exhibited high levels of national pride and moderate levels of 
chauvinism (i.e., creedal nationalists). These distinct configurations of nationalist beliefs served as important factors in Donald Trump's successful capture of the Republican Party before the 2016 general election. ${ }^{20}$ Indeed, once nationalist beliefs are accounted for, few of the standard sociodemographic predictors of voting preferences reach statistical significance (see Appendix E).

Do these patterns hold when Trump support is compared to support for Ted Cruz? Given the similarities between the two campaigns' rhetoric, we hypothesized that nationalist attitudes would not be an important distinguishing factor between Trump and Cruz supporters. As the lower-left panel of figure 2 illustrates, we find no significant relationships between nationalism and vote choice when comparing support for these two candidates. Because of the small sample size ( $\mathrm{N}=141$ in the baseline model) and resulting large standard errors, we hesitate to draw conclusive inferences from these results. Nonetheless, they do provide suggestive evidence in favor of hypothesis 2 .

Finally, we turn to our last cross-sectional analysis, comparing Clinton and Sanders support in the Democratic primary. We predicted that Sanders' reluctance to engage with identity-based appeals and with nationalist rhetoric in particular, along with his populist indictment of the current state of American society, should have made him more likely than Clinton to draw support from those voters who were disengaged from the nation (hypothesis 4). The results are presented in the bottom-right panels of figures 2 and 3. Consistent with our expectations, disengagement from the nation

\footnotetext{
${ }^{20}$ It is important to keep in mind that the dependent variable is based on retrospective accounts of primary voting behavior, so our estimates likely overestimate Trump support, making our analysis conservative.
} 
is associated with respondents' recall of having voted for Sanders over Clinton. Conversely, when compared to disengagement, all three of the remaining configurations of nationalist beliefs - whether inclusive or exclusionary, proud or unproud, moderately or strongly chauvinistic - appear to have been activated by Clinton's emphatic invocation of American nationhood. The probability of a disengaged respondent supporting Clinton over Sanders is 0.32 in the base model and 0.28 in the model with sociodemographic controls, compared to a sample mean of 0.59 . In contrast, restrictive and ardent nationalists favored Clinton over Sanders at a probability greater than 0.7 in the base model and greater than 0.6 in the full model. ${ }^{21}$

Taken together, the cross-sectional analyses confirm that nationalism played a significant role in the 2016 presidential election by way of multiple alternative attitudinal associations. Restrictive and ardent nationalists were more likely than creedal nationalists to support Trump over moderate candidates in the Republican primary and over Clinton in the general election, while the disengaged were more likely than all others to support Sanders over Clinton in the Democratic primary and more likely than creedals to support Trump over Clinton in the general election. Most of these associations held when sociodemographic variables - and in the general election, partisan identity - were included in the models. As demonstrated by the AMEs and predicted probabilities, the observed associations in all of the above models were

\footnotetext{
${ }^{21}$ Interestingly, we also observe a significant difference between creedal and ardent nationalism, which had not been anticipated by our hypotheses: respondents who combined high levels of national pride with exclusionary conceptions of national membership and strong chauvinism were more likely to support Clinton than Sanders, even net of sociodemographic controls. It appears that such voters found Sanders's inclusive and populist rhetoric particularly off-putting.
} 
substantively large, with some of the classes being less than half as likely — and others two times more likely — than the sample as a whole to support a given candidate.

\section{Did Trump Ride a Nativist Wave?}

Why was a political outsider wielding xenophobic, Islamophobic, racist, and darkly populist rhetoric able to capture the Republican Party and the presidency in 2016 ? Were the mid-2010s characterized by a sudden surge in conceptions of nationhood that variously combined ethnocultural exclusion, low national pride, and chauvinism across the U.S. population? Or were other temporal trends - such as the partisan sorting of nationalist beliefs (cf. Baldassarri and Gelman 2008) - more relevant for explaining nationalism's increased importance in the 2016 election? These questions led us to posit two temporal hypotheses: that ardent, restrictive, and disengaged forms of nationalism have been rising in general prevalence in the United States (hypothesis 5) and that ardent, restrictive, and disengaged forms of nationalism have become increasingly overrepresented among Republicans, while creedal nationalism

has become increasingly overrepresented among Democrats (hypothesis 6). In principle, these two scenarios could be independent of one another: it is possible that both are true or, alternatively, that only one is true. While both might also be false, it is unlikely that the Trump election, which marked a radical change in American politics, emerged out of a period of absolute stability in public beliefs vis-à-vis the nation.

In testing these predictions, we use cross-sectional data collected in 1996, 2004, 2012, 2014, and 2016 to identify long-term trends in the distribution of the four 
nationalism types, both in the aggregate and across the two parties. ${ }^{22}$ The aggregate results are presented in figure 5. The $\mathrm{X}$-axis represents time, while the $\mathrm{Y}$-axis indicates the relative proportion of the nationalism classes - visualized with the four trend lines - in each survey year.

The patterns in the top panel of figure 5, which plots the distribution of classes over time for all respondents, show little evidence of a sudden reshuffling of nationalist beliefs immediately before the 2016 election, as posited by hypothesis 5 . The four types of nationalism have certainly changed in prevalence over time, but the most radical shifts occurred not in 2016 but in 2004, following the September 11 attacks, when creedal nationalism declined to a 20-year low of 0.20 and restrictive nationalism rose to a 20-year high of 0.42 . The second inflection point was 2012 , which witnessed an increase in ardent nationalism to 0.30 and a decrease in disengagement from the nation to 0.11 (the origins of this shift are less obvious than they are for 2004). In both cases, the trends largely reverted to the status quo ante in subsequent years. Moreover, a comparison of 1996 and 2016, the two years bookending our time series, reveals a high degree of stability, with the 2016 proportions of the four nationalism types remaining within approximately 5 percentage points of their 1996 levels. The proportion of restrictive nationalism in the sample did increase by 0.07 between 2014 and 2016, but this was offset by decreases in ardent nationalism (by 0.03) and disengagement (by 0.05), as well as the continued secular rise of creedal nationalism,

\footnotetext{
${ }^{22}$ Although we have chosen to include the 2014 survey in the analysis, we are skeptical of its comparability to the other waves of data. In contrast to 1996, 2004, 2012, and 2016, 2014 was not a presidential election year, which likely affected the distribution and salience of nationalist beliefs in the sample.
} 

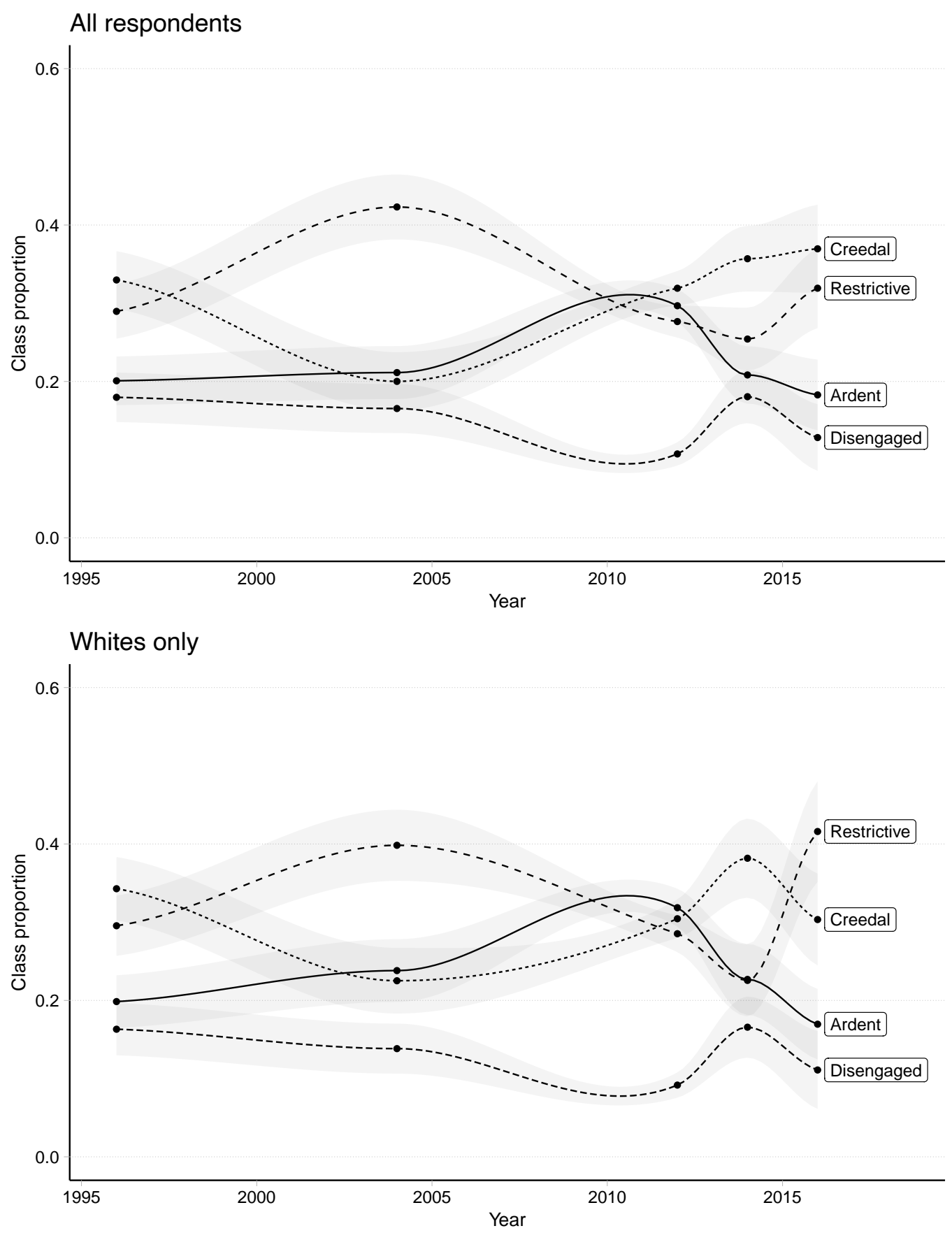

Figure 5: Class proportions by year, 1996-2016. Top, full sample; bottom, whites only. Data come from the 1996, 2004, and 2014 GSS; 2012 GfK KnowledgePanel; and 2016 YouGov online panel. 
which in 2016 reaches its highest level across all fives waves of data (at 0.37 ). It does not appear, then, that nationalist beliefs characterized by exclusion, low pride, or chauvinism surged on the eve of the 2016 election.

The above analysis includes ethnic and racial minorities, who are less likely to espouse the types of nationalism associated with Trump support. Was the relative long-term stability of nationalism also present among whites? The bottom panel in figure 5 reports the trends for the white subsample. The results are largely consistent with those for the sample as a whole, with one notable exception: the 2016 increase in restrictive nationalism is more dramatic among white respondents, reaching a 20year peak that exceeds the post-9/11 surge by 0.02 . While offset by a 0.06 decrease in ardent nationalism (and reversion to pre-2014 levels among the disengaged), this is nevertheless a notable finding. Even if the distribution of nationalism did not change much between 1996 and 2016 for Americans in general, white Americans appear to have become more exclusionary and unproud ahead of the 2016 election. An analysis of the partisan alignment of nationalist beliefs, to which we turn next, will help shed light on the likely source of this pattern.

Despite the finding that in 2016 nationalism in the general population remained at similar levels to 1996, it is possible that in the intervening years, the four types of nationalism became increasingly sorted between the two national parties, as predicted by hypothesis 6 . Figure 6 presents the distribution of nationalist beliefs over time broken down by partisan identification. These results differ sharply from what we observed in the sample as a whole: instead of short-term fluctuations around 

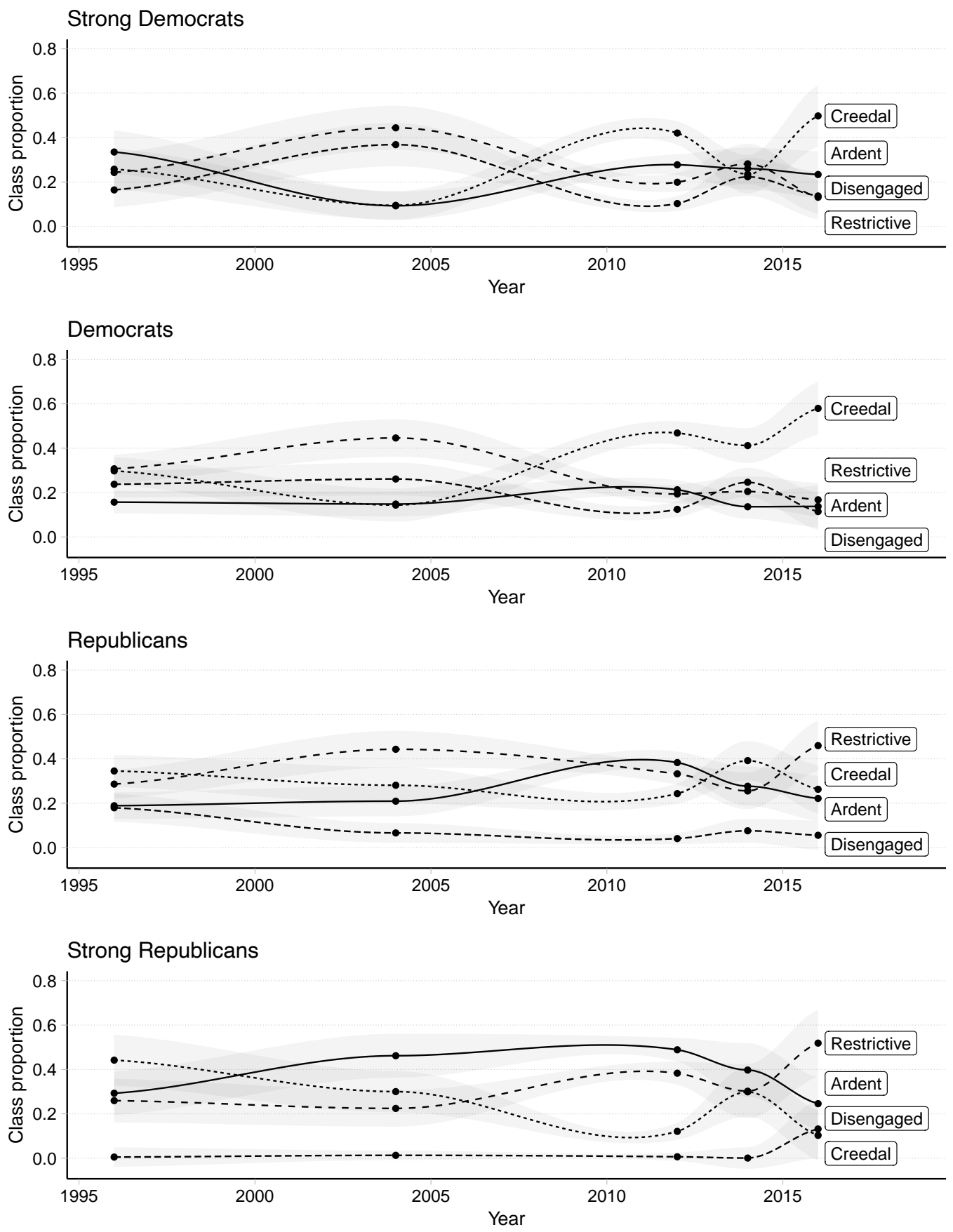

Figure 6: Class proportions by party and year, 1996-2016. Data come from the 1996, 2004, and 2014 GSS; 2012 GfK KnowledgePanel; and 2016 YouGov online panel. 
class-specific means, there is a sharp secular divergence in two of the four types of nationalism, both within and across the two parties.

The sorting trend is clearest among strong partisans, driven by particularly pronounced shifts among strong Republicans. Whereas in 1996, restrictive nationalism was common among strong Democrats (at 24\%, just below ardent and creedal nationalism), by 2016 it was the least prevalent form of nationalism in this group, found only among $13 \%$ of strong Democratic partisans. Similarly, ardent nationalism decreased in this group from $34 \%$ to $23 \%$. Over the same time period, in contrast, creedal nationalism increased dramatically among strong Democrats, from 26 percent in 1996 to 50 percent in 2016. Among strong Republicans, the opposite was true: restrictive nationalism increased between 1996 and 2016 from $26 \%$ to $52 \%$, while creedal nationalism declined precipitously, from $44 \%$ to $10 \%$. Ardent nationalism remained more stable, declining by a mere 4 points from $29 \%$ to $25 \%$. Interestingly the disengaged disposition toward the nation, which had been largely absent among strong Republicans from 1996 to 2014, surged in 2016 to 13\% of the sample.

Similar patterns - albeit more muted for Republicans - are present among less strongly committed partisans: an increase in creedal nationalism (from $30 \%$ to $58 \%$ ) and decrease in restrictive nationalism (from 31\% to 17\%) among Democrats and an increase in restrictive nationalism (from $29 \%$ to $46 \%$ ) and a decrease in creedal nationalism (from $35 \%$ to $26 \%$ ) among Republicans. ${ }^{23}$

\footnotetext{
${ }^{23}$ The temporal patterns among Independents, for whom we did not formulate hypotheses, are far more stable than among Democratic and Republican partisans,
} 
What these results reveal is that nationalism has become increasingly sorted by party in the United States. In 1996, it would have been difficult to predict a respondent's partisan identity on the basis of their nationalist beliefs (and vice versa), whereas by 2016, partisanship and nationalism had become tightly coupled: Republicans had become predominantly restrictive and Democrats had become overwhelmingly committed to creedal nationalism. These findings also help explain the increased prevalence of the restrictive class in the white sample: this form of nationalism had been on a secular rise - briefly interrupted by a downturn in 2014 (a year without a presidential election) - among Republicans, whose ranks have been increasingly dominated by white voters (Mason and Wronski 2018). ${ }^{24}$

To more formally capture the partisan sorting process, we calculated the difference between the Republican and Democratic probability of membership in each nationalist class for each year. The results broken down by nationalism type are presented in figure 7, whereas the aggregate association of nationalism with party over time (a mean of absolute party-class differences) is illustrated in figure 8 .

Consistent with the patterns observed in figure 6 , the association between restrictive and creedal nationalism and partisan identification increases dramatically over the span of our data. In 1996, the difference between the Republican and Democratic shares of creedal nationalism was 8 percentage points; by 2016, the share of Democratic creedal nationalists exceeded that of their Republican counterparts by 34 points. The change among restrictive nationalists was even more dramatic, with with all four nationalist classes in 2016 remaining within 2 percentage points of their 1996 levels.

${ }^{24}$ For a discussion of the robustness of our cross-sectional and trend results to missing data, see the online supplement. 


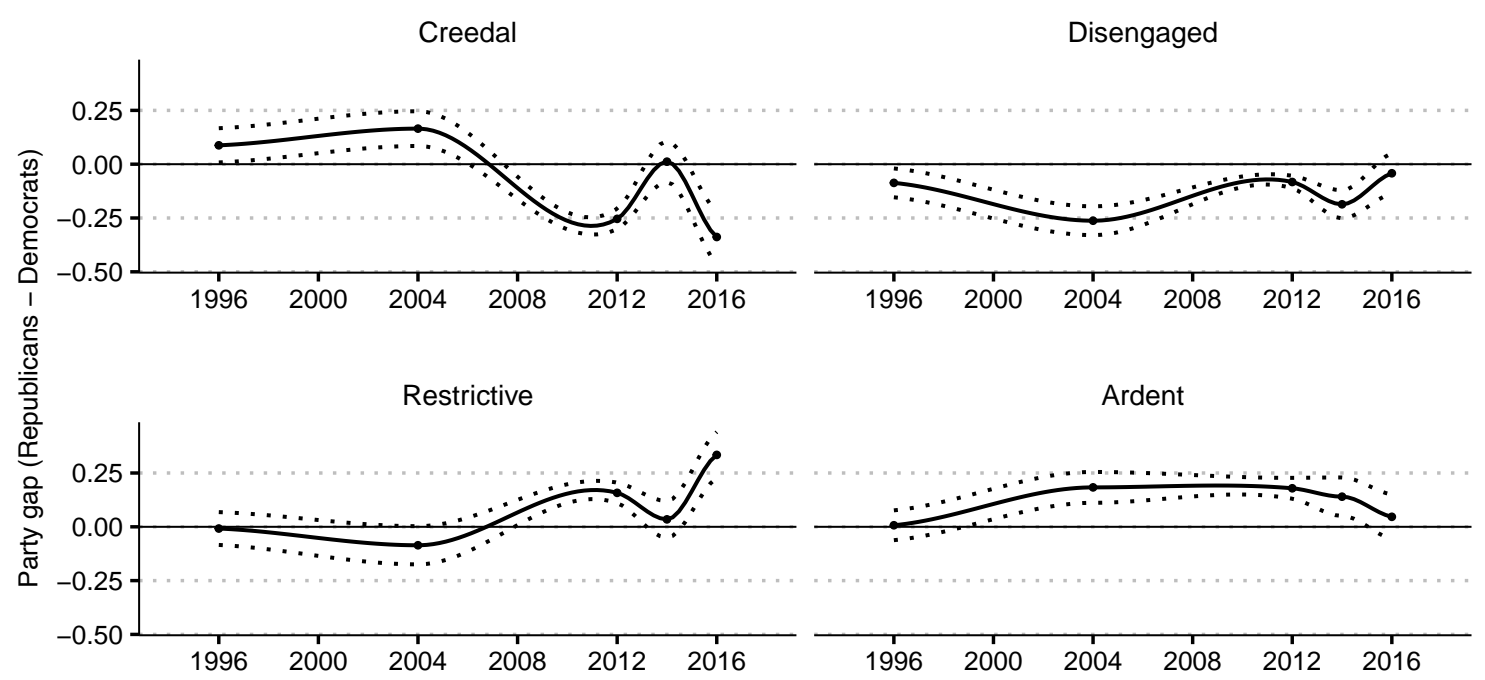

Figure 7: Probability of nationalist class membership by Republican versus Democratic identification, 1996-2016. Data come from the 1996, 2004, and 2014 GSS; 2012 GfK KnowledgePanel; and 2016 YouGov online panel.

the party gap growing from a single percentage point in 1996 to 33 points by 2016 . No comparable pattern is observed among the disengaged or ardent nationalists: the difference in the parties' share of these classes grew in 2004, but it reverted to near its 1996 levels by 2016, with disengagement remaining somewhat overrepresented among Democrats and ardent nationalism overrepresented among Republicans.

There are two other features of the figure 6 results worth noting. First, 2014 continues to stand out as an unusual year. As was the case in the aggregate and party-specific figures, the distribution of nationalism types in the 2014 GSS reflects a sharp but short-lived departure from the secular changes unfolding between 2004 and 2016. It is difficult to tell whether this is an artifact of that specific survey or a period effect associated with 2014 not being a presidential election year, in contrast to the 
other four waves of data in our study. Either way, we remain cautious in interpreting the unusual patterns observed in that survey. Second, 2014 aside, the partisan sorting observed in 2016 did not begin in that year; instead, it was a culmination of a longer-term trend first observed in 2012, but likely commencing sometime between the 2004 and 2012 wave. Explaining the causes of polarization is beyond the scope of our article, but its timing in our data is consistent with past research that sees the Trump election as in part a consequence of the Republican Party's active and racially charged vilification and delegitimization of the Obama presidency (Tesler 2016)..$^{25}$

The partisan sorting trends are further confirmed in figure 8, which illustrates the aggregate differences between the party-specific shares of all four nationalism classes. The figure provides an additional piece of information, however, regarding the timing of the partisan sorting trend. While the creedal and restrictive classes became strongly associated with the Democratic and Republican Parties, respectively, beginning in 2012, the sorting of nationalist beliefs in general began as early as 2004 - in the aftermath of the September 11 attacks and the wars in Afghanistan and Iraq - and remained at a high level through 2016 (here too 2014 marks a short-term deviation from the overall trend). The 2004 party differences are driven primarily by a rise in ardent and restrictive nationalism and a drop in creedal nationalism and

\footnotetext{
${ }^{25}$ The partisan sorting of nationalism appears to have been disproportionately influenced by attitudinal shifts among nonwhites. As analyses reported in the online supplement demonstrate, the prevalence of the four nationalism classes changed especially dramatically among African-Americans, who overwhelmingly support the Democratic Party. Restrictive nationalism decreased steadily between 1996 and 2016 among this demographic, while creedal nationalism surged over the same time period.
} 


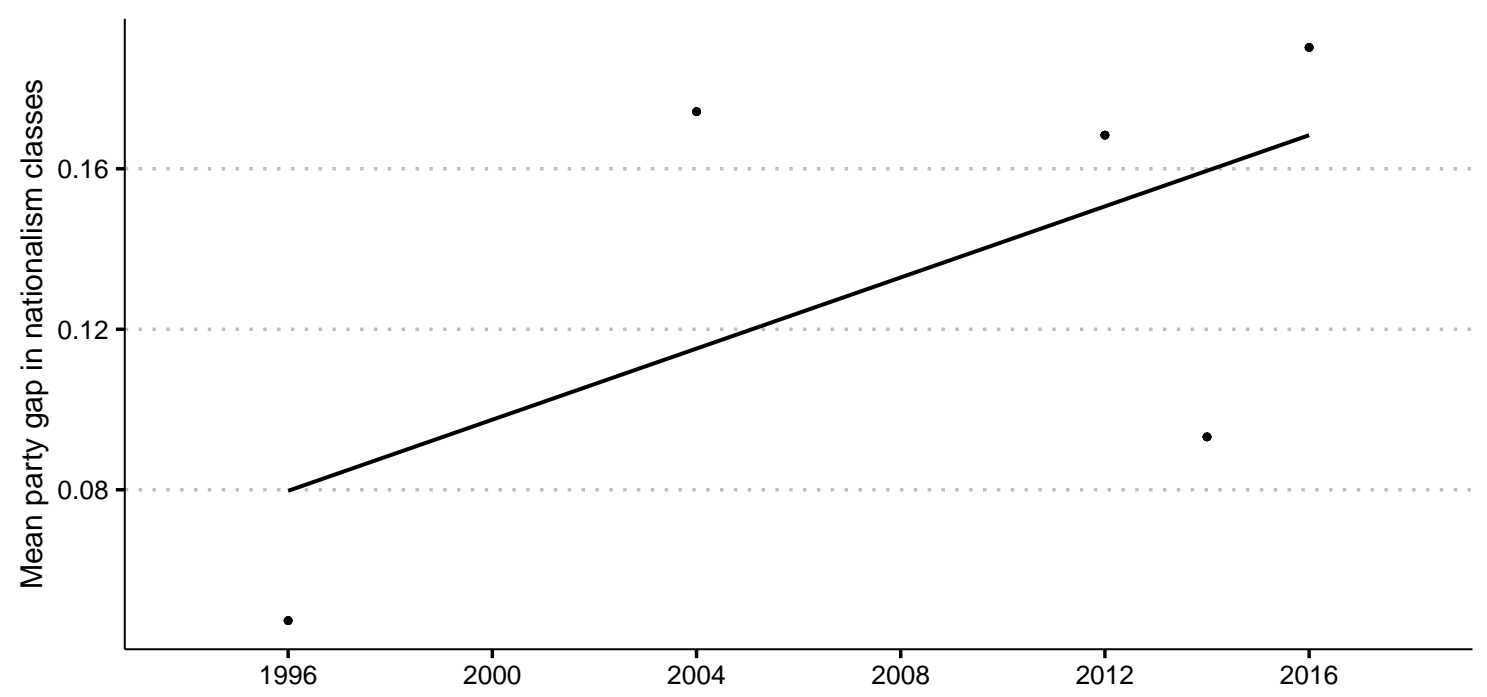

Figure 8: Mean absolute difference in probability of class membership by Republican versus Democratic identification across all nationalism types, 1996-2016. Data come from the 1996, 2004, and 2014 GSS; 2012 GfK KnowledgePanel; and 2016 YouGov online panel.

disengagement among Republicans, as well as an increase in disengagement and restrictive nationalism and a drop in ardent and creedal nationalism among Democrats. Whereas among Democrats these changes were fleeting and reverted back to baseline by 2012 , restrictive and ardent nationalism continued to dominate the Republican Party through 2016.

Together, the temporal results demonstrate that by 2016, Democrats and Republicans were sharply divided in their understanding of the nation, with Republicans overwhelmingly favoring ardent and restrictive nationalism (at a combined 71\%) and Democrats adhering to creedal nationalism (at 54\%). This was not a sudden change, however, but one that had been gradually building over the prior two decades, likely beginning with a reaction to the September 11 attacks and U.S. military engagements 
abroad and further intensifying as a consequence of the Republican Party's stoking of racial resentment and dissatisfaction with the nation's trajectory among its mostly white supporters during the Obama years. It appears then that Donald Trump did not catalyze a major shift in the political relevance of American nationalism, but rather capitalized on a demand for a politics of exclusion, populism, and discontent that had long been growing among Republican voters. Indeed, if there was a single watershed in the recent history of American popular nationalism, it was the George W. Bush presidency, which preceded the Trump campaign by over a decade. It was during this period that the two parties first set off on sharply divergent nationalist trajectories (Jacobson 2008).

\section{Discussion}

This study has used a unique combination of existing and original survey data to examine the relationship between multiple forms of American nationalism and voting preferences in the 2016 presidential election. Our cross-sectional analysis demonstrated that multiple configurations of nationalist beliefs variously combining exclusionary definitions of legitimate national membership, low levels of pride, and chauvinism provided a crucial base of support for Donald Trump, during both the Republican primary and the general election. The latter result held even once partisan identification - the strongest predictor of vote choice - was taken into account. The relevance of nationalism, however, was not limited to the general election contest between Trump and Clinton. Ardent and restrictive nationalism were also highly 
predictive of support for Trump over his moderate opponents in the Republican primary, whereas disengagement from the nation was associated with a preference for Sanders over Clinton in the Democratic primary.

As our longitudinal analysis demonstrates, the importance of nationalism in the 2016 election did not result from a sudden surge in the types of nationalism associated with Trump support. On the contrary, popular conceptions of nationhood, on average, were quite stable between 1996 and 2016 (though 2004 and 2012 marked temporary deviations from this trend). This does not imply, however, that public opinion trends were irrelevant for Donald Trump's success. What our analysis reveals is that over the same time period, Americans' nationalist beliefs became increasingly mapped onto their partisan identities. By 2016, most Republicans adhered to restrictive or ardent nationalism, while most Democrats espoused creedal nationalist beliefs. The sorting of nationalism by party represents a marked difference from the configuration of nationalist beliefs in 1996, the first wave of our data, when nationalist cleavages were largely cross-cutting with respect to party identification.

In identifying these empirical patterns, this study makes six primary contributions to the sociology and political science literature on radical politics and nationalism. First, it sets aside the vague category of "cultural" sources of radical-right support and offers a more theoretically precise and empirically grounded framework for understanding a common foundation for antipathies toward both native- and foreign-born ethnic, racial, and religious minorities, which is combined in various configurations with negative evaluations of the nation, skepticism toward established institutions and elites, and a belief in the superiority of the United States to other 
countries. These seemingly disparate sentiments are rooted in fundamental beliefs about the meaning of one's own national identity. Sharp distinctions in collective self-understanding constitute cultural cleavages in a national population that may be latent much of the time, but under particular circumstances can guide people's political decisions. The 2016 presidential election was clearly one such moment. In addition to a variety of structural changes that may have increased the resonance of distinct nationalist appeals, the partisan sorting of - but not aggregate changes in-nationalist beliefs appears to have been an important contributing factor.

Second, by relating the discursive strategies of the various campaigns in the 2016 election to the cultural schemas held by voters, the article draws attention to the importance of bringing together the supply and demand sides of politics. Our reading of the election media coverage, combined with the supplementary computational text analysis of campaign speeches (Appendix D), enabled us to posit a series of hypotheses about the likely sources of support for the various candidates. As our analyses reveal, in 2016, when identity concerns appear to have been highly salient, campaigns' decisions to rely on a particular forms of nationalist appeals - or to sidestep nationalism altogether - had important implications for respondents' evaluations of the candidates. While the ultimate outcomes of the primary and general elections were likely a function of a host of causal factors, both institutional and symbolic, the relative resonance of various forms of nationalist claims making appear to have played an important role in the process.

Third, we have demonstrated that nationalism represents yet another symbolic domain that has become increasingly sorted by party in recent decades. Given the 
cultural importance of nationalist beliefs, we view this trend as particularly concerning. Cultural schemas of the nation are not isolated social attitudes or policy preferences; they are master frames that organize people's collective self-understanding and shape their disposition toward other groups, their evaluation of the nation's past and future trajectories, and the structure and content of their interpersonal interactions (cf. Hetherington and Weiler 2009). When cultural rifts between alternative understandings of nationhood become mutually reinforcing with other sociodemographic and political cleavages, they are likely to further contribute to the erosion of social solidarity and democratic consensus building, with potentially deleterious consequences for long-term political stability. To put things more concretely, the fact that one of the two national parties has become a party of ethnoracial exclusion, nationalist discontent, and chauvinism is unlikely to produce a stable democratic equilibrium, particularly in the context of rapidly rising elite polarization, mass negative partisanship, and growing demographic diversity.

Fourth, our temporal analysis demonstrates that the partisan sorting of nationalist beliefs did not occur in the immediate prelude to the 2016 election. On the contrary, it was a product of a long-term process that appears to have begun in the aftermath of the September 11 attacks and to have become further exacerbated as a result of the Republican Party's racialized and democratically corrosive attacks on the Obama presidency. This suggests that symbolic crises may be more important in producing changes in nationalist beliefs than structural shocks, such as the Great Recession. Although the George W. Bush administration sought to unite the nation after $9 / 11$ and prevent the tragedy from generating excessive intergroup tensions, 
the choice to treat the event as an unprecedented national security crisis rather than a crime (Feinstein 2016b; Jacobson 2008), the concomitant radicalization of political discourse related to Islam and Muslims (Bail 2014), and the subsequent doubling down of Republican political elites on white identity politics (Bonikowski 2019; Jardina 2019; Tesler 2016) appear to have had long-term consequences.

In light of these trends, it makes more sense to view Donald Trump's successful campaign in the 2016 presidential election as a product of crescive changes in U.S. political culture, rather than as a cause in itself of the country's turn toward rightwing radicalism. Over the prior two decades, the demand for radical-right politics, characterized by ethnoracial exclusion, moral critique of political elites, and nostalgia for the nation's putative past glory, had been steadily growing among Republicans, whose ranks have been dominated by white Americans. This trend helps explain Republican voters' support for Sarah Palin vice presidential candidacy in the 2008 election and for the Tea Party's public protests and electoral activism in the early 2010s (Parker and Barreto 2014). Neither of these political projects, however, was able to give voice to, empower, and mobilize the growing ardent- and restrictive-nationalist Republican voting blocks with the same degree of efficacy as the Trump campaign. It is in part by skillfully articulating and amplifying the nationalist grievances of a growing majority of Republicans that Trump was able to capture the Republican Party and ultimately the presidency.

Fifth, the increased alignment between nationalist beliefs and partisan identity has substantive implications for the future of electoral politics in the United States. By foregrounding alternative visions of American nationhood, both parties' recent 
presidential campaigns have increased the political salience of nationalist beliefs, generating opportunities and constraints for future candidates. Among Democrats, the question is whether the increasingly vocal progressive wing of the party can craft a message that engages with the creedal nationalist majority of the party's supporters (Gidron 2018). Failure to do so may contribute to the party's continued dominance by its moderate core, which is at ease with creedal nationalist discourse. The Republican Party, in contrast, faces what is by now a familiar choice: whether to double down on the restrictive nationalism of its Trump wing or shift toward a more inclusive strategy that could facilitate outreach to conservative African-Americans and Latinos. The alignment of restrictive nationalism with Republican partisanship suggests that the former path is more likely. The GOP's actions in the aftermath of the 2020 electionfrom the unfounded moral panic about voting fraud and widespread support of the Capitol insurrection to the party elites' continued fealty to Donald Trump - are in line with this prediction. ${ }^{26}$

One potential solution to the nationalism-borne constraints facing both parties would be to change the topic of the public conversation in a way that decreases the

\footnotetext{
${ }^{26}$ Interestingly, even though there is little evidence of a changing alignment of the disengaged class with partisanship, we observed a significant association between this inclusive but low-pride and low-chauvinism type of nationalism and Trump support. Supplementary evidence further suggests that this association is particularly strong among nonwhite voters. Not only do these findings reaffirm our claim that ethnoracial exclusion is not the sole basis of radical-right support, but they also imply potential opportunities for the nationalist mobilization of a broadly disaffectedand possibly culturally conservative - constituency through a nostalgic and declinist nationalism that nonetheless frames the nation in inclusive terms. Such a strategy could allow Republicans to maintain their populist appeal without alienating nonwhite supporters, including potential swing voters from among the ranks of disillusioned Democrats. We thank the editor for suggesting this point.
} 
political salience of voters' nationalist beliefs. The conduct of the Biden administration in the first half of 2021 appears partly consistent with this strategy. Whether such a scenario is realistic in the longer term, however, is called into question by the fact that what is a constraint for some factions within the two parties is perceived as an opportunity by others. As long as nationalist appeals continue to be effective and cost free for both Democratic and Republican candidates - a calculus all but ensured by the homogenization of nationalist beliefs within both parties - public battles over the meaning of America are likely to persist. Yet, a symmetry of incentives does not imply a symmetry of consequences: only one of the two parties has undergone a process of radicalization that has unmoored it from its liberal democratic commitments. In an era of sustained nationalist discord, the Republican Party's active stoking of ethnoracial exclusion and declinist nostalgia will continue to pose a dire threat to the stability of U.S. political institutions.

Finally, in programmatic terms, this article demonstrates the value of bridging the divide between political science and sociology in the study of radical politics. By synthesizing insights concerning the conceptualization and measurement of belief structures from cultural sociology and the role of conflicting nationhood schemas from the nationalism literature with the focal subject matter of comparative party politics scholarship, we have sought to make contributions to both disciplines. We hope that our work will inspire political sociologists to continue their reengagement with the study of institutional politics, while prompting political scientists to take culture more seriously in their research on electoral outcomes. The areas of commonality between these historically related fields are expanding and our work is both inspired 
by and seeks to promote the continued cross-pollination of ideas between them. The value of such engagement is not purely academic: the dangers posed to the future of liberal democracy by the rise of radical politics demand rigorous, multicausal analyses that transcend disciplinary constraints. It is our view that nationalismclearly theorized and precisely measured-belongs at the center of such analyses.

One limitation of our study is that it is necessarily correlational rather than causal, because of the unavailability of panel data on nationalist beliefs. As a result, our analyses effectively treat political discourse and attitudes as exogenous and stable during the 2016 election. Of course, this is a simplification of how politics actually works. In reality, candidates engage in extensive public opinion polling, experiment with a variety of campaign frames, and adjust their messaging on the basis of audience reactions (the latter was especially true of Donald Trump's haphazard but effective approach to campaigning, which relied on real-time crowd feedback at mass rallies [McVeigh and Estep 2019]). Nationalist beliefs in the electorate are also likely to be activated - and perhaps even altered - depending on the specific frames chosen by candidates and amplified by the media (Flores 2017). Although we are unable to model these recursive processes directly, they are broadly consistent with our theoretical framework, which assumes that latent cultural cleavages are potentially mobilizable by the right type of political discourse in the right structural conditions (McDonnell et al. 2017). At the same time, the fact that the aggregate attitudinal stability and partisan polarization we observe in our data had preceded the 2016 election suggests that Donald Trump's campaign did not in itself generate a sudden nationalist upsurge in the American public. On the contrary, the necessary (but not 
sufficient) conditions for a takeover of the Republican Party by its radical wing had been in the making for the prior two decades.

Our theoretical model and empirical results suggest, therefore, that the key question facing scholars of contemporary radical politics is not whether nationalist campaign discourse generates attitudinal change or vice versa, but rather, why nationalism, which has long been a feature of political culture in most democracies, has become especially salient in recent years. A conclusive answer to this question is beyond the scope of this article, but what seems clear is that existing explanations invoking structural factors common across countries (e.g., growing economic inequality, trade shocks, economic crises, demographic change, labor union decline) and country-specific contingent events (e.g., racial backlash against President Barack Obama in the United States, the nationalist framing of the Smolensk plane crash by the PiS party in Poland) should be supplemented by greater attention to the longterm realignment of nationalist beliefs among democratic publics. In the United States, this trend had generated growing demand for radical-right politics among a large subset of white Americans, whose votes were then captured by an opportunistic politician relying on a persuasive combination of exclusionary, populist, and dystopian political claims. Whether these mechanisms have proximate parallels in other contemporary democracies that have faced a radical-right upsurge is a matter for future research. 


\section{References}

Abramowitz, Alan I and Steven Webster. 2016. "The Rise of Negative Partisanship and the Nationalization of US Elections in the 21st Century." Electoral Studies $41: 12-22$.

Akkerman, Agnes, Cas Mudde, and Andrej Zaslove. 2014. "How Populist Are the People? Measuring Populist Attitudes in Voters." Comparative political studies 47:1324-1353.

Alemán, José and Dwayne Woods. 2018. "Inductive Constructivism and National Identities: Letting the Data Speak." Nations and Nationalism 24:1023-1045.

Anderson, Carol. 2016. White Rage: The Unspoken Truth of Our Racial Divide. New York: Bloomsbury Publishing.

Ariely, Gal. 2012. "Do Those Who Identify with Their Nation Always Dislike Immigrants?: An Examination of Citizenship Policy Effects." Nationalism and Ethnic Politics 18:242-261.

Atkeson, Lonna Rae. 1999. "Sure, I Voted for the Winner!" Overreport of the Primary Vote for the Party Nominee in the National Election Studies." Political Behavior 21:197-215.

Bail, Christopher A. 2014. Terrified: How Anti-Muslim Fringe Organizations Became Mainstream. Princeton, NJ: Princeton University Press. 
Bakk, Zsuzsa, Fetene B Tekle, and Jeroen K Vermunt. 2013. "Estimating the Association between Latent Class Membership and External Variables Using BiasAdjusted Three-Step Approaches." Sociological Methodology 43:272-311.

Baldassarri, Delia and Andrew Gelman. 2008. "Partisans without Constraint: Political Polarization and Trends in American Public Opinion." American Journal of Sociology 114:408-446.

Balz, Dan. 2016. "Pushing Racial Boundaries, Trump Draws Rebuke from a Fretful GOP." The Washington Post .

Bartels, Larry. 2016. “2016 Was an Ordinary Election, Not a Realignment.” Monkey Cage, The Washington Post.

Blank, Thomas and Peter Schmidt. 2003. "National Identity in a United Germany: Nationalism or Patriotism? An Empirical Test with Representative Data." Political Psychology 24:289-312.

Bobo, Lawrence D. 1999. "Prejudice as Group Position: Microfoundations of a Sociological Approach to Racism and Race Relations." Journal of Social Issues 55:445-472.

Bobo, Lawrence D. 2017. "Racism in Trump's America: reflections on culture, sociology, and the 2016 US presidential election." The British Journal of Sociology 68:S85-S104. 
Bolck, Annabel, Marcel Croon, and Jacques Hagenaars. 2004. "Estimating Latent Structure Models with Categorical Variables: One-Step Versus Three-Step Estimators." Political Analysis 12:3-27.

Bonikowski, Bart. 2016. "Nationalism in Settled Times." Annual Review of Sociology 42:427-449.

Bonikowski, Bart. 2017a. "Ethno-Nationalist Populism and the Mobilization of Collective Resentment." The British Journal of Sociology 68:S181-S213.

Bonikowski, Bart. 2017b. "Nationhood as Cultural Repertoire: Collective Identities and Political Attitudes in France and Germany." In Everyday Nationhood: Theorising Culture, Identity and Belonging after Banal Nationalism, edited by Michael Skey and Michael Antonsich, pp. 147-174. London, UK: Palgrave.

Bonikowski, Bart. 2019. "Trump's Populism: The Mobilization of Nationalist Cleavages and the Future of U.S. Democracy." In When Democracy Trumps Populism, edited by Kurt Weyland and Raúl L Madrid, pp. 110-131. New York: Cambridge University Press.

Bonikowski, Bart and Paul DiMaggio. 2016. "Varieties of American Popular Nationalism." American Sociological Review 81:949-980.

Bonikowski, Bart and Paul DiMaggio. 2021. "Mapping culture with latent class analysis: A response to Eger and Hjerm." Nations and Nationalism .

Bonikowski, Bart and Noam Gidron. 2016. "The Populist Style in American Politics: Presidential Campaign Discourse, 1952-1996." Social Forces 94:1593-1621. 
Boutyline, Andrei and Stephen Vaisey. 2017. "Belief Network Analysis: A Relational Approach to Understanding the Structure of Attitudes." American journal of sociology 122:1371-1447.

Brooks, David. 2015. "The Talented Mr. Rubio."

Brubaker, Rogers. 2009. "Ethnicity, Race, and Nationalism." Annual Review of Sociology 35:21-42.

Carson, Jamie L, Michael H Crespin, Charles J Finocchiaro, and David W Rohde. 2007. "Redistricting and Party Polarization in the US House of Representatives." American Politics Research 35:878-904.

Cassidy, John. 2016. "Bernie Sanders and the New Populism." The New Yorker.

Castanho Silva, Bruno, Sebastian Jungkunz, Marc Helbling, and Levente Littvay. 2019. "An Empirical Comparison of Seven Populist Attitudes Scales." Political Research Quarterly.

Citrin, Jack, Cara Wong, and Brian Duff. 2001. "The Meaning of American National Identity." In Social Identity, Intergroup Conflict, and Conflict Reduction, edited by Richard D. Ashmore, Lee J. Jussim, and David Wilder, pp. 71-100. New York: Oxford University Press.

de Figueiredo Jr, Rui JP and Zachary Elkins. 2003. "Are Patriots Bigots? An Inquiry into the Vices of In-Group Pride." American Journal of Political Science 47:171-188. 
Delehanty, Jack, Penny Edgell, and Evan Stewart. 2018. "Christian America? Secularized Evangelical Discourse and the Boundaries of National Belonging." Social Forces 97:1283-1306.

DellaPosta, Daniel. 2020. "Pluralistic collapse: The "oil spill" model of mass opinion polarization." American Sociological Review 85:507-536.

DiMaggio, Paul. 1997. "Culture and Cognition." Annual Review of Sociology 23:263287.

DiMaggio, Paul, John Evans, and Bethany Bryson. 1996. "Have Americans' Social Attitudes Become More Polarized?" American Journal of Sociology 102:690-755.

Druckman, James N, Erik Peterson, and Rune Slothuus. 2013. "How Elite Partisan Polarization Affects Public Opinion Formation." American Political Science Review 107:57-79.

Edgell, Penny and Eric Tranby. 2010. "Shared Visions? Diversity and Cultural Membership in American Life." Social Problems 57:175-204.

Elgenius, Gabriella and Jens Rydgren. 2019. "Frames of nostalgia and belonging: The resurgence of ethno-nationalism in Sweden." European Societies 21:583-602.

Evans, Mariah DR and Jonathan Kelley. 2002. "National Pride in the Developed World: Survey Data from 24 Nations." International journal of public opinion research 14:303-338. 
Feinstein, Yuval. 2016a. "Pulling the Trigger: How Threats to the Nation Increase Support for Military Action via the Generation of Hubris." Sociological Science $3: 317-334$.

Feinstein, Yuval. 2016b. "Rallying Around the President: When and Why Do Americans Close Ranks Behind Their Presidents During International Crisis and War?" Social Science History 40:305-338.

Feinstein, Yuval. 2018. "One flag, two rallies: Mechanisms of public opinion in Israel during the 2014 Gaza war." Social science research 69:65-82.

Feinstein, Yuval and Bart Bonikowski. 2019. "Nationalist Narratives and AntiImmigrant Attitudes: Exceptionalism and Collective Victimhood in Contemporary Israel." Journal of Ethnic and Migration Studies 47:741-61.

Fiorina, Morris P and Samuel J Abrams. 2008. "Political Polarization in the American Public." Annual Review of Political Science 11:563-588.

Flores, René D. 2017. "Do anti-immigrant laws shape public sentiment? A study of Arizona's SB 1070 using Twitter data." American Journal of Sociology 123:333384 .

Gangl, Katharina, Benno Torgler, and Erich Kirchler. 2016. "Patriotism's Impact on Cooperation with the State: An Experimental Study on Tax Compliance." Political Psychology 37:867-881.

Gerber, Alan S, James G Gimpel, Donald P Green, and Daron R Shaw. 2011. "How Large and Long-Lasting Are the Persuasive Effects of Televised Campaign Ads? 
Results from a Randomized Field Experiment." American Political Science Review $105: 135-150$.

Gest, Justin, Tyler Reny, and Jeremy Mayer. 2018. "Roots of the Radical Right: Nostalgic Deprivation in the United States and Britain." Comparative Political Studies 51:1694-1719.

Gidron, Noam. 2018. "The Left Shouldn't Fear Nationalism. It Should Embrace It." Vox Feb. 8.

Gidron, Noam and Peter A Hall. 2017. "The Politics of Social Status: Economic and Cultural Roots of the Populist Right." The British Journal of Sociology 68:S57S84.

Gilens, Martin. 2009. Why Americans Hate Welfare: Race, Media, and the Politics of Antipoverty Policy. Chicago, IL: University of Chicago Press.

Goldberg, Amir. 2011. "Mapping Shared Understandings Using Relational Class Analysis: The Case of the Cultural Omnivore Reexamined." American journal of sociology 116:1397-1436.

Golder, Matt. 2016. "Far Right Parties in Europe." Annual Review of Political Science 19:477-497.

Guynn, Jessica. 2016. "'Massive Rise' in Hate Speech on Twitter During Presidential Election." USA Today . 
Hanson, Kristin and Emma O’Dwyer. 2018. "Patriotism and Nationalism, Left and Right: AQ-Methodology Study of American National Identity." Political Psychology .

Hawkins, Kirk A. 2009. "Is Chávez Populist? Measuring Populist Discourse in Comparative Perspective." Comparative Political Studies 42:1040-1067.

Hetherington, Marc J and Jonathan D Weiler. 2009. Authoritarianism and Polarization in American Politics. New York: Cambridge University Press.

Higham, John. 1955. Strangers in the Land: Patterns of American Nativism, 18601925. New Brunswick, NJ: Rutgers University Press.

Hohmann, James. 2016. "The Daily 202: Democrats Claim Patriotism, God and American Exceptionalism at Convention." The Washington Post .

Hopkins, Daniel J. 2018. The Increasingly United States: How and Why American Political Behavior Nationalized. Chicago, IL: University of Chicago Press.

Huddy, Leonie and Nadia Khatib. 2007. "American Patriotism, National Identity, and Political Involvement." American journal of political science 51:63-77.

Hunzaker, MB Fallin and Lauren Valentino. 2019. "Mapping Cultural Schemas: From Theory to Method." American Sociological Review 84:950-981.

Ivarsflaten, Elisabeth. 2008. "What Unites Right-Wing Populists in Western Europe? Re-Examining Grievance Mobilization Models in Seven Successful Cases." Comparative Political Studies 41:3-23. 
Iyengar, Shanto and Adam F Simon. 2000. "New Perspectives and Evidence on Political Communication and Campaign Effects." Annual review of psychology $51: 149-169$.

Jacobson, Gary C. 2008. A Divider, Not a Uniter: George W. Bush and the American People. New York: Longman Publishing Group.

Jacobson, Gary C. 2015. "How Do Campaigns Matter?" Annual Review of Political Science 18:31-47.

Jardina, Ashley. 2019. White Identity Politics. Cambridge Studies in Public Opinion and Political Psychology. Cambridge University Press.

Jones, Bradley. 2019. "Majority of Americans Continue to Say Immigrants Strengthen the U.S." Technical report, Pew Research Center, Washington, DC.

Jones, David R. 2001. "Party Polarization and Legislative Gridlock." Political Research Quarterly 54:125-141.

Kankaraš, Miloš, Guy Moors, and Jeroen K Vermunt. 2012. "Testing for Measurement Invariance with Latent Class Analysis." In Cross-Cultural Analysis, pp. 381-406. London, UK: Routledge.

Karni, Annie. 2016. "Hillary Clinton's Star-Spangled Bus Tour." Politico .

Kazin, Michael. 2016. "Trump and American Populism: Old Whine, New Bottles." Foreign Affairs . 
Kendi, Ibram X. 2017. Stamped from the Beginning: The Definitive History of Racist Ideas in America. New York: Random House.

Kim, Seung Min. 2015. "Sanders and immigration? It's Complicated." Politico .

Knight, Carly R and Mary C Brinton. 2017. "One Egalitarianism or Several? Two Decades of Gender-Role Attitude Change in Europe." American Journal of Sociology 122:1485-1532.

Kosterman, Rick and Seymour Feshbach. 1989. "Toward a Measure of Patriotic and Nationalistic Attitudes." Political psychology pp. 257-274.

Kozlowski, Austin C., Matt Taddy, and James A. Evans. 2019. "The Geometry of Culture: Analyzing the Meanings of Class Through Word Embeddings." American Sociological Review 84:905-949.

Kunovich, Robert M. 2009. "The Sources and Consequences of National Identification." American Sociological Review 74:573-593.

Lamont, Michèle, Bo Yun Park, and Elena Ayala-Hurtado. 2017. "Trump's Electoral Speeches and His Appeal to the American White Working Class." The British Journal of Sociology 68:S156-S180.

Layman, Geoffrey C and Thomas M Carsey. 2002. "Party Polarization and Party Structuring of Policy Attitudes: A Comparison of Three NES Panel Studies." Political Behavior 24:199-236.

Levendusky, Matthew. 2009. The Partisan Sort: How Liberals Became Democrats and Conservatives Became Republicans. Chicago, IL: University of Chicago Press. 
Levendusky, Matthew S. 2013. "Why Do Partisan Media Polarize Viewers?" American Journal of Political Science 57:611-623.

Levitsky, Steven and Daniel Ziblatt. 2018. How Democracies Die. New York: Crown.

Li, Qiong and Marilynn B Brewer. 2004. "What Does It Mean to Be an American? Patriotism, Nationalism, and American Identity after 9/11." Political Psychology $25: 727-739$.

Lipset, Seymour Martin. 1967. The First New Nation: The United States in Historical and Comparative Perspective. Piscataway, NJ: Transaction Publishers.

Lipset, Seymour Martin and Earl Raab. 1970. The Politics of Unreason: Right Wing Extremism in America, 1790-1970. New York: Harper \& Row.

Long, J Scott and Sarah A Mustillo. 2018. "Using Predictions and Marginal Effects to Compare Groups in Regression Models for Binary Outcomes." .

Lubbers, Marcel and Marcel Coenders. 2017. "Nationalistic Attitudes and Voting for the Radical Right in Europe." European Union Politics 18:98-118.

Lucassen, Geertje and Marcel Lubbers. 2012. "Who Fears What? Explaining FarRight-Wing Preference in Europe by Distinguishing Perceived Cultural and Economic Ethnic Threats." Comparative Political Studies 45:547-574.

Manza, Jeff and Clem Brooks. 1999. Social Cleavages and Political Change: Voter Alignments and U.S. Party Coalitions. New York: Oxford University Press. 
Manza, Jeff and Ned Crowley. 2018. "Ethnonationalism and the Rise of Donald Trump." Contexts 17:28-33.

Mason, Lilliana. 2018. Uncivil Agreement: How Politics Became Our Identity. Chicago, IL: University of Chicago Press.

Mason, Lilliana and Julie Wronski. 2018. "One Tribe to Bind Them All: How Our Social Group Attachments Strengthen Partisanship." Political Psychology 39:257277.

McCarty, Nolan, Keith T Poole, and Howard Rosenthal. 2016. Polarized America: The Dance of Ideology and Unequal Riches. Cambridge, MA: MIT Press.

McCutcheon, Allan L. 1987. Latent Class Analysis. Number 64. Thousand Oaks, CA: Sage.

McDonnell, Terence E., Christopher A. Bail, and Iddo Tavory. 2017. "A Theory of Resonance." Sociological Theory 35:1-14.

McVeigh, Rory and Kevin Estep. 2019. The Politics of Losing: Trump, the Klan, and the Mainstreaming of Resentment. New York: Columbia University Press.

Mercieca, Jennifer. 2020. Demagogue for President: The Rhetorical Genius of Donald Trump. College Station, TX: Texas A\&M University Press.

Mikolov, Tomas, Kai Chen, Greg Corrado, and Jeffrey Dean. 2013. "Efficient estimation of word representations in vector space." arXiv preprint arXiv:1301.3781 
Mize, Trenton D., Long Doan, and J. Scott Long. 2019. "A General Framework for Comparing Predictions and Marginal Effects across Models." Sociological Methodology pp. 1-38.

Mohr, John W. 1998. "Measuring Meaning Structures." Annual Review of Sociology $24: 345-370$.

Morgan, Stephen L. 2018. "Correct Interpretations of Fixed-effects Models, Specification Decisions, and Self-reports of Intended Votes: A Response to Mutz." Socius 4:2378023118811502.

Morgan, Stephen L and Jiwon Lee. 2017. "The White Working Class and Voter Turnout in US Presidential Elections, 2004 to 2016." Sociological Science 4:656685.

Mudde, Cas. 2007. Populist Radical Right Parties in Europe. Cambridge, UK: Cambridge University Press.

Müller-Peters, Anke. 1998. "The Significance of National Pride and National Identity to the Attitude Toward the Single European Currency: A Europe-Wide Comparison." Journal of economic psychology 19:701-719.

Mutz, Diana C. 2018. "Status Threat, Not Economic Hardship, Explains the 2016 Presidential Vote." Proceedings of the National Academy of Sciences 115:E4330E4339.

Newmyer, Tory. 2015. "Ted Cruz Just Upped the Populist Ante for 2016 Republicans." Fortune . 
Norris, Pippa and Ronald Inglehart. 2018. Cultural Backlash: Trump, Brexit, and Authoritarian Populism. New York: Cambridge University Press.

Parker, Christopher S. 2010. "Symbolic Versus Blind Patriotism: Distinction Without Difference?" Political Research Quarterly 63:97-114.

Parker, Christopher Sebastian. 2016. "Race and Politics in the Age of Obama." Annual Review of Sociology 42:217-230.

Parker, Christopher S. and Matt A. Barreto. 2014. Change They Can't Believe In: The Tea Party and Reactionary Politics in America-Updated Edition. Princeton, NJ: Princeton University Press.

Pehrson, Samuel, Vivian L Vignoles, and Rupert Brown. 2009. "National Identification and Anti-Immigrant Prejudice: Individual and Contextual Effects of National Definitions." Social Psychology Quarterly 72:24-38.

Raju, Manu. 2016. "Election 2016: Ted Cruz's Immigration Reversal." CNN .

Reny, Tyler T, Loren Collingwood, and Ali A Valenzuela. 2019. "Vote Switching in the 2016 Election: How Racial and Immigration Attitudes, Not Economics, Explain Shifts in White Voting." Public Opinion Quarterly 83:91-113.

Roberts, Sarah T, Brian P Flaherty, Ruth Deya, Linnet Masese, Jacqueline Ngina, R Scott McClelland, Jane Simoni, and Susan M Graham. 2018. "Patterns of Gender-Based Violence and Associations with Mental Health and HIV Risk Behavior Among Female Sex Workers in Mombasa, Kenya: A Latent Class Analysis." AIDS and Behavior 22:3273-3286. 
Rohde, David W. 1991. Parties and Leaders in the Postreform House. Chicago, IL: University of Chicago Press.

Rokkan, Stein and Seymour Martin Lipset. 1967. Party Systems and Voter Alignments: Cross-National Perspectives. New York: Free Press.

Rooduijn, Matthijs. 2014. "The Nucleus of Populism: In Search of the Lowest Common Denominator." Government and Opposition 49:573-599.

Rooduijn, Matthijs. 2019. "State of the Field: How to Study Populism and Adjacent Topics? A Plea for Both More and Less Focus." European Journal of Political Research 58:362-372.

Rydgren, Jens. 2017. "Radical right-wing parties in Europe." Journal of Language and Politics 16:485-496.

Schatz, Robert T, Ervin Staub, and Howard Lavine. 1999. "On the Varieties of National Attachment: Blind Versus Constructive Patriotism." Political Psychology 20:151-174.

Schildkraut, Deborah J. 2010. Americanism in the Twenty-First Century: Public Opinion in the Age of Immigration. New York: Cambridge University Press.

Sidanius, Jim, Seymour Feshbach, Shana Levin, and Felicia Pratto. 1997. "The Interface Between Ethnic and National Attachment: Ethnic Pluralism or Ethnic Dominance?" The Public Opinion Quarterly 61:102-133. 
Sides, John, Michael Tesler, and Lynn Vavreck. 2018. Identity Crisis: The 2016 Presidential Campaign and the Battle for the Meaning of America. Princeton, NJ: Princeton University Press.

Smith, Rogers M. 1997. Civic Ideals: Conflicting Visions of Citizenship in US History. New Haven, CT: Yale University Press.

Sotoudeh, Ramina and Paul DiMaggio. 2021. "Coping With Plenitude: A Computational Approach to Selecting the Right Algorithm." Sociological Methods \& Research p. 00491241211031273.

Stevens, Heidi. 2016. "It's Official: 2016 Is the Year of Xenophobia." The Chicago Tribune .

Stroud, Natalie Jomini. 2010. "Polarization and Partisan Selective Exposure." Journal of Communication 60:556-576.

Taggart, Paul. 2000. Populism: Concepts in the Social Sciences. Philadelphia, PA. Open Press.

Tesler, Michael. 2016. Post-Racial or Most-Racial?: Race and Politics in the Obama Era. Chicago, IL: University of Chicago Press.

Theiss-Morse, Elizabeth. 2009. Who Counts as an American?: The Boundaries of National Identity. New York: Cambridge University Press.

Thompson, Chrissie. 2015. "Jeb Bush, John Kasich Take Similar Stances, Different Approaches." The Cincinnati Enquirer . 
Thompson, Jack. 2021. "What it means to be a "true American": Ethnonationalism and voting in the 2016 US presidential election." Nations and Nationalism 27:279297.

Vermunt, Jeroen K. 1997. "Log-Linear Models for Event Histories."

Viterna, Jocelyn S. 2006. "Pulled, Pushed, and Persuaded: Explaining Women's Mobilization into the Salvadoran Guerrilla Army." American Journal of Sociology $112: 1-45$.

Whitehead, Andrew L and Samuel L Perry. 2020. Taking America Back for God: Christian Nationalism in the United States. Oxford University Press.

Wimmer, Andreas. 2013. Ethnic Boundary Making: Institutions, Power, Networks. New York: Oxford University Press.

Wright, Matthew. 2011. "Diversity and the Imagined Community: Immigrant Diversity and Cconceptions of National Identity." Political Psychology 32:837-862.

Yeung, King-To. 2005. "What Does Love Mean? Exploring Network Culture in Two Network Settings." Social Forces 84:391-420.

Zerubavel, Eviatar. 2009. Social Mindscapes: An Invitation to Cognitive Sociology. Cambridge, MA: Harvard University Press. 


\section{Appendices}

A Nationalism Variables, 2016 YouGov Survey 


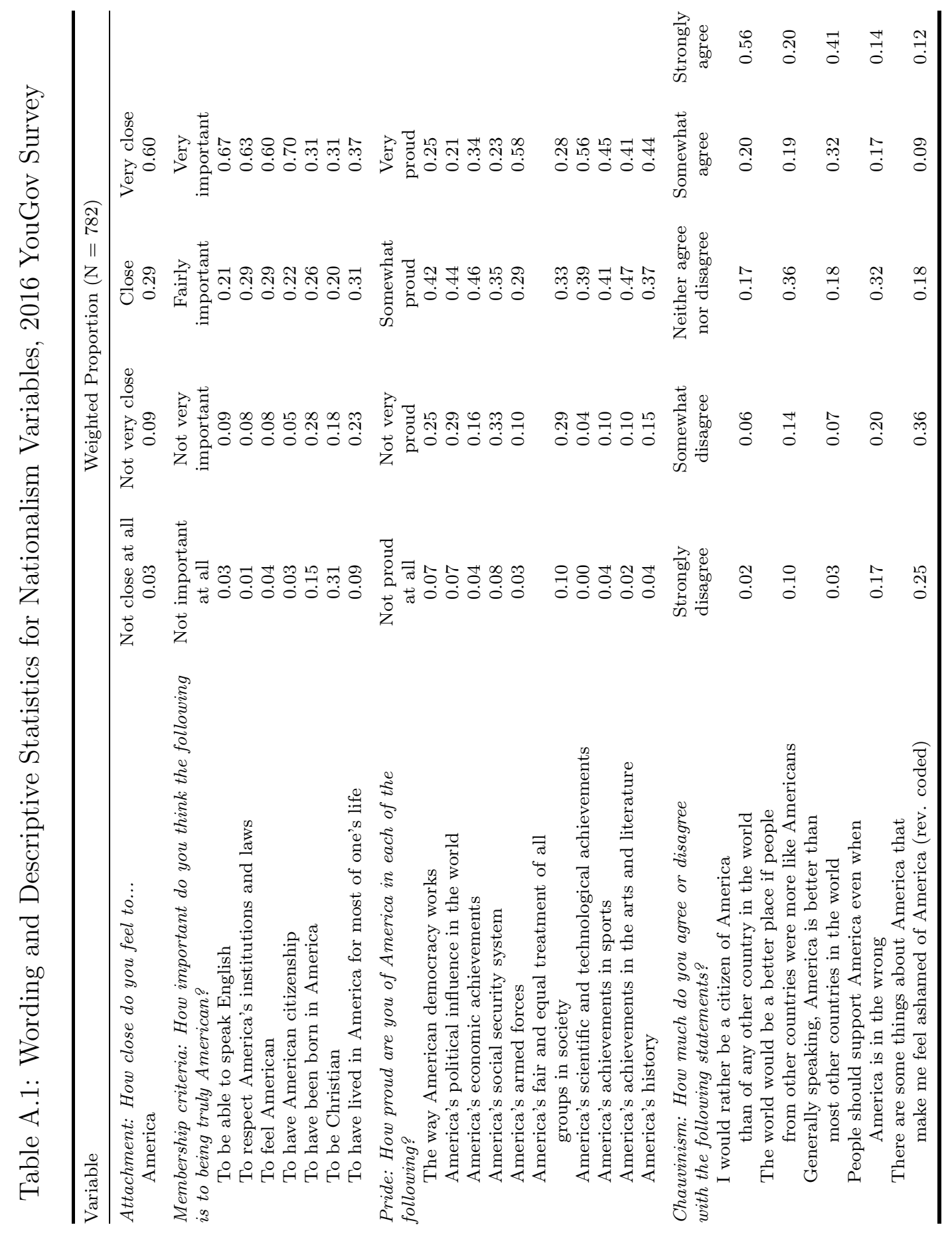




\section{B Sample Characteristics, 1996-2016}

Table B.1: Descriptive Statistics for Five Waves of Nationalism Survey Data

\begin{tabular}{|c|c|c|c|c|c|}
\hline \multirow[b]{2}{*}{ Variable } & \multicolumn{5}{|c|}{ Survey year } \\
\hline & 1996 & 2004 & 2012 & 2014 & 2016 \\
\hline \multicolumn{6}{|l|}{ Party ID } \\
\hline Strong Democrat (N) & 937 & 905 & 2,183 & 778 & 754 \\
\hline Mean & 0.14 & 0.16 & 0.21 & 0.17 & 0.20 \\
\hline $\mathrm{SD}$ & 0.35 & 0.37 & 0.41 & 0.38 & 0.40 \\
\hline Democrat (N) & 937 & 905 & 2,183 & 778 & 754 \\
\hline Mean & 0.32 & 0.28 & 0.21 & 0.31 & 0.24 \\
\hline $\mathrm{SD}$ & 0.47 & 0.45 & 0.41 & 0.46 & 0.42 \\
\hline Independent (N) & 937 & 905 & 2,183 & 778 & 754 \\
\hline Mean & 0.13 & 0.13 & 0.17 & 0.16 & 0.23 \\
\hline $\mathrm{SD}$ & 0.34 & 0.34 & 0.38 & 0.37 & 0.42 \\
\hline Republican (N) & 937 & 905 & 2,183 & 778 & 754 \\
\hline Mean & 0.29 & 0.26 & 0.21 & 0.24 & 0.21 \\
\hline $\mathrm{SD}$ & 0.45 & 0.44 & 0.41 & 0.43 & 0.41 \\
\hline Strong Republican (N) & 937 & 905 & 2,183 & 778 & 754 \\
\hline Mean & 0.12 & 0.16 & 0.20 & 0.12 & 0.13 \\
\hline $\mathrm{SD}$ & 0.33 & 0.37 & 0.40 & 0.33 & 0.34 \\
\hline Not Born in US (N) & 955 & 916 & - & 805 & 782 \\
\hline Mean & 0.08 & 0.10 & - & 0.14 & 0.28 \\
\hline $\mathrm{SD}$ & 0.27 & 0.30 & - & 0.35 & 0.45 \\
\hline Age $(\mathrm{N})$ & 953 & 916 & 2,341 & 803 & 782 \\
\hline Mean & 43.2 & 44.61 & 51.2 & 48.17 & 45.73 \\
\hline $\mathrm{SD}$ & 16.19 & 16.01 & 16.46 & 17.24 & 17.43 \\
\hline Male (N) & 956 & 916 & 2,341 & 805 & 782 \\
\hline Mean & 0.50 & 0.47 & 0.51 & 0.50 & 0.48 \\
\hline $\mathrm{SD}$ & 0.50 & 0.50 & 0.50 & 0.50 & 0.50 \\
\hline \multicolumn{6}{|l|}{ Race } \\
\hline White (N) & 956 & 916 & 2,341 & 805 & 782 \\
\hline Mean & 0.83 & 0.78 & 0.77 & 0.69 & 0.65 \\
\hline
\end{tabular}


Table B.1 - continued from previous page

\begin{tabular}{|c|c|c|c|c|c|}
\hline \multirow[b]{2}{*}{ Variable } & \multicolumn{5}{|c|}{ Survey year } \\
\hline & 1996 & 2004 & 2012 & 2014 & 2016 \\
\hline $\mathrm{SD}$ & 0.38 & 0.42 & 0.42 & 0.46 & 0.48 \\
\hline Black (N) & 956 & 916 & 2,341 & 805 & 782 \\
\hline Mean & 0.09 & 0.12 & 0.07 & 0.13 & 0.12 \\
\hline $\mathrm{SD}$ & 0.29 & 0.32 & 0.26 & 0.34 & 0.33 \\
\hline Hispanic (N) & 956 & 916 & 2,341 & 805 & 782 \\
\hline Mean & 0.04 & 0.06 & 0.10 & 0.12 & 0.16 \\
\hline $\mathrm{SD}$ & 0.20 & 0.24 & 0.29 & 0.33 & 0.37 \\
\hline Other $(\mathrm{N})$ & 956 & 916 & 2,341 & 805 & 782 \\
\hline Mean & 0.04 & 0.05 & 0.06 & 0.06 & 0.07 \\
\hline $\mathrm{SD}$ & 0.19 & 0.22 & 0.23 & 0.23 & 0.26 \\
\hline \multicolumn{6}{|l|}{ Region } \\
\hline North East (N) & 956 & 916 & 2,341 & 805 & 782 \\
\hline Mean & 0.20 & 0.19 & 0.18 & 0.17 & 0.18 \\
\hline $\mathrm{SD}$ & 0.4 & 0.39 & 0.39 & 0.37 & 0.38 \\
\hline Midwest (N) & 956 & 916 & 2,341 & 805 & 782 \\
\hline Mean & 0.24 & 0.25 & 0.24 & 0.24 & 0.21 \\
\hline $\mathrm{SD}$ & 0.42 & 0.43 & 0.43 & 0.43 & 0.41 \\
\hline South (N) & 956 & 916 & 2,341 & 805 & 782 \\
\hline Mean & 0.31 & 0.33 & 0.34 & 0.36 & 0.37 \\
\hline $\mathrm{SD}$ & 0.46 & 0.47 & 0.47 & 0.48 & 0.48 \\
\hline Mountatin $(\mathrm{N})$ & 956 & 916 & 2,341 & 805 & 782 \\
\hline Mean & 0.09 & 0.07 & 0.07 & 0.09 & 0.08 \\
\hline $\mathrm{SD}$ & 0.28 & 0.26 & 0.25 & 0.28 & 0.27 \\
\hline Pacific (N) & 956 & 916 & 2,341 & 805 & 782 \\
\hline Mean & 0.16 & 0.16 & 0.16 & 0.15 & 0.16 \\
\hline $\mathrm{SD}$ & 0.37 & 0.36 & 0.37 & 0.36 & 0.36 \\
\hline \multicolumn{6}{|l|}{ Education } \\
\hline Less than HS (N) & 956 & 916 & 2,341 & 805 & 782 \\
\hline Mean & 0.13 & 0.10 & 0.07 & 0.10 & 0.08 \\
\hline $\mathrm{SD}$ & 0.33 & 0.29 & 0.25 & 0.30 & 0.27 \\
\hline HS or Some College $(\mathrm{N})$ & 956 & 916 & 2,341 & 805 & 782 \\
\hline
\end{tabular}


Table B.1 - continued from previous page

\begin{tabular}{|c|c|c|c|c|c|}
\hline \multirow[b]{2}{*}{ Variable } & \multicolumn{5}{|c|}{ Survey year } \\
\hline & 1996 & 2004 & 2012 & 2014 & 2016 \\
\hline Mean & 0.58 & 0.56 & 0.59 & 0.54 & 0.68 \\
\hline $\mathrm{SD}$ & 0.49 & 0.50 & 0.49 & 0.50 & 0.47 \\
\hline Bachelor's Degree (N) & 956 & 916 & 2,341 & 805 & 782 \\
\hline Mean & 0.16 & 0.20 & 0.20 & 0.20 & 0.16 \\
\hline SD & 0.36 & 0.40 & 0.4 & 0.40 & 0.37 \\
\hline Advanced Degree (N) & 956 & 916 & 2,341 & 805 & 782 \\
\hline Mean & 0.14 & 0.14 & 0.14 & 0.16 & 0.08 \\
\hline $\mathrm{SD}$ & 0.35 & 0.34 & 0.35 & 0.37 & 0.28 \\
\hline \multicolumn{6}{|l|}{ Religious Tradition } \\
\hline Protestant (N) & 956 & 916 & 2,135 & 805 & 782 \\
\hline Mean & 0.53 & 0.45 & 0.41 & 0.45 & 0.24 \\
\hline $\mathrm{SD}$ & 0.50 & 0.50 & 0.49 & 0.50 & 0.43 \\
\hline Roman Catholic (N) & 956 & 916 & 2,135 & 805 & 782 \\
\hline Mean & 0.26 & 0.27 & 0.27 & 0.26 & 0.26 \\
\hline $\mathrm{SD}$ & 0.44 & 0.44 & 0.44 & 0.44 & 0.44 \\
\hline Jewish $(\mathrm{N})$ & 956 & 916 & 2,135 & 805 & 782 \\
\hline Mean & 0.02 & 0.03 & 0.02 & 0.02 & 0.01 \\
\hline $\mathrm{SD}$ & 0.12 & 0.17 & 0.15 & 0.12 & 0.11 \\
\hline Other $(\mathrm{N})$ & 956 & 916 & 2,135 & 805 & 782 \\
\hline Mean & 0.09 & 0.12 & 0.11 & 0.10 & 0.19 \\
\hline $\mathrm{SD}$ & 0.28 & 0.33 & 0.31 & 0.30 & 0.39 \\
\hline None $(\mathrm{N})$ & 956 & 916 & 2,135 & 805 & 782 \\
\hline Mean & 0.11 & 0.13 & 0.19 & 0.18 & 0.29 \\
\hline $\mathrm{SD}$ & 0.31 & 0.33 & 0.40 & 0.39 & 0.46 \\
\hline Religiosity (N) & 918 & 910 & 2,267 & 802 & 782 \\
\hline Mean & 0.36 & 0.39 & 0.43 & 0.37 & 0.41 \\
\hline $\mathrm{SD}$ & 0.48 & 0.49 & 0.50 & 0.48 & 0.49 \\
\hline Income $(2004)(\mathrm{N})$ & 877 & 846 & - & 760 & 692 \\
\hline Mean & $\$ 63,108$ & $\$ 78,969$ & - & $\$ 68,620$ & $\$ 47,726$ \\
\hline $\mathrm{SD}$ & $\$ 1,864$ & $\$ 2,752$ & - & $\$ 2,786$ & $\$ 2,399$ \\
\hline
\end{tabular}

Note: Data come from the 1996, 2004, and 2014 GSS; 2012 GfK KnowledgePanel; and 2016 YouGov online panel. 


\section{Latent Class Analysis Model Selection}

Model selection in LCA is typically guided by statistical goodness-of-fit measures and interpretability. Accordingly, we ran multiple models with a single latent categorical variable and varying number of classes (i.e., latent variable categories), while also adding to some models direct effects that relaxed assumptions about the local independence of specific pairs of indicators (these were successively added in descending order of their model residuals until further additions yielded no further improvement in model fit). All the models included standard survey weights, which were rescaled to ensure that each wave of data (i.e., 1996, 2004, 2012, 2014, and 2016) contributed equally to the solution. The goodness-of-fit statistics are provided in table C.1. The four-class model with 11 direct effects yielded the lowest Bayesian Information Criterion (BIC). Moreover, adding a fifth class did not provide significant new information to the results from the four-class model: the fifth class represented a small variation on the existing four classes.

To minimize the effects of year-specific measurement error on the overall LCA solution, we estimated the latent classes using a fully heterogeneous model, which allows not only the prevalence of classes but also the conditional probabilities of nationalist item responses (i.e., the class content) to vary from year to year. Although this makes the classes more closely reflective of the data in each survey year, it raises the question of how comparable the classes are across years. Figure C.1 presents the class-specific means of the nationalism indicators for the five waves of data. Overall, the response patterns look very similar over time, reassuring us that we have identified the same four classes in all five years. To the degree that there are year-specific deviations from the overall pattern, they are primarily concentrated in the 2004 and 2014 GSS. The former survey was administered within two years of 9/11, when nationalist beliefs were likely to be particularly intense, whereas the latter was the only wave of data in our study to not be fielded during a presidential election year. In both cases, minor deviations are to be expected and the fully heterogeneous model ensures that they do not skew the results for the remaining years. Even with those deviations taken into account, however, the classes remain substantively similar over time, which increases our confidence in our over-time comparisons. 
Table C.1: LCA Model Fit Comparison

\begin{tabular}{lcccc}
\hline Model & \multicolumn{3}{c}{ Log } & Classification \\
& Parameters & Likelihood & BIC & Error \\
\hline 1 class & 370 & $-125,689$ & 254,530 & 0 \\
2 classes & 490 & $-118,201$ & 240,573 & 0.04 \\
3 classes & 610 & $-115,797$ & 236,789 & 0.07 \\
4 classes & 730 & $-113,983$ & 234,185 & 0.08 \\
$\mathbf{4}$ classes, 5 direct effects* & $\mathbf{7 3 5}$ & $\mathbf{- 1 1 2 , 5 2 4}$ & $\mathbf{2 3 1 , 3 0 8}$ & $\mathbf{0 . 0 9}$ \\
5 classes & 850 & $-113,165$ & 233,569 & 0.09 \\
6 classes & 970 & $-112,332$ & 232,925 & 0.10 \\
7 classes & 1,090 & $-111,839$ & 232,961 & 0.11 \\
8 classes & 1,210 & $-111,306$ & 232,917 & 0.12 \\
9 classes & 1,330 & $-110,897$ & 233,122 & 0.12 \\
10 classes & 1,450 & $-110,436$ & 233,223 & 0.13 \\
\hline
\end{tabular}

* Direct effects for the following pairs of indicators: importance of birth and importance of lifelong residence, America a better country and better if others were more like Americans, pride in accomplishments in art and pride in accomplishments in sports, pride in accomplishments in art and pride in accomplishments in science and technology, and importance of citizenship and importance of speaking English.

Note: Data come from the 2016 YouGov online panel. 

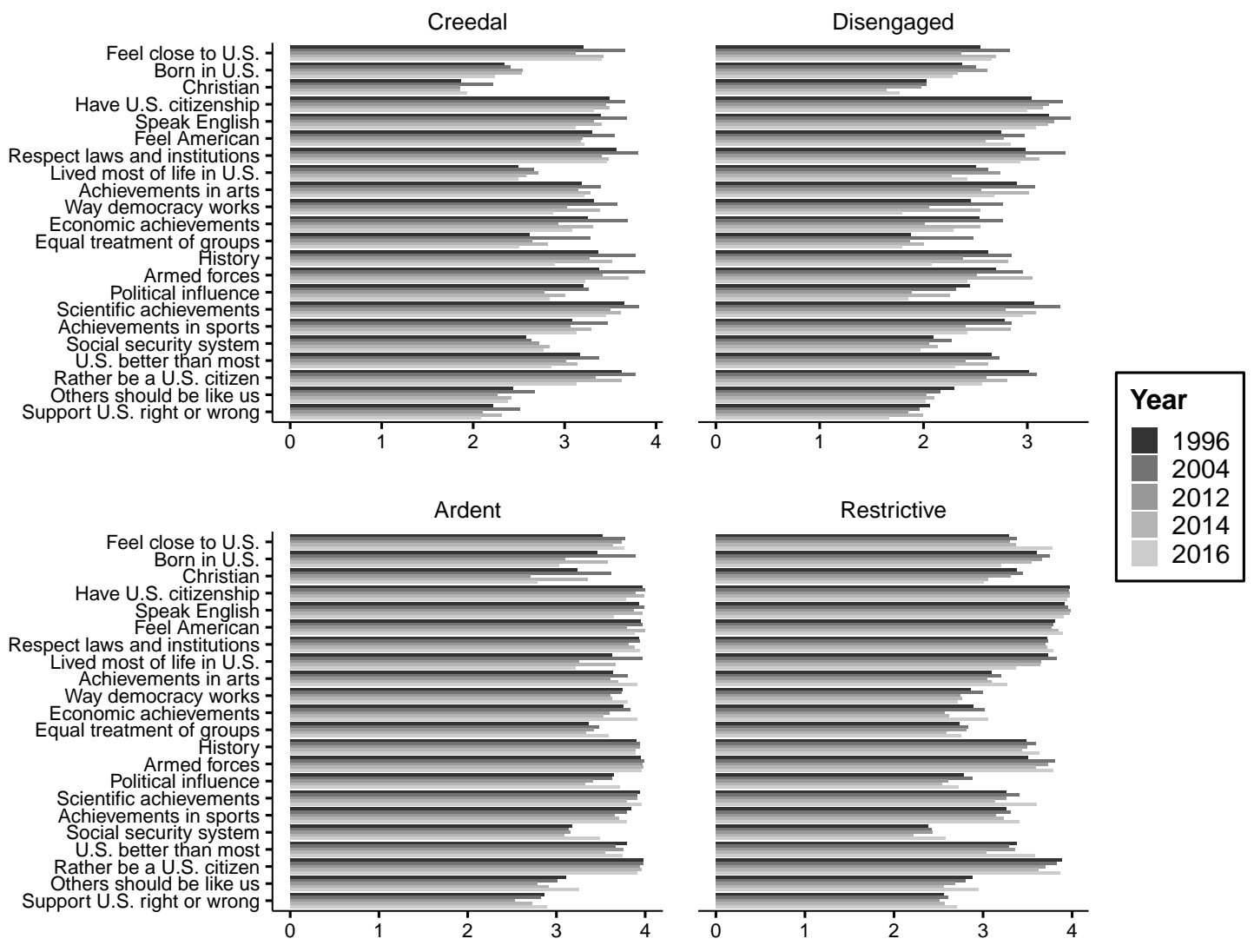

Figure C.1: Conditional probabilities of mean item response by survey year, fully heterogeneous LCA model. Data come from the 1996, 2004, and 2014 GSS; 2012 GfK KnowledgePanel; and 2016 YouGov online panel. 


\section{Campaign Speech Analysis}

To gain a better understanding of the nationalist frames used by the presidential candidates in the 2016 primary and general elections, we carried out an analysis of all available campaign speeches using word embeddings models (Mikolov et al. 2013; Kozlowski et al. 2019. One of the many affordances of this method is that it allows for the visualization of a word's meaning in a given corpus (assuming that meaning emerges out of the relations of similarity and difference between symbols [Mohr 1998]). We take advantage of this feature to compare the meanings of key words across the campaign-specific text corpora. These results inform our subsequent hypotheses about the relationship between campaign content and nationalist beliefs. The counts of the candidates' speeches are summarized in table D.1.

To highlight differences in the campaigns' rhetoric, we focus on the candidatespecific meanings of two terms: "dangerous" and "politics." The former term identifies what the candidate views as the most pressing concerns facing the country (e.g., terrorism, immigration, partisan polarization) and, given the word's potency, is likely to elicit morally charged content typical of nationalist discourse. ${ }^{27}$ The second focal term of the embeddings analysis - "politics" - reveals whether a candidate frames

Table D.1: Counts of Speeches by Campaign

\begin{tabular}{llc}
\hline Campaign & Source & $\mathrm{N}$ \\
\hline Hillary Clinton (D) & UCSB American Presidency Project & 36 \\
Donald Trump (R) & Factba.se & 99 \\
Bernie Sanders (D) & UCSB American Presidency Project & 28 \\
Republican moderates & & \\
(i.e., Kasich, Bush, and Rubio) & UCSB American Presidency Project & 8 \\
Ted Cruz (R) & UCSB American Presidency Project & 3 \\
\hline
\end{tabular}

\footnotetext{
${ }^{27}$ Our choice of this term is additionally informed by the likelihood that candidates invoking exclusionary conceptions of national membership are less likely to make affirmative statements about what the nation is (e.g., "America is a white nation") than negative statements about what the nation is not (e.g., "Americans should be protected from immigrants and Muslims"). By examining meanings contained in such negative statements, as reflected by terms co-occurring with the word "dangerous," we can gain a better understanding of how candidates define the boundaries of legitimate nationhood.
} 
the political establishment in morally negative terms typical of populist discourse (Hawkins 2009). Such antielite appeals may activate varieties of nationalism that score low on institutional pride. ${ }^{28}$ Taken together, the embedding analyses of the candidates' conceptualizations of national boundaries and of political institutions allow us to capture the specific type of nationalism on which each candidate relied in the 2016 election.

Figures D.1 and D.2 illustrate the discursive content of the general and primary campaigns, respectively. ${ }^{29}$ In addition to visualizing the vector-space neighborhoods of the two key terms, the figures highlight terms that are of particular interest for differentiating the candidates' use of nationalist appeals. In the the left-hand panels of figures D.1 and D.2, we focus on nouns and adjectives that describe the sources of danger to the country. In the right-hand panels, we examine nouns and adjectives that capture the speaker's characterization of the field of politics. ${ }^{30}$

The results of the word embedding analysis are broadly consistent with our description of the campaigns based on media sources. Donald Trump's discourse stands out in its alarmist conflation of "aliens" and "refugees" with "gangs," "cartels," "syndicates," "terror[ists]," "traffickers," "violent" "offenders," and other "radical" and "criminal" actors, thus depicting America as a nation in "turmoil" "invade[d]" by dangerous outsiders. This is combined with an acrimonious view of politics (fig. D.1b) as characterized by the "elitism," "cynicism," and "stupidity" of the "cor-

\footnotetext{
${ }^{28}$ Whether populist claims mobilize specifically populist attitudes or help activate other beliefs, including those related to nationalism, is a topic of active debate in the political science literature (e.g., Akkerman et al. 2014; Castanho Silva et al. 2019; Rooduijn 2019). Weighing in on this debate is outside of the scope of this article; instead, we simply note that individuals with low levels of pride in the nation and the state may be particularly responsive to political claims that depict the nation as having lost its way become of the self-interested actions of morally corrupt political, economic, or cultural elites.

${ }^{29}$ Because of the small number of speeches by moderate Republican primary candidates, we group them into a single corpus, visualized in fig. D.2. Only three speeches were available for Ted Cruz, so we exclude his campaign from the word embedding analysis. A close reading of these documents, however, supports our earlier description of the Cruz campaign as similarly exclusionary and antiestablishment to Trump's rhetoric (though the former featured stronger appeals to Evangelical Christians); we illustrate these conclusions with selected quotes from Cruz below.

${ }^{30}$ Given the relatively small number of words in the figure, we rely on hand coding instead of more complex (and potentially more error-prone) automated methods, like part-of-speech tagging and sentiment analysis.
} 
rupt," "bitter," and "entrenched" "establishment," whose "failures" have betrayed the people.

Clinton's claims about the problems facing America are starkly different. Rather than identifying specific groups of people and their allegedly threatening deeds, she focuses on the dangers posed by "reckless" and "divisive" "bullying," "harassment," and "discrimination." 31 Her view of politics (fig. D.1d) is largely positive, as indicated by terms such as "inclusive," "unifying," "respect," and "participate." To the degree that there are problems with politics, they are due to "cynical" "fear" mongering, not any fundamental attribute of the elites.

Whereas the Republican moderates are generally similar to Clinton in their depictions of danger and politics, the same cannot be said of Sanders (fig. D.2). In contrast to Trump, Sanders's conceptions of danger lack references to immigrants or minorities and instead focus on geopolitical and economic risks associated with specific countries. ${ }^{32}$ His populist depiction of politics, however, shares the critical tone observed in Trump's discourse, though Sanders was more focused on the influence of money on democratic representation. In particular, he described the "establishment" as having been "bought" and "corrupted" by the "rich," a "tragic" situation that disadvantages those who are "struggling."

Finally, a close reading of Ted Cruz's speeches (which were too few to include in the computational analysis) reveals patterns similar to those observed for Trump. Cruz repeatedly makes reference to "the evil of Islamists and ISIS," "radical Islamic terrorism" and (in reference to Hamas) "terrorist monsters" "that celebrate the murder of women and children," while presenting himself as an "outsider" who can aid "towns and faces ... weathered with trouble, joblessness, and fear." He claims to be free of the influence of "bundlers and special interests" and instead to draw "fuel ... directly from the people," in sharp contrast to the Obama administration that "led to more elitist control from Washington [and] [1] ess freedom for the People."

\footnotetext{
${ }^{31}$ One term seemingly at odds with this interpretation is "Mexican," but a close reading of Clinton's speeches reveals that this word was used solely in critiques of Trump's xenophobic discourse.

${ }^{32}$ A close readings of Sanders's speeches suggests that he referred to Britain, Japan, Sweden, and Argentina as exemplars of progressive social and economic policies that could be adopted in the United States to address rising inequality. His references to Saudi Arabia were more critical: he argued that the country should do more to help the United States battle ISIS.
} 

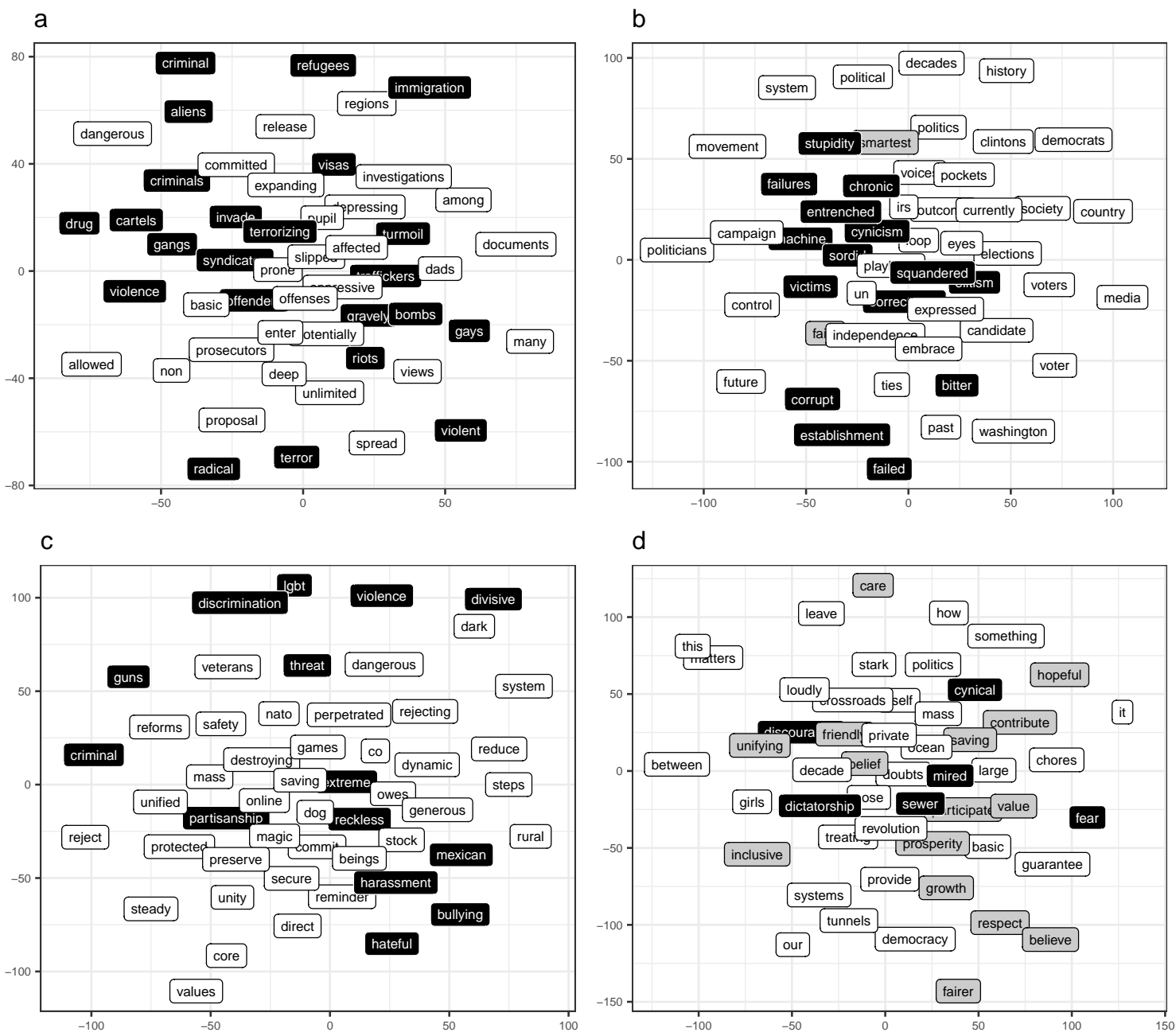

Figure D.1: Fifty most proximate word vectors by campaign and key term, general election candidates: a, Trump, "dangerous"; $b$, Trump, "politics"; $c$, Clinton, "dangerous"; $d$, Clinton, "politics." Dark shading: sources of danger to the country ( $a$, $c)$ and negative claims about politics $(b, d)$; light shading: positive claims about politics $(b, d)$. 
a

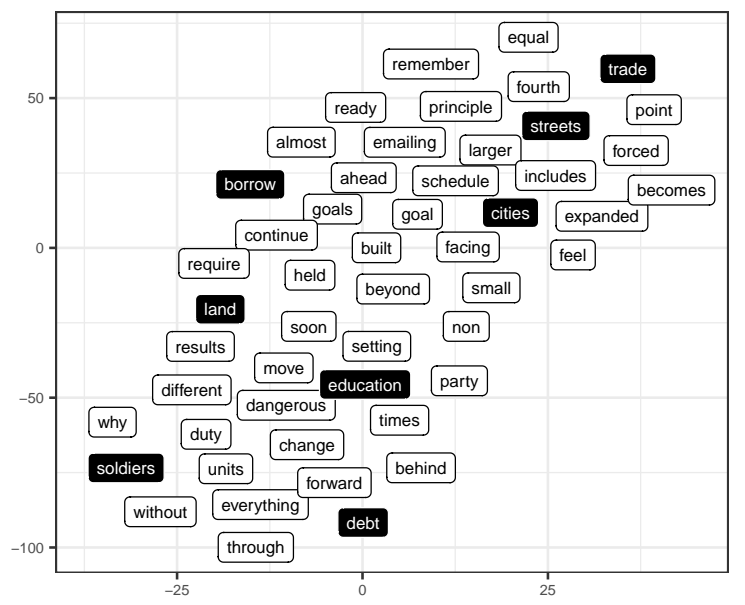

C

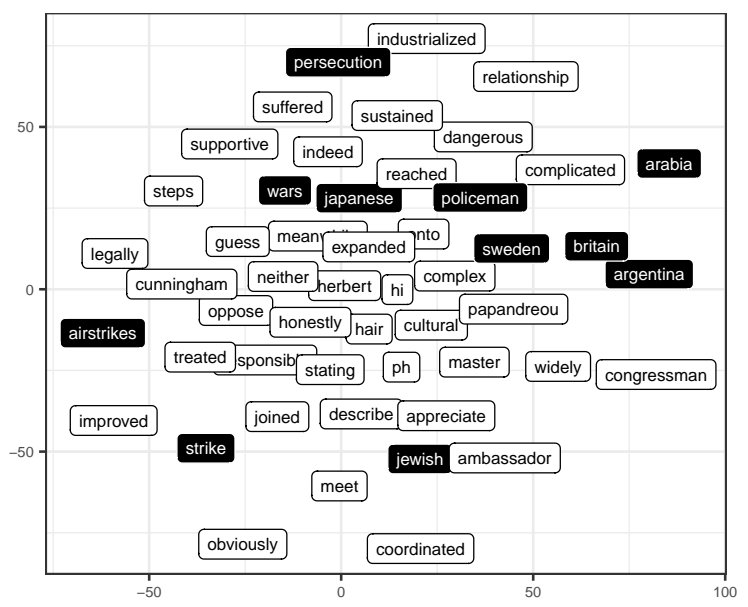

b

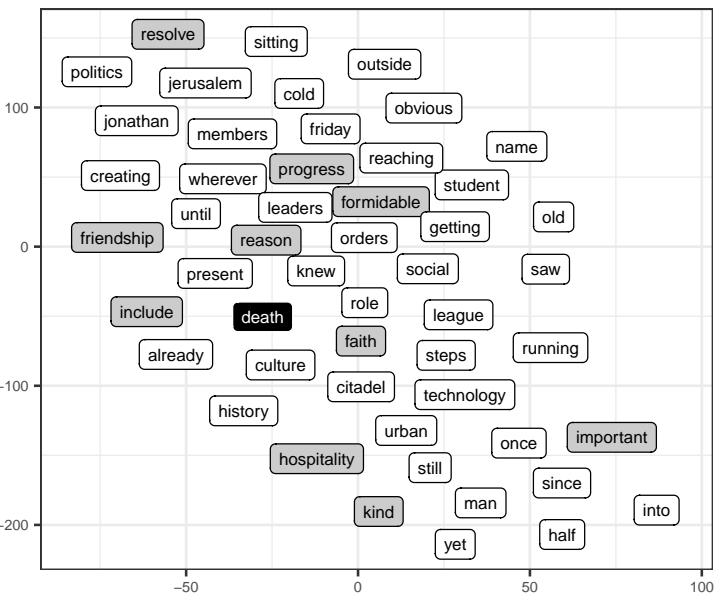

d

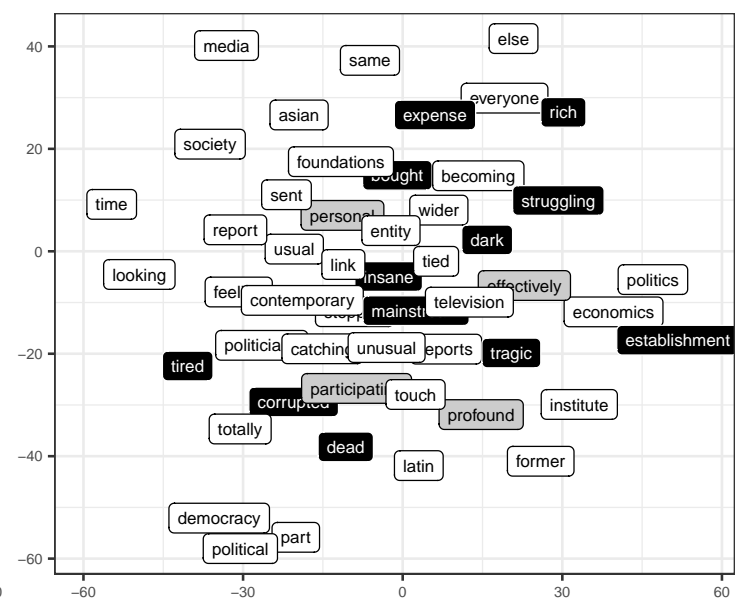

Figure D.2: Fifty most proximate word vectors by campaign and key term, primary candidates: $a$, Republican moderates, "dangerous"; $b$, Republican moderates, "politics"; c, Sanders, "dangerous"; $d$, Sanders, "politics." Dark shading: sources of danger to the country $(a, c)$ and negative claims about politics $(b, d)$; light shading: positive claims about politics $(b, d)$. 


\section{Technical notes}

The data for the analysis of campaign speeches were obtained from two online sources: Factba.se, a database of all public statements made by Donald Trump over his lifetime, and the American Presidency Project at the University of California, Santa Barbara, a compendium of political statements by prominent U.S. politicians, which we used a source of Hillary Clinton's, Bernie Sanders', Ted Cruz's, and the moderate Republican candidates' (i.e., John Kasich's, Jeb Bush's, and Marco Rubio's) campaign discourse. We limited the corpus to speeches delivered during the 2016 primary and general elections, beginning with each candidate's presidential run announcement and ending with his or her concession speech (for Trump and Clinton, we focus specifically on the general election, from the Republican and Democratic National Conventions to Election Day). After scraping and cleaning the speech transcripts, we used a word embedding model (specifically word2vec) and tensorflow visualization to examine differences between the campaigns in the meaning of key terms relevant to our research question. Data collection and analysis were performed in Python using a variety of web scraping and text analysis packages, including scrapy and gensim.

Word embedding models use shallow neural networks to arrive at a representation of each word in a corpus as a dense k-dimensional vector, such that distance between words in the resulting $\mathrm{k}$-dimensional space is indicative of the proximity of the words to one another in the corpus (the algorithm arrives at the solution by predicting the probability of each word's occurrence given the copresence of its neighboring words; Mikolov et al. 2013). We selected a 200-dimensional vector space for representing the terms in the campaign speeches. This space was reduced to two dimensions using a tensorflow algorithm in order to visualize the word relationships in figures D.1 and D.2 (importantly, the orientation and scale of the axes are not meaningful). 
E Results of Regressions of Voting Preferences on Nationalism Variables and Covariates 


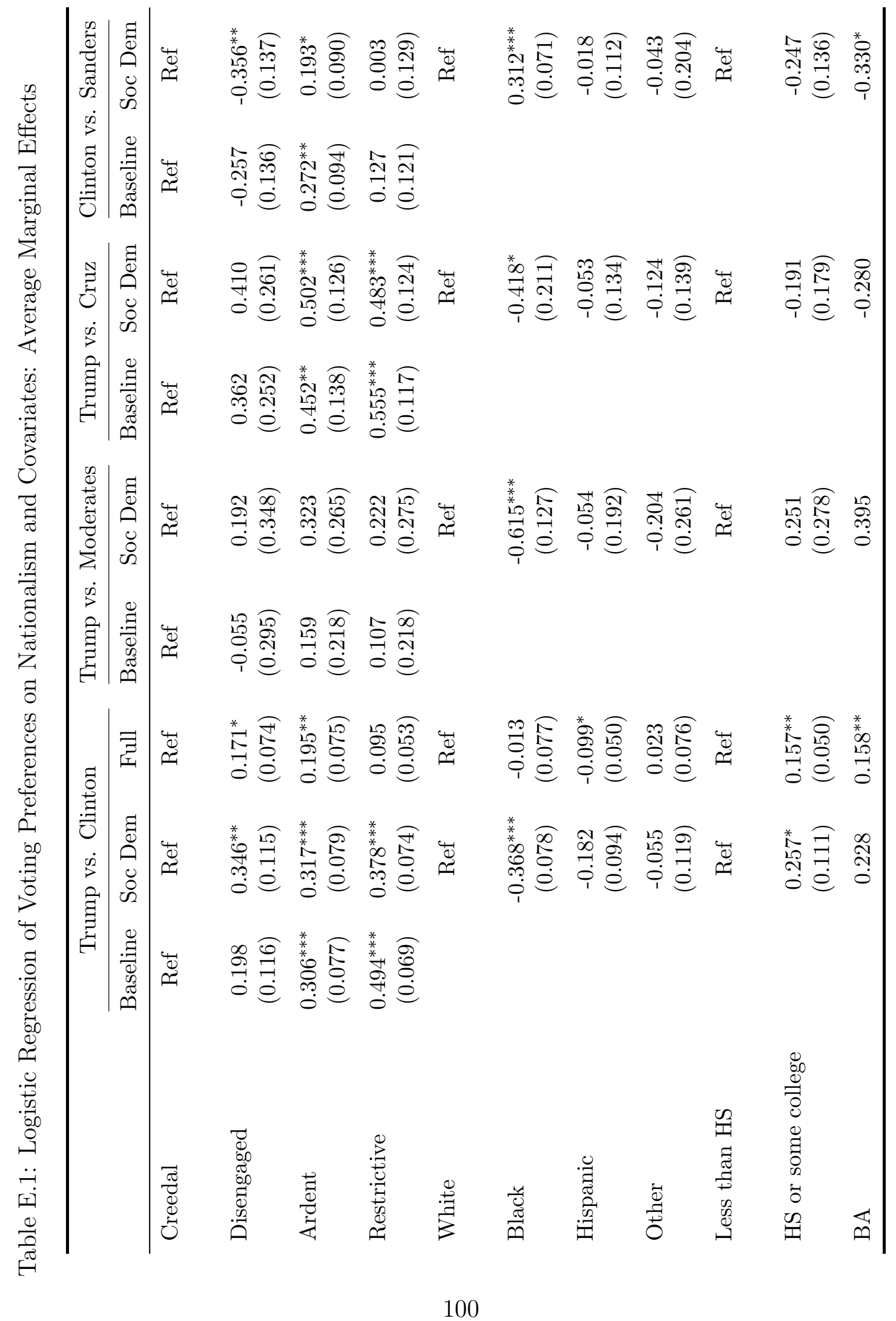




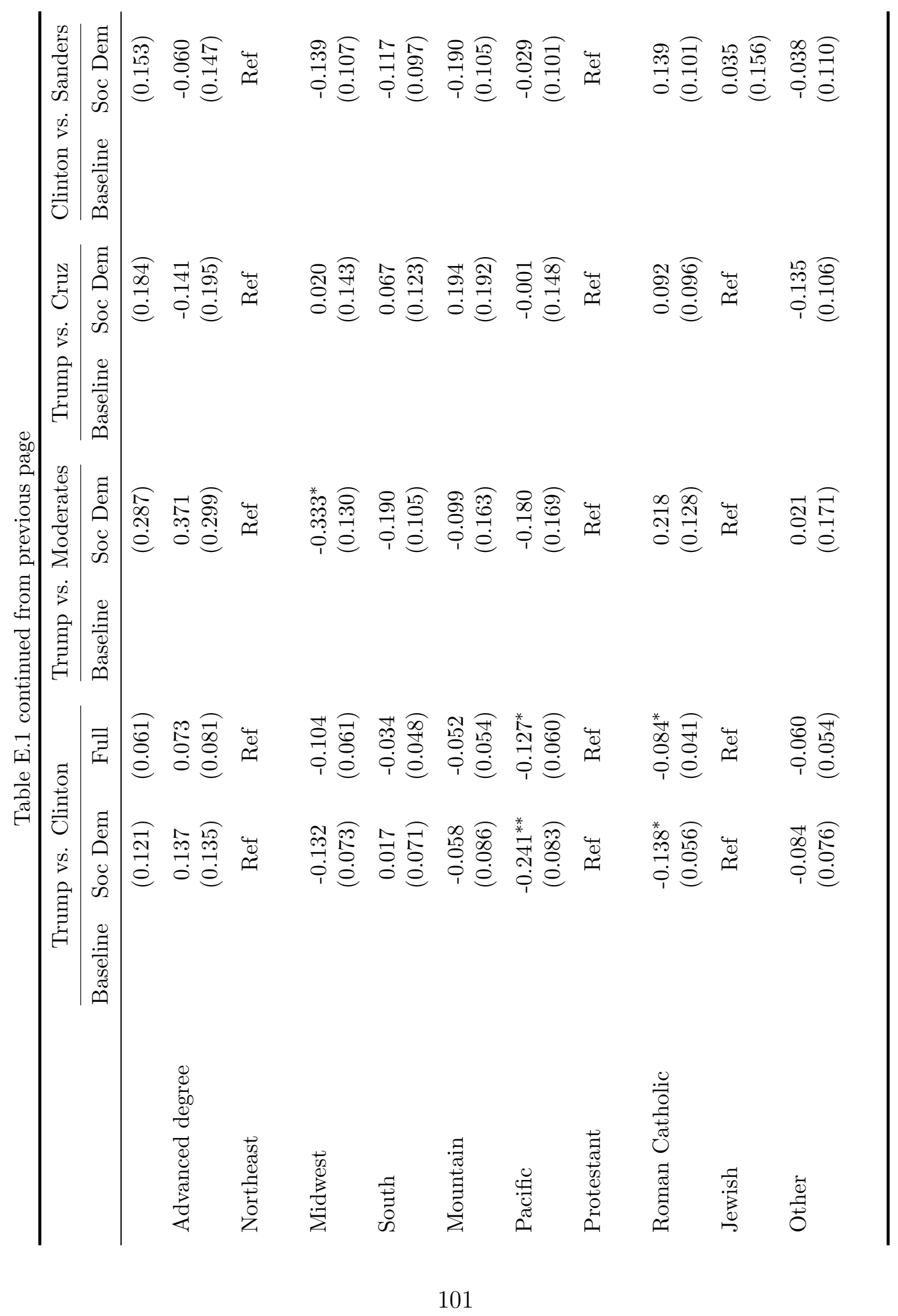




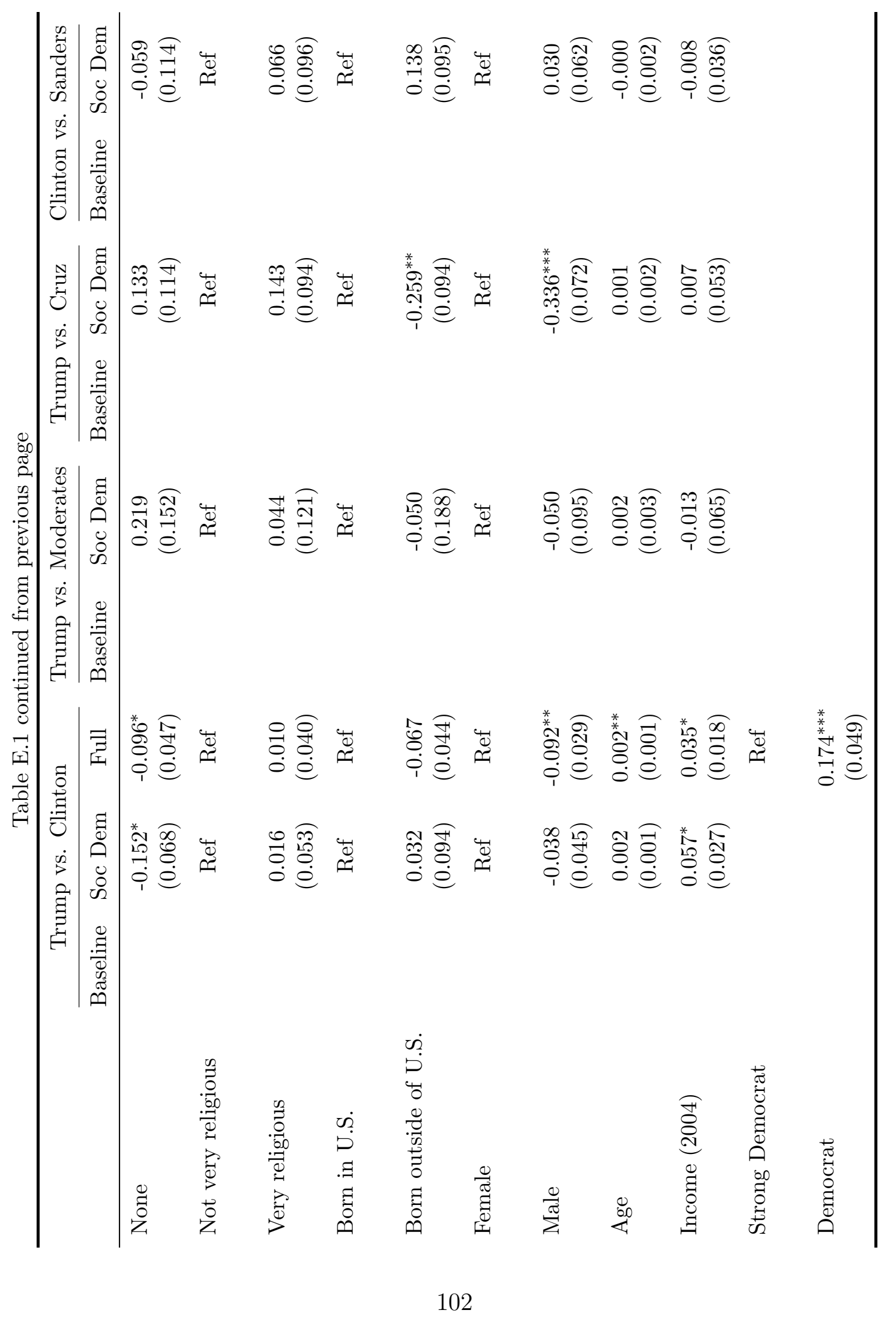




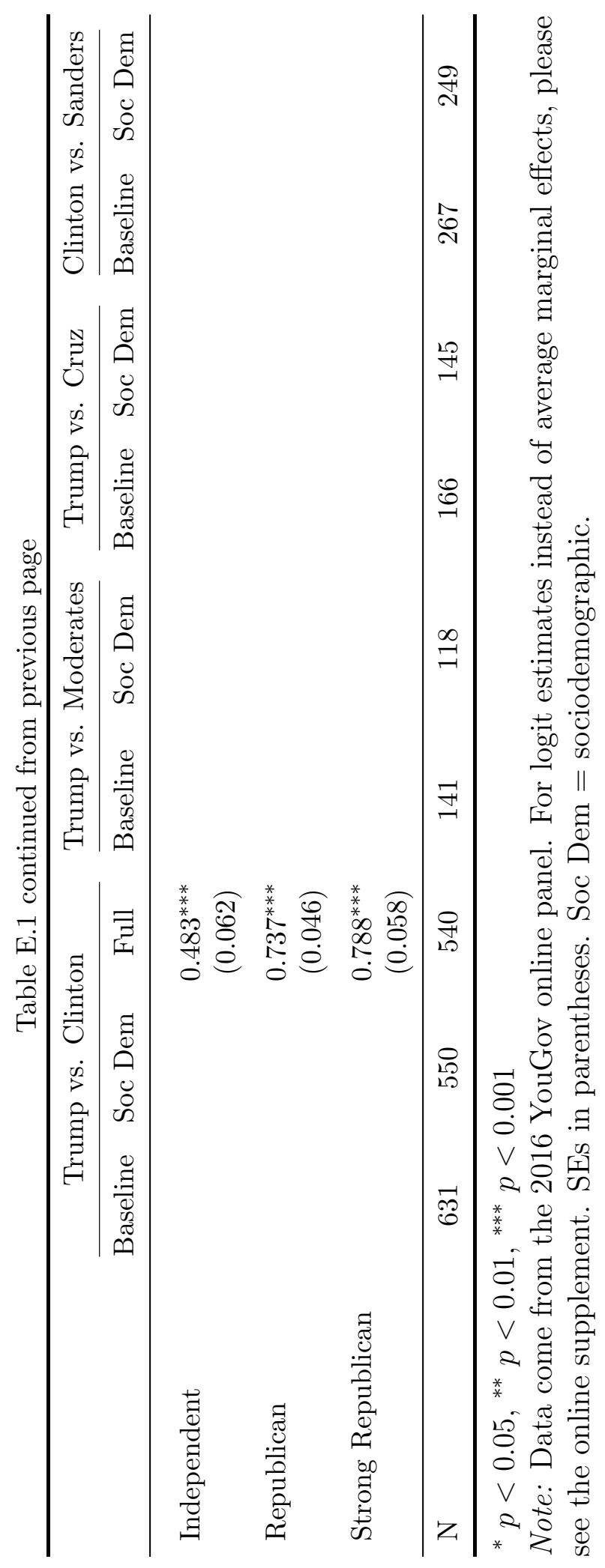

103 


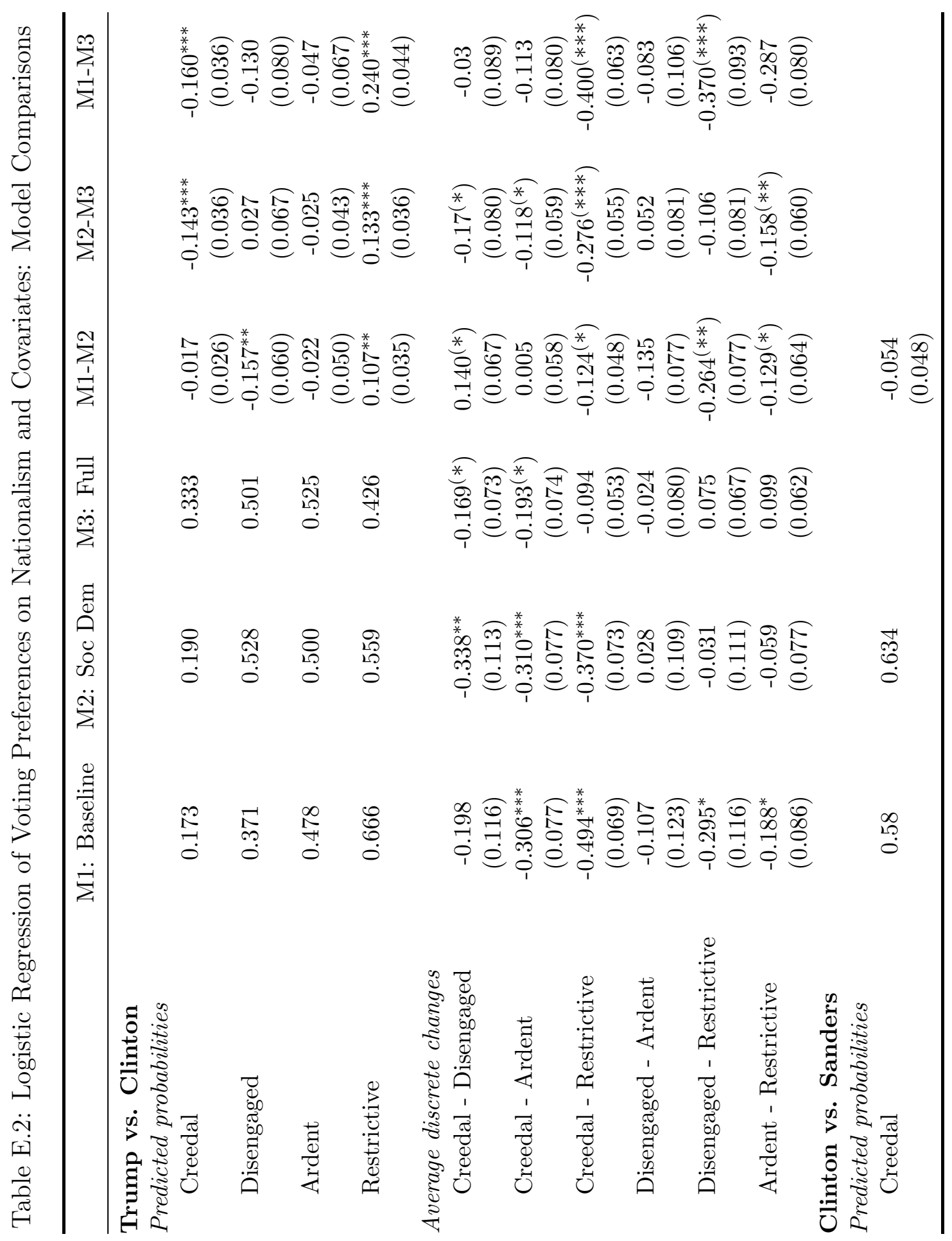




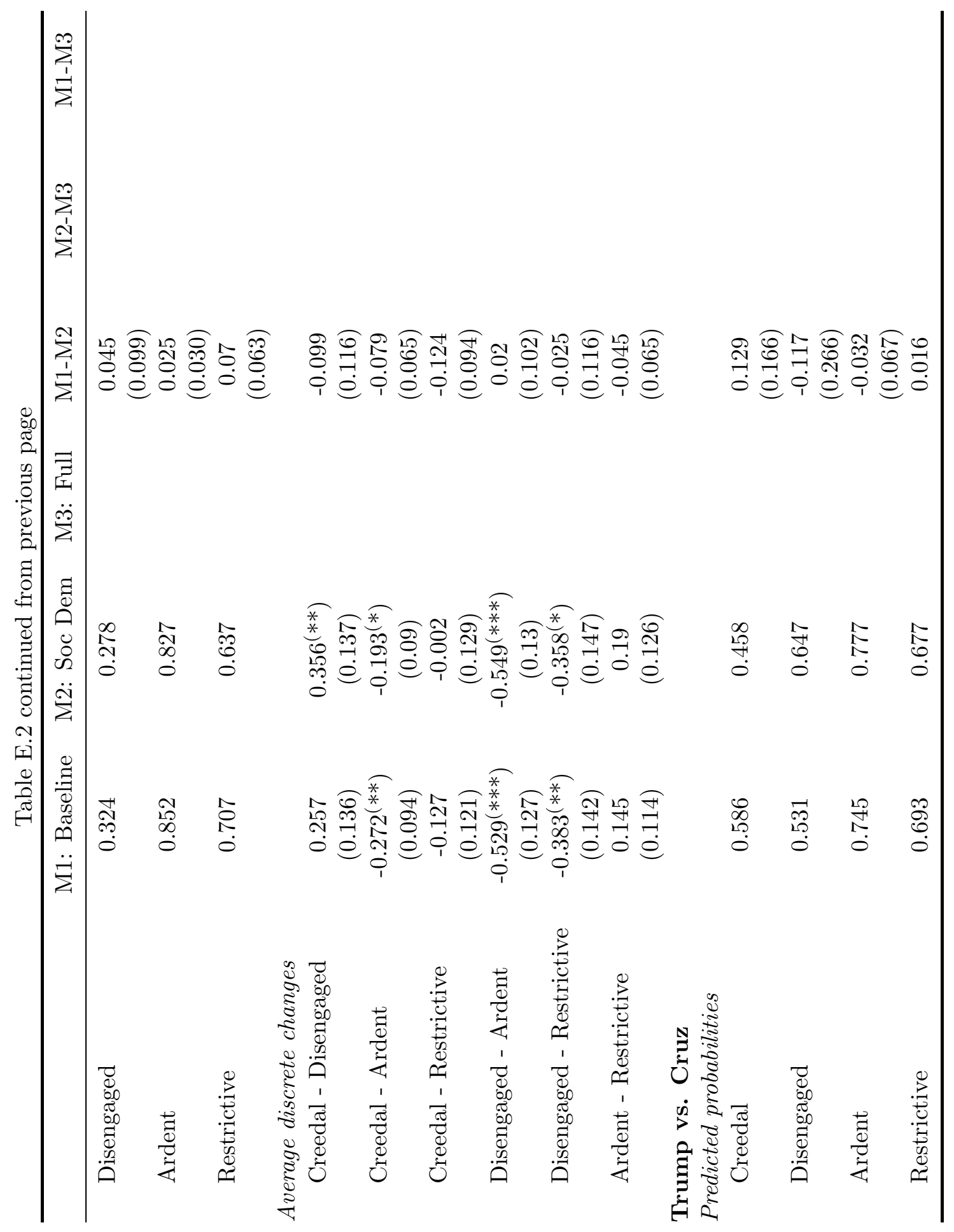




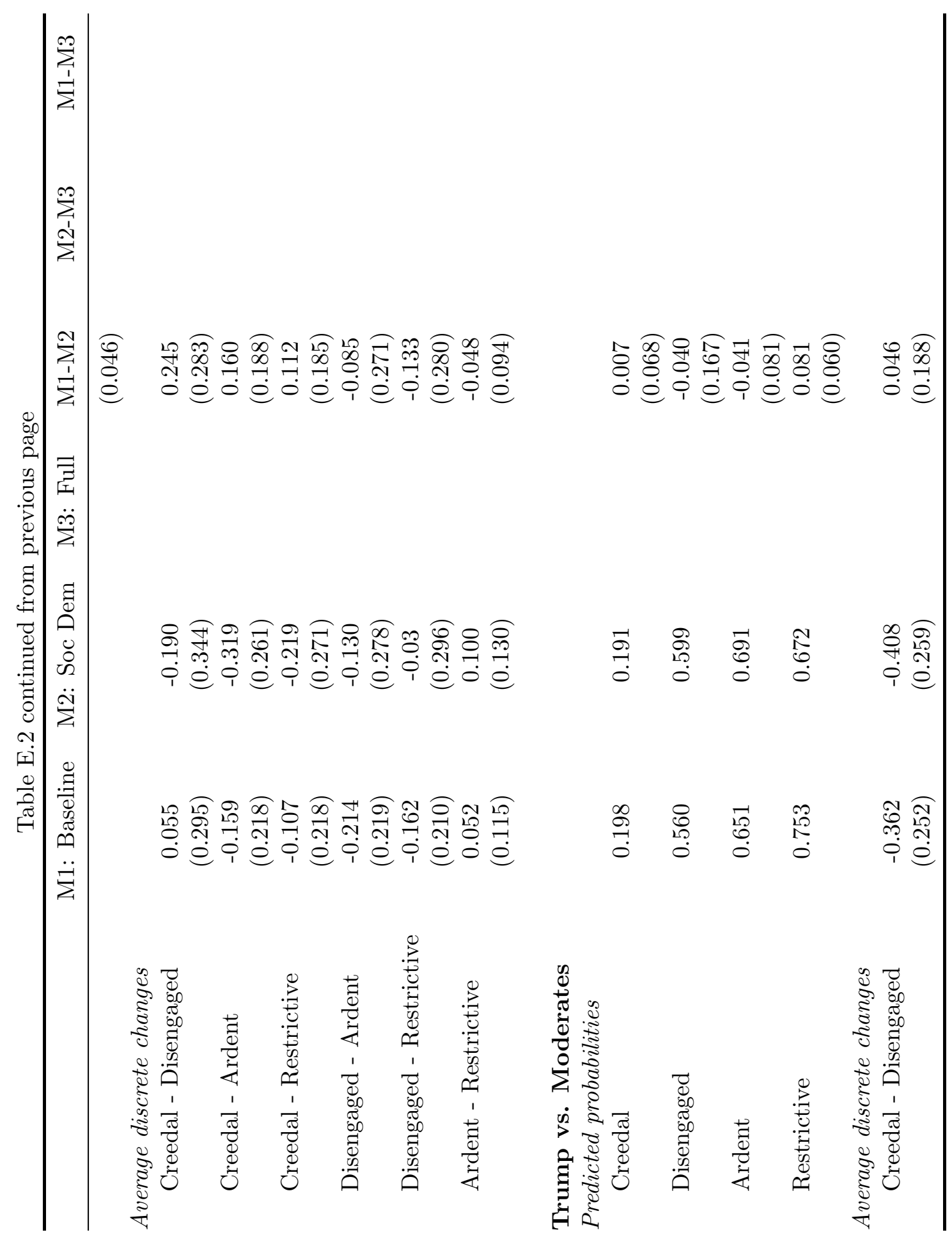




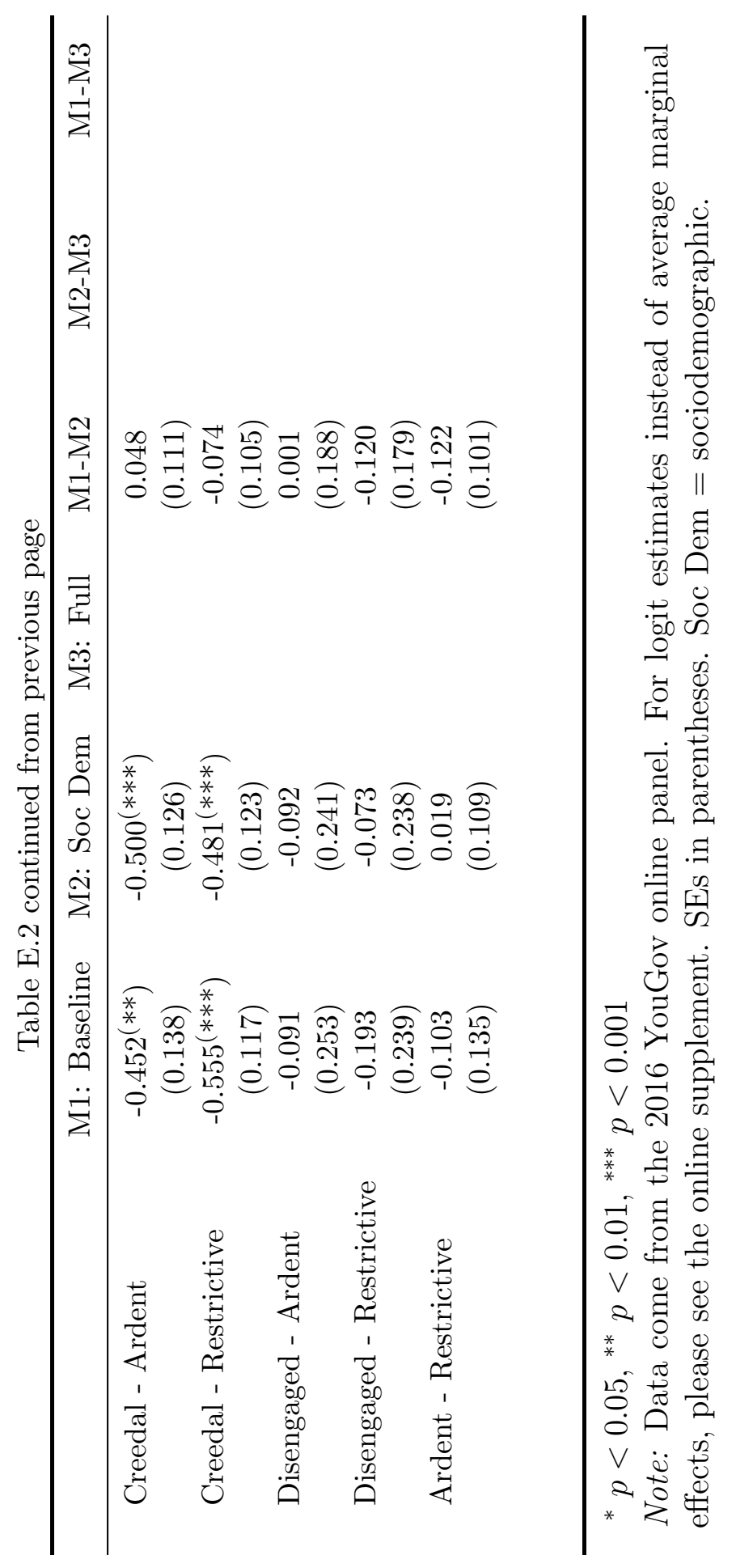




\section{F Comparison of Race and Nationalism as Pre- dictors of General-Election Voting Preferences}

To better understand the relationship between race and nationalism, we performed three supplementary analyses. First, to establish that nationalism is indeed associated with a variety of specific out-group antipathies, we regressed sentiments toward minority groups on the nationalism classes and sociodemographic controls. Second, we examined whether the inclusion of antiminority sentiments in the general election regression models affects the association between nationalist beliefs and voting preferences. Third, we performed a similar step-wise regression analysis for racial self-identification instead of antiminority sentiments. These analyses support our claims that nationalism can be viewed as a common denominator between various forms of ethnoracial prejudice, but that it is not reducible to the latter sentiments, as demonstrated by its persistent net associations with voting preferences.

Results of the first analysis are illustrated in figure F.1. The dependent variable is the difference between white respondents' sentiments toward their own group and their sentiments toward minorities, all measured using feeling thermometers with a range from 1 to 100. We report predicted probabilities for two sets of independent variables: the nationalism classes used in our other analyses and nationalism classes estimated with an additional item - the importance of ancestry for national membership — which is only available in the 2004 and 2016 data. Doing so allows to verify whether this more stringent criterion of ethnoracial exclusion makes a difference for the construct validity of our models (it does not). The results confirm that white respondents' membership in nationalism classes characterized by the endorsement of ascriptive criteria of national membership is predictive of lower values on feeling thermometers toward African-Americans, Asian Americans, Latinos, and Muslims. These are the only proxy measures for out-group sentiment available to us, but the analyses tell a story similar to that shown in other research: when white respondents define "real" Americans in ascriptive terms - by stressing the importance of native birth, lifelong residence in the country, Christianity, or ancestry - what they actually mean is that white Christians have privileged access to legitimate national belonging. Greater antipathy toward minorities is a logical correlate of such beliefs.

Next, we turn to the results of a mediation analysis of the association between nationalism and Trump support by racial attitudes (Mize et al. 2019), illustrated in figure F.2. We first estimate a model featuring only the nationalism classes and then introduce a composite measure of out-group sentiment to determine whether the latter attenuates the regression coefficients for the former. Both models are restricted to white respondents. We measure out-group sentiments using an additive 


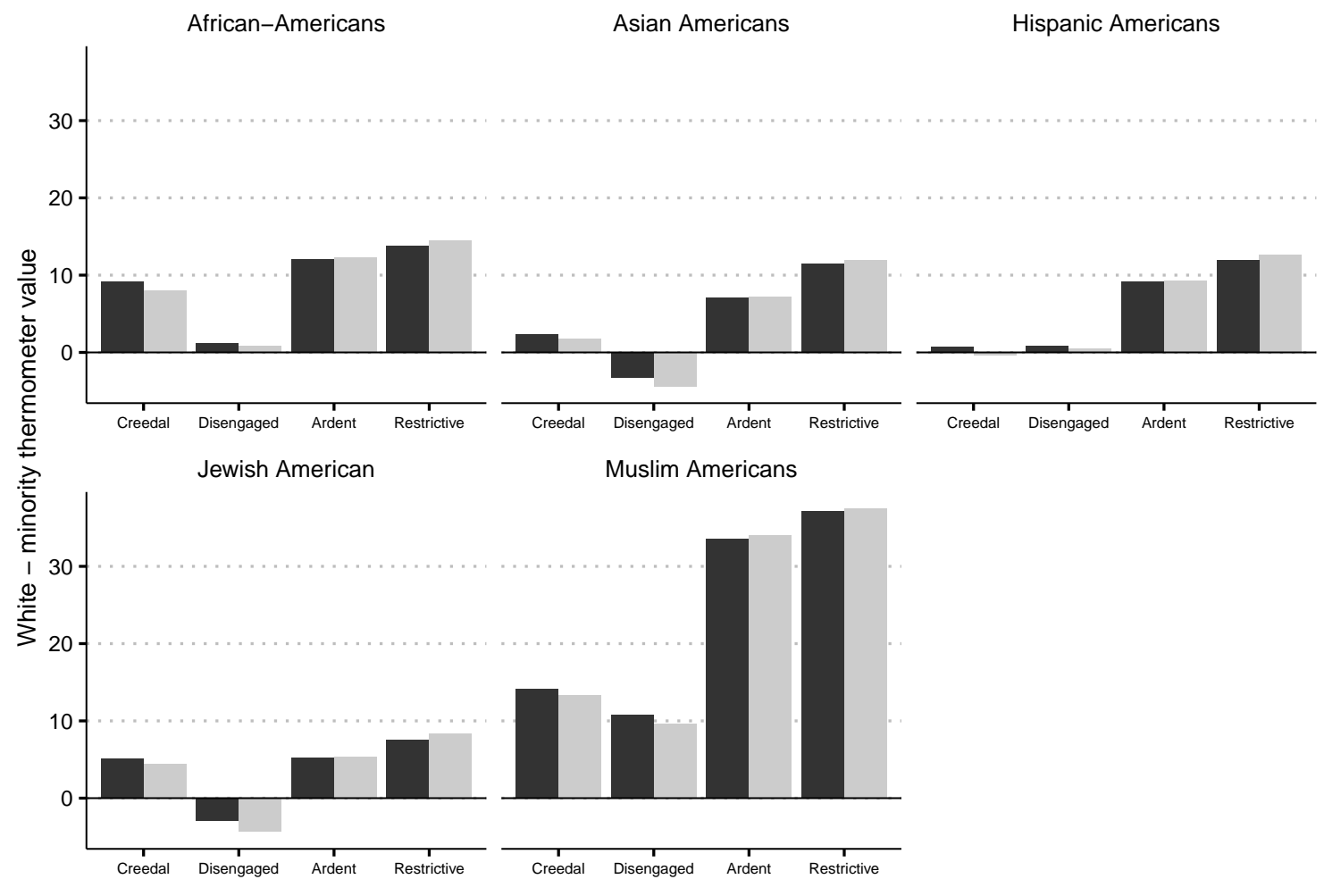

Model $\square$ With ancestry $\square$ Without ancestry

Figure F.1: Associations between nationalism and racial feeling thermometers. Data come from the 2016 YouGov online panel. 


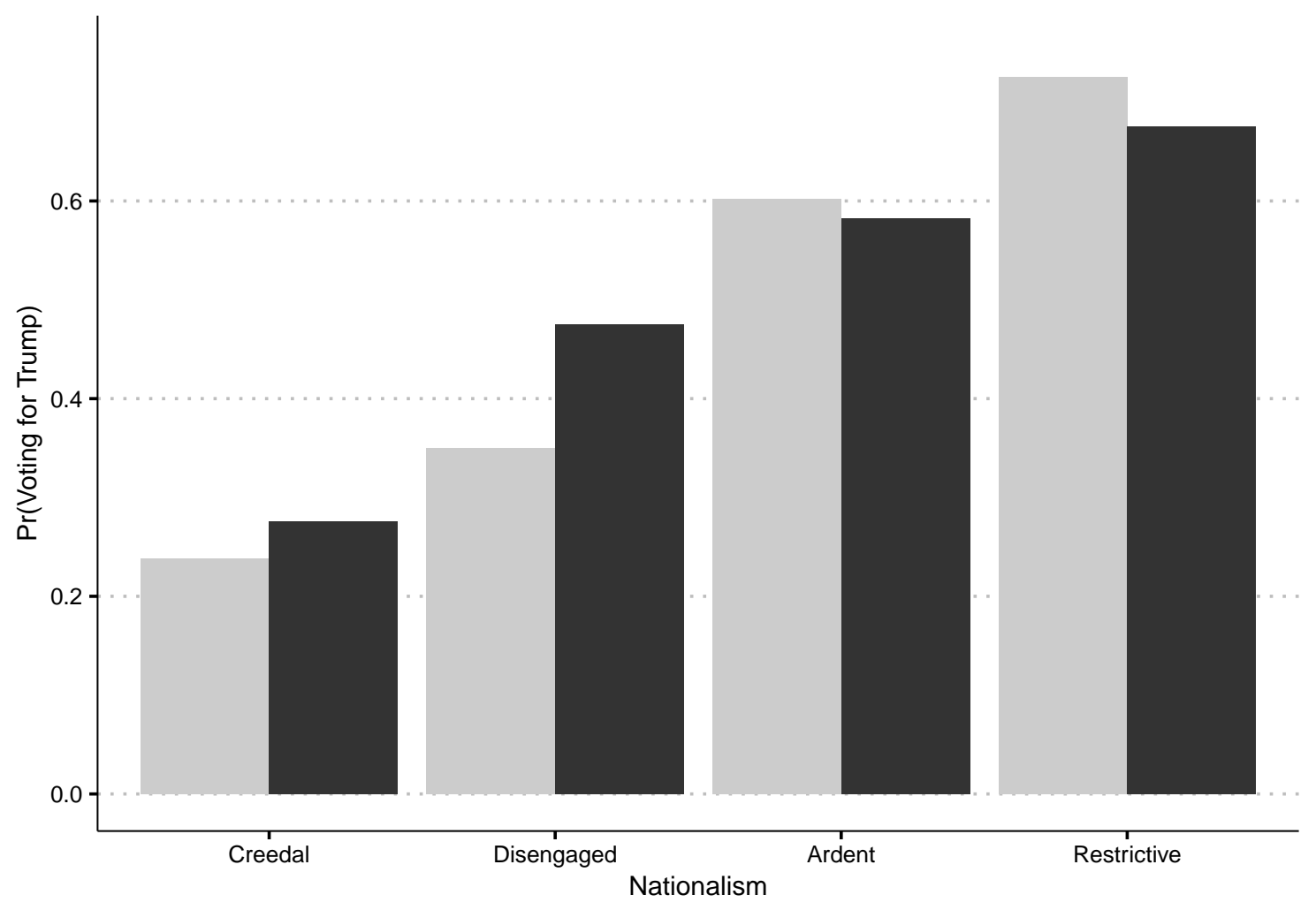

Model Nationalism only $\square$ Nationalism + ethnoracial sentiments

Figure F.2: Mediation analysis of nationalism by antiminority sentiment in models predicting support for Trump over Clinton in 2016 general election. Data come from the 2016 YouGov online panel.

scale composed of differences in feeling thermometer scores comparing whites with minority groups, including African-Americans, Latinos, Jews, Muslims, and Native Americans. Higher composite scores represent higher favorability toward whites compared to minority groups. The results demonstrate that the addition of the out-group sentiment scale results in a modest attenuation of the association of restrictive and ardent nationalism with Trump support, but nonetheless, the predicted probabilities for both types of nationalism remain sizable and significant.

Finally, we examine the mediation of nationalism by racial self-identification and vice versa. As shown in figure F.3, adding race to models containing nationalist class membership and sociodemographic controls has only a modest impact on the pre- 
dicted probabilities of Trump support. The differences between the models are not significant for creedal and ardent nationalists, whereas the inclusion of race modestly increases the predicted probability for the disengaged and decreases it for restrictive nationalism (at $\mathrm{p}<0.05$ and $\mathrm{p}<0.01$, respectively). Conversely, the addition of nationalism items to models containing race and controls has no significant impact on any of the race coefficients. The addition of partisan identification to the models reduces the modest mediation effect of nationalism by race to nonsignificance, whereas in the case of the mediation of race by nationalism, it results in a small but significant mediation of the residual "other" racial category by the nationalism items.

Together, the results of the three analyses demonstrate that nationalism is closely associated with ethnoracial antipathies, but that it is not reducible to them. The four types of nationalism identified in our study remain important for understanding the 2016 election even once out-group sentiments are taken into account. 

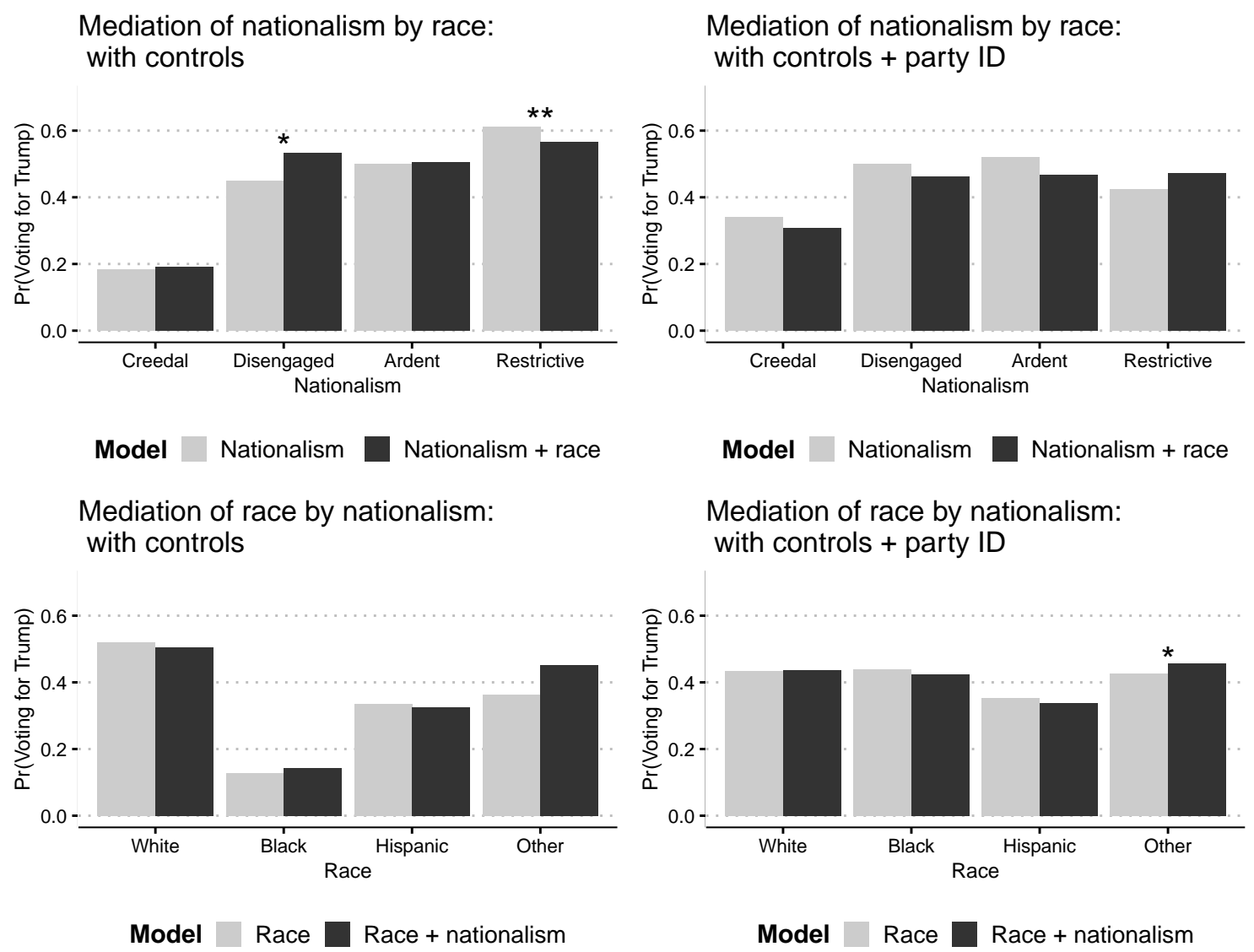

Figure F.3: Mediation analysis of race by nationalism and nationalism by race in models predicting support for Trump over Clinton in 2016 general election. Data come from the 2016 YouGov online panel. 